\author{
ARGONNE NATIONAL LABORATORY \\ 9700 South Cass Avenue, Argonne, Illinois 60439
}

FINAL REPORT:

\title{
USE OF SONICATION FOR IN-WELL SOFTENING OF SEMIVOLATILE ORGANIC COMPOUNDS
}

GRANT PROJECT OFFICER: Chet Miller

Grant No.: W-31-109-ENG-38

Project No.: 55374

Prepared and Submitted by:

Robert W. Peters*, Ph.D., P.E.

Energy Systems Division

Argonne National Laboratory

9700 South Cass Avenue

Argonne, Illinois 60439

phone: (630)-416-1435

e-mail: rpeters@anl.gov

Submitted to:

U.S. Department of Energy

Environmental Management Science Program (EMSP)

Idaho Operations Office

850 Energy Drive

Idaho Falls, Idaho 83401-1563

Attn: Doreen Leonard, DOE-ID Procurement

September 27, 2000

The submitted manuscript has been created by the University of
Chicago as Operator of Argonne National Laboratory ("Argonne")
under Contract No. W-31-109-Eng- 38 with the U.S. Department of
Energy. The U.S. Government retains for itself, and others acting
on behalf, a paid-up, nonexclusive, irrevocable worldwide license
and said article to reproduce, prepare derivative works, distribute
copies to the public, and perform publicly and display publicly, by
or on behalf of the Government. 


\title{
FINAL REPORT: \\ USE OF SONICATION FOR IN-WELL SOFTENING OF \\ SEMIVOLATILE ORGANIC COMPOUNDS
}

GRANT PROJECT OFFICER: Chet Miller

Grant No.: W-31-109-ENG-38

Project No.: 55374

\section{PRINCIPAL INVESTIGATOR/PROJECT MANAGER:}

\author{
Robert W. Peters*, Ph.D., P.E. \\ Energy Systems Division \\ Argonne National Laboratory \\ 9700 South Cass Avenue \\ Argonne, Illinois 60439 \\ Phone: (630)-416-1435 \\ E-mail: rpeters@anl.gov \\ *Current address: TechSavants, Inc. \\ 309 Sawmill Road, Naperville, Illinois 60565 \\ Phone: (630)-416-1435 \\ E-mail: rwpetersphd@aol.com
}

\section{Co-Principal Investigators:}

- John Manning**, Environmental Research Division, Argonne National Laboratory, Argonne, IL.

- Michael R. Hoffmann, W.M. Keck Laboratories, California Institute of Technology, Pasadena, CA.

- Steven Gorelick, Department of Geological and Environmental Sciences, Stanford University, Stanford, CA.

**Current address: Vanderbilt University Medical Center, Vanderbilt University, Nashville, TN.

\section{Additional Project Staff:}

- Linda Pierce, Energy Systems Division, Argonne National Laboratory, Argonne, IL.

- Ramaraj Boopathy, Department of Biological Sciences, Nicholls State University, Thibodeaux, LA.

- Michael L. Wilkey, TechSavants, Inc., Oak Park, IL.

- Onder Ayyildiz and Po-Yao Kuo (Graduate Students), Department of Chemical and Environmental Engineering, Illinois Institute of Technology, Chicago, IL.

- Mary Quinn (Graduate Student), Governor's State University.

- Hui-Ming Hung (Graduate Student), W.M. Keck Laboratories, California Institute of Technology, Pasadena, CA. 


\section{EXECUTIVE SUMMARY}

This project investigates the in-situ degradation of semivolatile organic compounds (SVOCs) and volatile organic compounds (VOCs) using in-well sonication, in-well vapor stripping, and bioremediation. Pretreating groundwaters with sonication techniques in-situ would form VOCs that can be effectively removed by in-well vapor stripping and bioremediation. The mechanistic studies focus on the coupling of megasonics and ultrasonics to "soften" (i.e., partially degrade) the SVOCs; oxidative reaction mechanism studies; surface corrosion studies (on the reactor walls/well); enhancement due to addition of oxidants, quantification of the hydroxyl radical formation; identification/quantification of degradation products; volatility/degradability of the treated waters; development of a computer simulation model to describe combined in-well sonication/in-well vapor stripping/bioremediation; systems analysis/economic analysis; large laboratory-scale experiment verification; and field demonstration of the integrated technology. Benefits of this approach include: (1) Remediation is performed in-situ; (2) The treatment systems complement each other; their combination can drastically reduce or remove SVOCs and VOCs; (3) Ability to convert hard-to-degrade organics into more volatile organic compounds; (4) Ability to remove residual VOCs and "softened" SVOCs through the combined action of in-well vapor stripping and biodegradation; (5) Does not require handling or disposing of water at the ground surface; and (6) Cost-effective and improved efficiency, resulting in shortened clean-up times to remediate a site.

This study examined the ability of an integrated treatment system involving combined sonication and vapor stripping to remove/destroy chlorinated organic compounds from groundwater. The chlorinated solvents studied included carbon tetrachloride $\left(\mathrm{CCl}_{4}\right)$, trichloroethylene (TCE), trichlorethane (TCA), and tetrachloroethylene (PCE). Contaminant concentrations studied ranged from $\sim 1$ to $\sim 100 \mathrm{mg} / \mathrm{L}$. Sonication/vapor stripping experiments were performed in a reactor used to treat the chlorinated organic contaminants in groundwater employing sonication alone, vapor stripping alone, and combined sonication/vapor stripping. The sonicator has an ultrasonic frequency of $20-\mathrm{kHz}$; the applied power intensity was $12.3-$, 25.3-, and $35.8-\mathrm{W} / \mathrm{cm}^{2}$. The batch reactions were operated normally for up to 10 minutes treatment time, with samples drawn for GC analysis every 2 minutes. Air injection rates (for the vapor stripping) were nominally 0 - (sonication alone), 500-, 1000-, and $1500-\mathrm{mL} / \mathrm{min}$. In the continuous flow studies, the residence time in the reactor was set at 5, 8, and 10 minutes.

Results were obtained from batch experiments performed on the various chlorinated organic contaminants $\left(\mathrm{CCl}_{4}, \mathrm{TCE}, \mathrm{TCA}\right.$, and PCE) using sonication alone, vapor stripping alone, and combined sonication/vapor stripping. For all four chlorinated solvent species, the first order rate constants were in the range of 0.02 to $0.06 \mathrm{~min}^{-1}, 0.23$ to $0.53 \mathrm{~min}^{-1}$, and 0.34 to $0.90 \mathrm{~min}^{-1}$.for sonication alone, vapor stripping alone, and combined sonication/vapor stripping.

For all four chlorinated organic contaminants under batch treatment conditions (total treatment time $\sim 10$ minutes), the fraction remaining after by sonication and vapor stripping alone ranged from $62 \%$ to $82 \%$, while the fraction remaining from the combined sonication/vapor stripping system was typically less than 3\% in all cases after 10 minutes processing time. Even after 6 minutes treatment time, the removal of all the chlorinated organic contaminants exceeded $90 \%$. 
Similar results were obtained for the continuous flow system. For continuous flow operation (with a residence time between 5 and 10 minutes), removal of $\mathrm{CCl}_{4}$ ranged from $17.1 \%$ to $17.9 \%, 68.4 \%$ to $80.3 \%$, and $74.0 \%$ to $87.9 \%$ for the using sonication system, the vapor stripping system, and the combined sonication/vapor stripping system (using a air injection rate of 500-mL/min), respectively. Similarly, for continuous treatment of TCE (with a residence time between 5 and 10 minutes), removal of TCE ranged from $14.6 \%$ to $36.6 \%, 55.6 \%$ to $75.4 \%$, and $72.3 \%$ to $97.3 \%$ for the using sonication system, the vapor stripping system, and the combined sonication/vapor stripping system (using a air injection rate of 500-mL/min), respectively.

Results from the batch and continuous flow treatment of the chlorinated organic contaminants indicated that the combined sonication/vapor stripping system operated in a synergistic fashion; the removals and first-order degradation constants were significantly improved over the case of sonication alone or vapor stripping alone. The first-order rate constant for the combined system was significantly greater than the sum of the rate constants for the sonication alone and vapor stripping alone systems, indicating the system operates in a synergistic fashion. This is likely the result of a much greater degree of mixing being associated with sonication of the gas bubbles, resulting in much finer-sized bubbles being used in solution; this causes a significantly increased degree of mass transfer of the organic components into the gas phase, and hence provides much greater removals of the contaminants (and hence larger first-order rate constants). Increasing the air injection rate did not linearly increase the first-order rate constant associated with vapor stripping. The first-order rate constants compared favorably between the batch and continuous flow systems, indicating that batch experiments can be used to provide a quick estimate of the first-order rate constant expected for continuous flow conditions.

Removal of the various chlorinated organic contaminants followed the order involving their Henry's law constants $\left(\mathrm{CCl}_{4}>\mathrm{TCE}>\mathrm{TCA}>\mathrm{PCE}\right)$. It should be noted that while vapor stripping does a reasonable job in removing the chlorinated compounds from solution, it merely transfers the contaminant from the liquid phase to the gaseous phase; it does not destroy the organic contaminant. The sonication and the combined sonication/vapor stripping system are much more effective in destroying the chlorinated solvent contaminants. Analysis of the degradation products (by-products) indicated that the degradation products constituted a very small percentage of the original parent compounds $(<1 \%)$.

Results of the biodegradation studies indicated that the sonicated samples supported bacterial growth compared to the unsonicated samples, indicating that the degradation products of the chlorinated organic contaminants were being successfully degraded by common soil bacteria.

Numerical simulations were performed based upon a numerical model MT3D, an existing groundwater contaminant transport code. Numerical modelings were performed for the sonication alone, vapor stripping alone, and the combined sonication/vapor stripping system. The modeling was performed on the basis of hypothetical parameter values. The simulations indicated that the contaminant is removed quite rapidly, although higher concentration regions existed in the corners of the tank (used in the modeling). The concentrations of the contaminants drop more rapidly at higher pumping rates; removals exceeding $90 \%$ were achieved within 4 days at the higher pumping rate $\left(1.26 \mathrm{~m}^{3} /\right.$ day $)$ and within 8 days at the lower pumping rate $\left(0.63 \mathrm{~m}^{3} /\right.$ day $)$. 
Results of the power requirements for removal of the chlorinated organic contaminants indicated that the combined in-well sonication/in-well vapor stripping system was considerably less energy intensive than using sonication alone; the power requirement for a given removal efficiency of $\mathrm{CCl}_{4}$ or TCE was nearly an order of magnitude lower for the combined in-well sonication/in-well vapor stripping system as compared to the sonication system alone.

In summary, this innovative technology shows great promise as a remediation tool to treat organic contaminants in-situ, without having to bring the contaminated groundwaters to the surface for treatment. The science of this innovative technology involving in-well sonication combined with in-well vapor stripping has been sufficiently demonstrated and the fundamentals understood at the laboratory-scale, to warrant performing pilot-scale and field demonstrations of the technology. 


\section{TABLE OF CONTENTS}

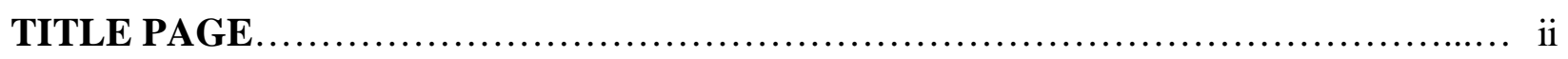

EXECUTIVE SUMMARY ...............................................................

TABLE OF CONTENTS .................................................................

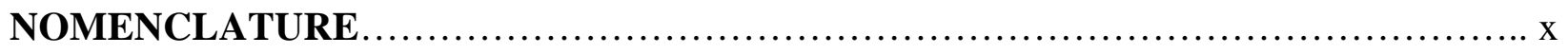

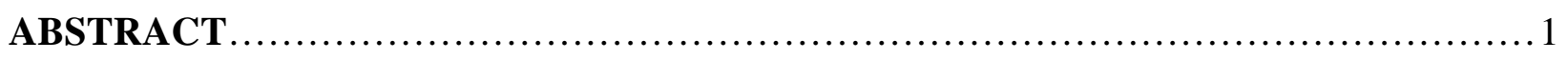

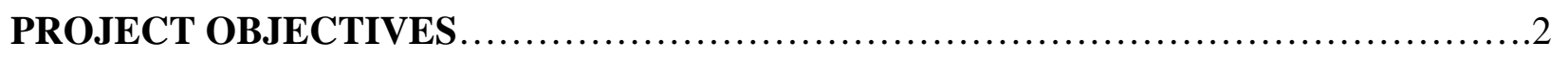

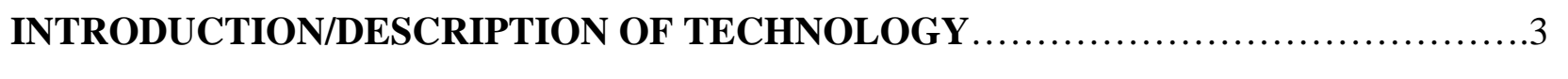

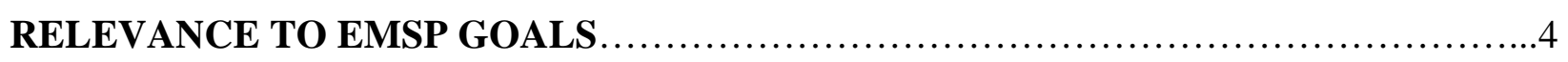

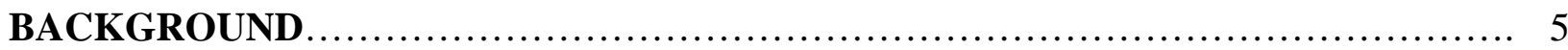

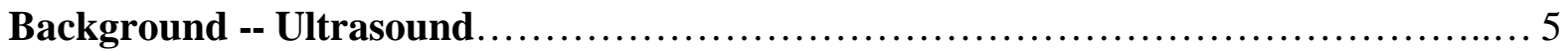

Physical and Chemical Principles -- Ultrasound .......................................

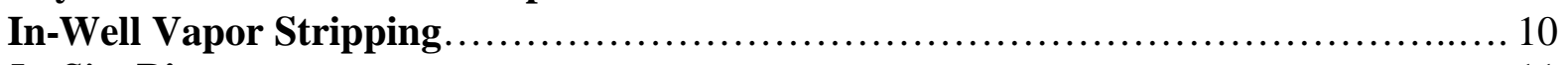

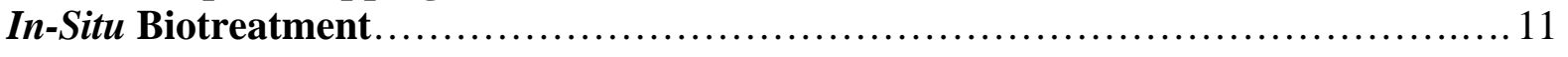

ADVANTAGES OF THE IN-WELL SONICATION/IN-WELL VAPOR
STRIPPING/IN-SITU BIODEGRADATION APPROACH.......................... 12

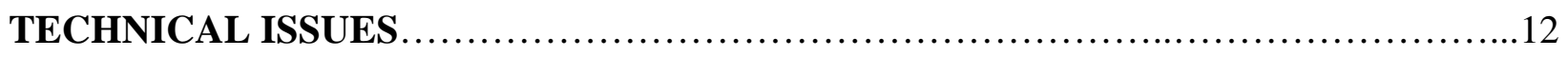

RESEARCH PROGRESS ....................................................... 14

Initial Quality Assurance/Quality Control Methods Development................... 14

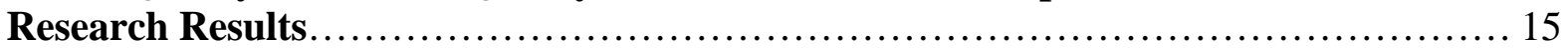

Task 1.Quantify representative VOC and SVOC contaminants at DOE facilities....... 15

Task 2.Conduct batch sonication experiments to determine preliminary optimal conditions for subsequent continuous-flow experiments............... 15

Temperature Increase Due to Sonication.................................. 15

Sonication of Target Compounds at Different Initial Concentrations........... 15

Varying Power Intensities of the Ultrasonic Irradiation...................... 16

The Effect of Initial $\mathrm{pH}$ values.......................................... 16

The Effect of Adding Hydrogen Peroxide................................. 16

Duplication of Experimental Results.................................... 16

Results from Batch Sonication and Batch Sonication/Vapor Stripping Experiments. . 17

Task 3.Perform batch experiments for measuring hydroxyl/hydrogen radicals in solution

Task 4. Conduct continuous-flow experiments for degradation of SVOCs and identification or quantification of by-products. 
Task 5.Investigate the chemical reaction mechanism to improve system

Performance. Degradation Products/Kinetic Modeling.

Task 6.Perform batch or continuous-flow experiments to determine the effects of oxidants $\left(\mathrm{H}_{2} \mathrm{O}_{2}\right.$, Fenton's Reagent, etc.) on SVOC degradation and the biodegradability of the resultant product.

Task 7. Identify and quantify corrosion potential and salt formation.

Task 8 . Determine the volatility and biodegradability of the treated waters (and compare to untreated waters) ................................... 44

Treatment ............................................................ 44

Microorganisms.................................................. 45

Growth Conditions................................................... 45

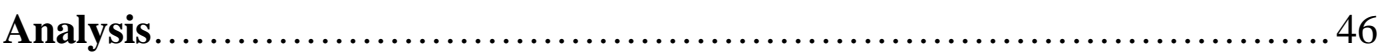

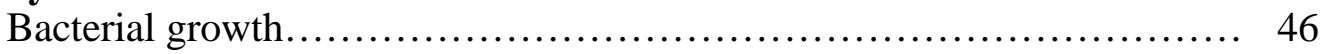

GC Analysis.................................................... 46

Experimental Scheme............................................ 46

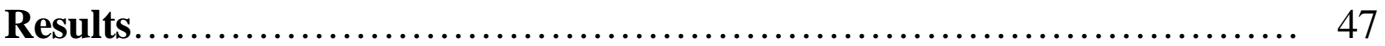

Bacterial Growth.................................................... 47

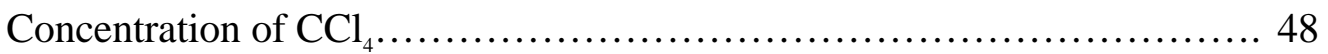

Future Work on Biodegradation Studies............................ 49

Experimental Approach.............................................. 49

Collection of Samples and Analyses................................ 49

Selection of Microbial System for the Study........................... 49

Laboratory Enrichment Studies................................... 49

Aerobic bacteria............................................. 49

Anaerobic bacteria............................................

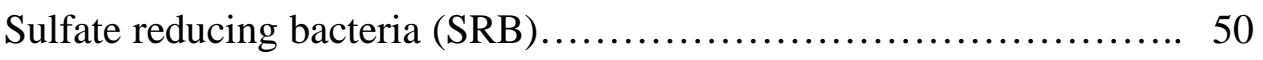

Nitrate reducing bacteria.................................... 50

Iron reducing bacteria..........................................

Methanogenic bacteria..........................................

Fermenting Bacteria......................................... 51

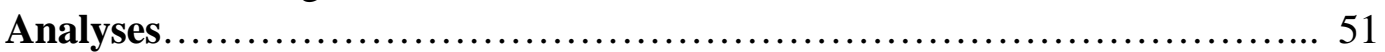

Bacterial growth....................................................

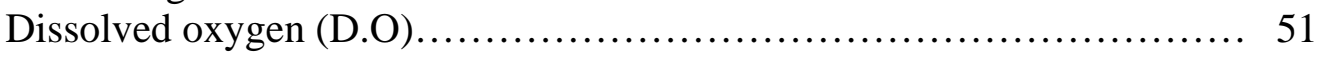

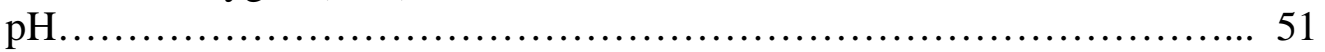

Nitrogen, Ammonia and Phosphorus............................... 51

VOC and SVOC .................................................. 51

Task 9. Develop computer simulation model to describe combined in-well sonication/in-well vapor stripping, and biodegradation.................. 52

Task 10. Perform large-scale experiments with a laboratory in-well sonication/in-well vapor stripping/bioremediation system................ 55

Task 11. Perform systems analysis and economic analysis for system scale-up for a field demonstration.......................................... 55

ANNUAL SONICATION WORKSHOP ........................................... 56

TECHNOLOGY TRANSFER ACTIVITIES ..................................

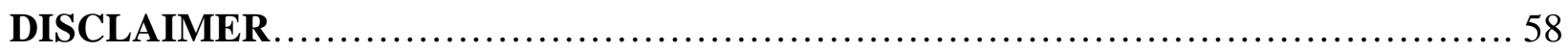

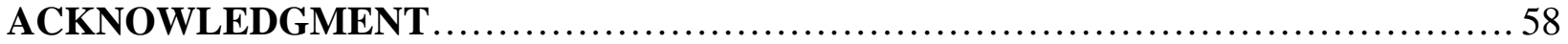

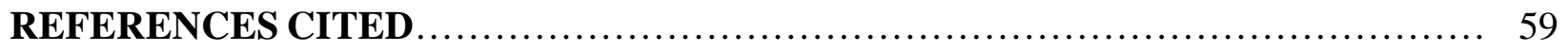




\section{FIGURES}

Figure 1. Residual chlorinated organic compound remaining after batchlsonication and sonication+vapor stripping treatment

Figure 2. Residual chlorinated organic compound remaining after continuous sonication and sonication+vapor stripping treatment

Figure 3. Comparison of $\mathrm{CCl}_{4}$ removal by sonication+vapor stripping (air injection rate $\sim 500-\mathrm{mL} / \mathrm{min})$ to sonication alone $(20 \mathrm{kHz})$

Figure 4. Comparison of TCE removal by sonication+vapor stripping (air injection rate $\sim 500-\mathrm{mL} / \mathrm{min})$ to sonication alone $(20 \mathrm{kHz})$.

Figure 5. Comparison of first-order rate constants for removal of $\mathrm{CCl}_{4}$ from groundwater using sonication, vapor stripping, and combined sonication/vapor stripping....... 21

Figure 6. Removal efficiency of $\mathrm{CCl}_{4}$ and TCE as a function of the batch treatment time using combined sonication/vapor stripping techniques.

Figure 7. Comparison of first-order rate constants for removal of $\mathrm{CCl}_{4}$ and TCE from groundwater using sonication, vapor stripping, and combined sonication/vapor stripping.

Figure 8. Fraction of chlorinated contaminant remaining in groundwater for various batch treatment times via sonication alone $\left(20 \mathrm{kHz}, 12.3 \mathrm{~W} / \mathrm{cm}^{2}\right)$ and via sonication+vapor stripping (air injection rate $500 \mathrm{~mL} / \mathrm{min}$ ).

Figure 9. Fraction of chlorinated contaminant remaining in groundwater for various batch treatment times via sonication alone $\left(20 \mathrm{kHz}, 25.3 \mathrm{~W} / \mathrm{cm}^{2}\right)$ and via sonication+vapor stripping (air injection rate $\sim 500 \mathrm{~mL} / \mathrm{min}$ )

Figure 10. Fraction of chlorinated contaminant remaining in groundwater for various batch treatment times via sonication alone $\left(20 \mathrm{kHz}, 35.8 \mathrm{~W} / \mathrm{cm}^{2}\right)$ and via sonication+vapor stripping (air injection rate $\sim 500 \mathrm{~mL} / \mathrm{min}$ ). . .

Figure 11. Fraction of chlorinated contaminant remaining in groundwater for various batch treatment times via sonication alone $(20 \mathrm{kHz})$ for various applied power intensities (12.3-, 25.3-, and 35.8-W/ $\left.\mathrm{cm}^{2}\right)$.

Figure 12. Fraction of chlorinated contaminant remaining in groundwater for various batch treatment times via combined sonication $(20 \mathrm{kHz}) / \mathrm{vapor}$ stripping (air injection rate $\sim 500-\mathrm{mL} / \mathrm{min}$ ) for various applied power intensities (12.3-, 25.3-, and 35.8-W/ $\left.\mathrm{cm}^{2}\right)$.

Figure 13. First-order rate constants for removal of TCA from groundwater using sonication alone $(20 \mathrm{kHz})$ for various applied power intensities and various initial TCA concentrations

Figure 14. Comparison of fraction TCA remaining using sonication+vapor stripping (500-mL/min air injection rate) to sonication alone $\left(20 \mathrm{kHz}, 35.8 \mathrm{~W} / \mathrm{cm}^{2}\right)$.

Figure 15. Comparison of fraction $\mathrm{CCl}_{4}$ remaining using sonication+vapor stripping
(500-mL/min air injection rate) to sonication alone $\left(20 \mathrm{kHz}, 35.8 \mathrm{~W} / \mathrm{cm}^{2}\right) \ldots \ldots$.
Figure 16. Comparison of fraction TCA remaining using sonication $\left(20 \mathrm{kHz} ; 35.8 \mathrm{~W} / \mathrm{cm}^{2}\right)$
+ vapor stripping to vapor stripping alone $(500-\mathrm{mL}$ air injection rate $) \ldots \ldots \ldots$
Figure 17. Comparison of fraction $\mathrm{CCl}_{4}$ remaining using sonication $\left(20 \mathrm{kHz} ; 35.8 \mathrm{~W} / \mathrm{cm}^{2}\right)$

Figure 15. Comparison of fraction $\mathrm{CCl}_{4}$ remaining using sonication+vapor stripping
(500-mL/min air injection rate) to sonication alone $\left(20 \mathrm{kHz}, 35.8 \mathrm{~W} / \mathrm{cm}^{2}\right) \ldots \ldots$.
Figure 16. Comparison of fraction TCA remaining using sonication $\left(20 \mathrm{kHz} ; 35.8 \mathrm{~W} / \mathrm{cm}^{2}\right)$
+ vapor stripping to vapor stripping alone $(500-\mathrm{mL}$ air injection rate)........
Figure 17. Comparison of fraction $\mathrm{CCl}_{4}$ remaining using sonication $\left(20 \mathrm{kHz} ; 35.8 \mathrm{~W} / \mathrm{cm}^{2}\right)$

Figure 15. Comparison of fraction $\mathrm{CCl}_{4}$ remaining using sonication+vapor stripping
(500-mL/min air injection rate) to sonication alone $\left(20 \mathrm{kHz}, 35.8 \mathrm{~W} / \mathrm{cm}^{2}\right) \ldots \ldots$.
Figure 16. Comparison of fraction TCA remaining using sonication $\left(20 \mathrm{kHz} ; 35.8 \mathrm{~W} / \mathrm{cm}^{2}\right)$
+ vapor stripping to vapor stripping alone $(500-\mathrm{mL}$ air injection rate $) \ldots \ldots \ldots$
Figure 17. Comparison of fraction $\mathrm{CCl}_{4}$ remaining using sonication $\left(20 \mathrm{kHz} ; 35.8 \mathrm{~W} / \mathrm{cm}^{2}\right)$

Figure 15. Comparison of fraction $\mathrm{CCl}_{4}$ remaining using sonication+vapor stripping
(500-mL/min air injection rate) to sonication alone $\left(20 \mathrm{kHz}, 35.8 \mathrm{~W} / \mathrm{cm}^{2}\right) \ldots \ldots$.
Figure 16. Comparison of fraction TCA remaining using sonication $\left(20 \mathrm{kHz} ; 35.8 \mathrm{~W} / \mathrm{cm}^{2}\right)$
+ vapor stripping to vapor stripping alone $(500-\mathrm{mL}$ air injection rate $) \ldots \ldots \ldots$. + vapor stripping to vapor stripping alone $(500-\mathrm{mL}$ air injection rate)...

Figure 17. Comparison of fraction $\mathrm{CCl}_{4}$ remaining using sonication $\left(20 \mathrm{kHz} ; 35.8 \mathrm{~W} / \mathrm{cm}^{2}\right)$

Figure 18. Comparison of batch and continuous flow rate constants for removal for $\mathrm{CCl}_{4}$ and TCA from groundwater using combined in-well sonication/in-well

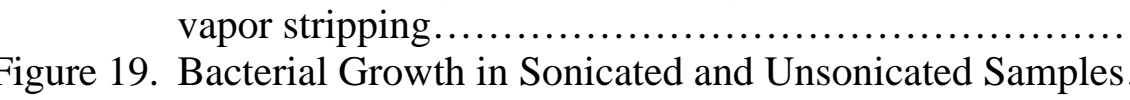

Figure 19. Bacterial Growth in Sonicated and Unsonicated Samples...................... 47 
Figure 20. Energy requirements as a function of contaminant removal efficiency using sonication alone and sonication+vapor stripping....

\section{TABLES}

Table 1. Comparison of First-Order Rate Constants $\left(\mathrm{min}^{-1}\right)$ by Acoustic Cavitation for Removal of $\mathrm{CCl}_{4}$ and TCE from Groundwater.

Table 2. Comparison of First-Order Rate Constants for Removal of $\mathrm{CCl}_{4}$ and TCE from Groundwater Using Vapor Stripping Techniques.

Table 3. Comparison of First Order Rate Constants for Removal of Carbon Tetrachloride $\left(\mathrm{CCl}_{4}\right)$ from Groundwater.

Table 4. Comparison of First Order Rate Constants for Removal of Trichloroethylene (TCE) from Groundwater.

Table 5. First-Order Rate Constants for Removal/Destruction of Chlorinated Organic Compounds from Groundwater Using Sonication Alone, Vapor Stripping Alone, and Combined Sonication/Vapor Stripping in Continuous Flow

Operations.

Table 6. Final Distribution of Chlorine Atoms in a Sonicated Solution of $\mathrm{CCl}_{4}$ after 90 Minutes of Sonolysis [Hua and Hoffmann, 1996a].

Table 7. Results of Calorimetry Measurements [Hung and Hoffmann, 1999]...

Table 8. Normalized Rate Constants for the Sonolytic Degradation of $\mathrm{CCl}_{4}$ in Water at $\mathrm{pH}_{\mathrm{o}} \sim 7, \mathrm{pH}_{\infty} \sim 3.5$, and $\mathrm{T} \sim 286^{\circ} \mathrm{K}$ with $\left[\mathrm{CCl}_{4}\right]_{0} \sim 0.2 \mathrm{mM}$ [Hung and Hoffmann, 1999]

Table 9. Summary of Metal Thickness Loss and Corrosion Rate for Continuous Sonication $\left(20-\mathrm{kHz}, 35.8-\mathrm{W} / \mathrm{cm}^{2}\right)$ of Metal Coupons Placed in Solution Containing Chlorinated Compounds

\section{APPENDICES}

APPENDIX I. Schematic Diagram of a Single Treatment Well in Which In-Well Sonication Softens and Partially Destroys VOCs and SVOCs and In-Well Vapor Stripping is Used to Remove the VOCs as a Vapor. The treatment process is performed completely in-situ wherein no water is brought to the surface. 


\section{NOMENCLATURE}

A Corrosion coupon surface area, $\left(\mathrm{cm}^{2}\right)$

AFB Air Force Base

Ar Argon gas

$\mathrm{CaCl}_{2} \quad$ Calcium chloride

$: \mathrm{CCl}_{2} \quad$ Dichlorocarbene

$\cdot \mathrm{CCl}_{3} \quad$ Trichloromethyl radical

$\mathrm{CCl}_{4} \quad$ Carbon tetrachloride

$\mathrm{C}_{2} \mathrm{Cl}_{4} \quad$ Perchloroethylene, also called tetrachloroethylene

$\mathrm{C}_{2} \mathrm{H}_{6} \quad$ Hexachloroethane

$\mathrm{CHCl}_{3} \quad$ Chloroform

$\mathrm{C}_{\mathrm{i}}, \mathrm{C}_{\mathrm{f}} \quad$ Initial and final contaminant concentrations, (mg/L)

$\mathrm{Cl}^{-} \quad$ Chloride ion

Cl• Chloride radical

$\mathrm{COCl}_{2} \quad$ Phosgene

$\mathrm{CO} \quad$ Carbon monoxide

$\mathrm{CO}_{2} \quad$ Carbon dioxide

$\mathrm{C}_{2} \mathrm{Cl}_{4} \quad$ Tetrachloroethylene

$\mathrm{C}_{2} \mathrm{Cl}_{6} \quad$ Hexachloroethane

d Metal/alloy density, $\left(\mathrm{g} / \mathrm{cm}^{3}\right)$

D Exposure time, (days)

DNAPLs Dense non-aqueous phase liquids

D.O. Dissolved oxygen

DOE U.S. Department of Energy 


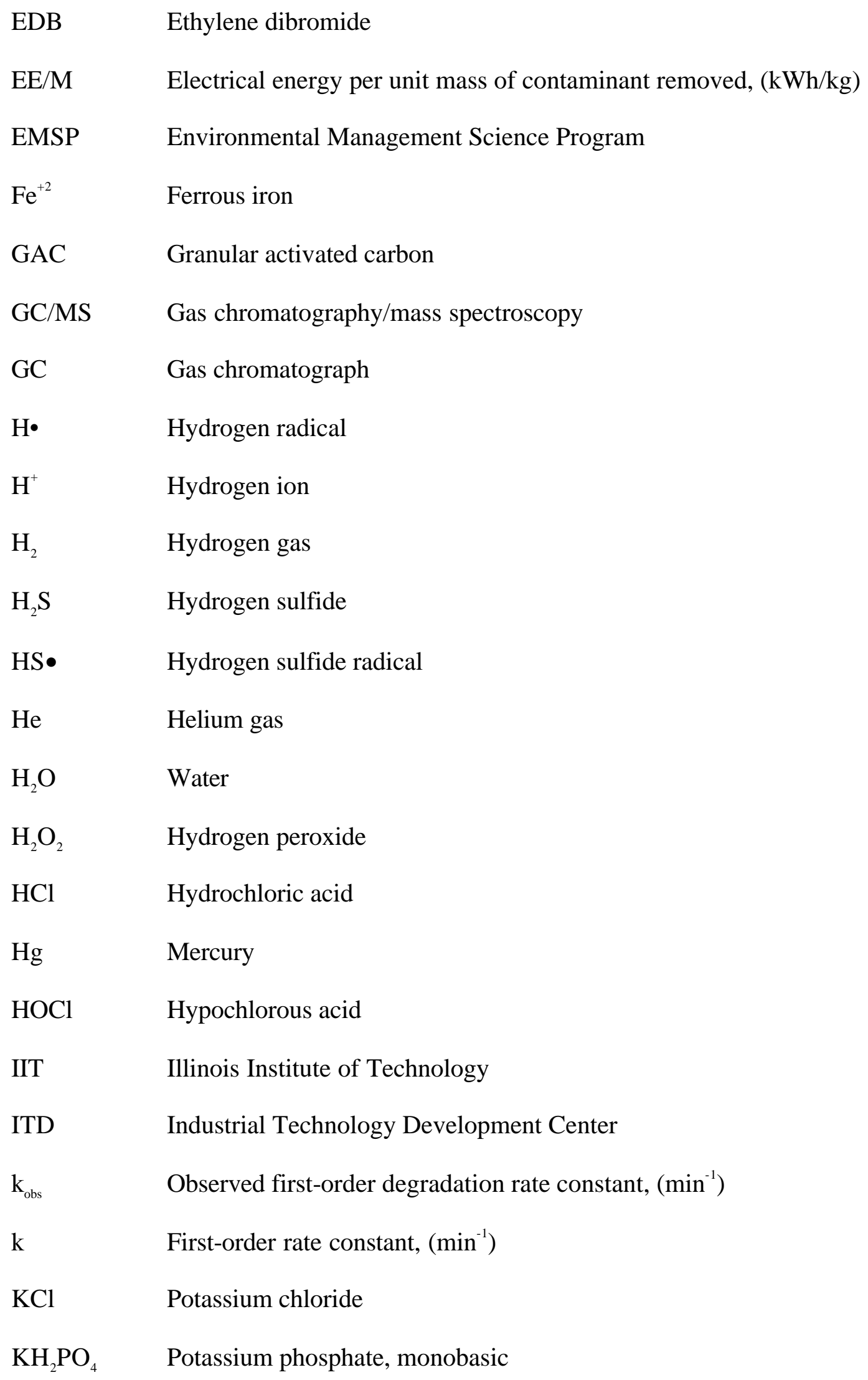




\begin{tabular}{|c|c|}
\hline $\mathrm{K}_{2} \mathrm{HPO}_{4}$ & Potassium phosphate, dibasic \\
\hline $\mathrm{kHz}$ & Kilohertz \\
\hline KI & Potassium iodide \\
\hline $\mathrm{Kr}$ & Krypton gas \\
\hline $\mathrm{m}^{3}$ & Cubic meters \\
\hline $\mathrm{mM}$ & Millimolar concentration, (mmoles/L) \\
\hline M & Molar concentration, (moles/L) \\
\hline $\mathrm{MgCl}_{2}$ & Magnesium chloride \\
\hline $\mathrm{MgSO}_{4}$ & Magnesium sulfate \\
\hline $\mathrm{MHz}$ & Megahertz \\
\hline $\mathrm{N}_{2}$ & Nitrogen gas \\
\hline $\mathrm{NaCl}$ & Sodium chloride \\
\hline $\mathrm{Na}_{2} \mathrm{CO}_{3}$ & Sodium carbonate \\
\hline $\mathrm{Na}_{2} \mathrm{~S}$ & Sodium sulfide \\
\hline $\mathrm{NH}_{4} \mathrm{Cl}$ & Ammonium chloride \\
\hline$\left(\mathrm{NH}_{4}\right)_{2} \mathrm{SO}_{4}$ & Ammonium sulfate \\
\hline $\mathrm{O}_{3}$ & Ozone \\
\hline $\mathrm{O}_{2}$ & Oxygen gas \\
\hline $\mathrm{OCl}^{-}$ & Hypochlorous ion \\
\hline$\cdot \mathrm{OH}$ & Hydroxyl radical \\
\hline $\mathrm{P}$ & Power, $(\mathrm{kW})$ \\
\hline $\mathrm{P}$ & Pressure \\
\hline PCE & Perchloroethylene, also called tetrachloroethylene \\
\hline $\mathrm{pH}$ & $-\log \left[\mathrm{H}^{+}\right]$ \\
\hline
\end{tabular}




$\begin{array}{ll}\text { PI } & \text { Principal Investigator } \\ \text { R } & \text { Corrosion rate, (mils/year) } \\ \text { SCFA } & \text { Subsurface Contaminant Focus Area } \\ \text { SRB } & \text { Sulfate reducing bacteria } \\ \text { SVOCs } & \text { Semivolatile organic compounds } \\ \text { t } & \text { Treatment time, (min) } \\ \text { T } & \text { Temperature } \\ \text { T } & \text { Metal thickness loss, (mils) } \\ \text { TCA } & \text { Trichloroethane } \\ \text { TCE } & \text { Trichloroethylene } \\ \mu M & \text { Micromolar concentration, ( } \mu \text { moles/L) } \\ \text { UV } & \text { Ultraviolet light } \\ \text { V } & \text { Total volume of solution, (L) } \\ \text { VOCs } & \text { Volatile organic compounds } \\ \text { v/v } & \text { Volume per volume basis } \\ \text { W } & \text { Power wattage } \\ \text { W }, W_{2} & \text { Initial and final metal coupon weight, (g) } \\ 3 D & \text { Three dimensions }\end{array}$

\section{Subscripts:}

$\begin{array}{ll}\mathrm{i} & \text { Initial value (at time } \mathrm{t}=0 \text { ) } \\ \mathrm{o} & \text { Original value (at time } \mathrm{t}=0 \text { ) } \\ 4 & \text { Final value (at infinite time) }\end{array}$




\title{
FINAL REPORT: \\ USE OF SONICATION FOR IN-WELL SOFTENING OF SEMIVOLATILE ORGANIC COMPOUNDS
}

\section{PROJECT TITLE: "Use of Sonication for In-Well Softening of Semivolatile Organic Compounds"}

PRINCIPAL INVESTIGATORS: $\quad$ Robert W. Peters, Argonne National Laboratory

John Manning, Argonne National Laboratory

Michael R. Hoffmann, California Institute of Technology

Steven Gorelick, Stanford University

\begin{abstract}
ADDITIONAL PROJECT STAFF: Linda Pierce, Argonne National Laboratory
Ramaraj Boopathy, Argonne National Laboratory

Michael L. Wilkey, Argonne National Laboratory

Onder Ayyildiz and Po-Yao Kuo (Graduate Students), Illinois Institute of Technology

Mary Quinn (Graduate Student), Governor's State University

Hui-Ming Hung (Graduate Student), California Institute of Technology
\end{abstract}

\begin{abstract}
This project investigates the in-situ degradation of semivolatile organic compounds (SVOCs) and volatile organic compounds (VOCs) using in-well sonication, in-well vapor stripping, and bioremediation. Pretreating groundwaters with sonication techniques in-situ would form VOCs that can be effectively removed by in-well vapor stripping and bioremediation. The mechanistic studies focus on the coupling of megasonics and ultrasonics to "soften" (i.e., partially degrade) the SVOCs; oxidative reaction mechanism studies; surface corrosion studies (on the reactor walls/well); enhancement due to addition of oxidants, quantification of the hydroxyl radical formation; identification/quantification of degradation products; volatility/degradability of the treated waters; development of a computer simulation model to describe combined in-well sonication/in-well vapor stripping/bioremediation; systems analysis/economic analysis; large laboratory-scale experiment verification; and field demonstration of the integrated technology. Benefits of this approach include: (1) Remediation is performed in-situ; (2) The treatment systems complement each other; their combination can drastically reduce or remove SVOCs and VOCs; (3) Ability to convert hard-to-degrade organics into more volatile organic compounds; (4) Ability to remove residual VOCs and "softened" SVOCs through the combined action of in-well vapor stripping and biodegradation; (5) Does not require handling or disposing of water at the ground surface; and (6) Cost-effective and improved efficiency, resulting in shortened clean-up times to remediate a site. It should be noted that while vapor stripping does a reasonable job in removing the chlorinated compounds from solution, it merely transfers the contaminant from the liquid phase to the gaseous phase; it does not destroy the organic contaminant. The sonication and the combined sonication/vapor stripping system are much more effective in destroying the chlorinated solvent contaminants
\end{abstract}




\section{PROJECT OBJECTIVES}

The specific objective of the proposed work is to investigate the in-situ degradation of semivolatile organic compounds (SVOCs) and to:

- Determine the system performance of the combined in-well sonication, vapor stripping, and biodegradation to destroy volatile organic compounds (VOCs) and change SVOCs into VOCs;

- Determine how the combined in-well vapor stripping, sonication, and in-situ biodegradation remedial system functions together at the laboratory-scale to remove SVOCs and VOCs;

- Determine the chemical reaction mechanisms for destroying VOCs and changing the SVOCs into VOCs, and improve the overall system performance;

- Quantify the roles of the individual treatment components (sonication, in-well vapor stripping, and biodegradation) on the overall effectiveness of the remediation, and acceleration. It deals with novel bioremediation reactions, alternative electron acceptor conditions, and modeling the overall system;

- After water is treated in the well with sonication and VOCs are partially removed through in-well vapor stripping, determine the role of volatilization and microbial activity on water containing VOCs that is forced to infiltrate through the unsaturated zone;

- Determine the effect of sonication/megasonics on well corrosion, and

- Identify the appropriate system design for scale-up of the remedial system for demonstration in the field and deployment.

This project has as its goal the softening of the more recalcitrant organic compounds (e.g., SVOCs and nonvolatile organic compounds) in order to convert them into compounds that are more amenable to both vapor stripping and biological treatment. The SVOCs are not effectively removed from solution using air sparging techniques. Conversion of SVOCs to VOCs could allow effective removal of the organics with vacuum extraction techniques or insitu biotreatment. This project investigates the combined treatment using in-well sonication, inwell vapor stripping, and biodegradation. The research examined the use of sound-wave energies (e.g., ultrasonics and megasonics) to transform the SVOCs to VOCs. Performing the softening in-well would permit the treated organics to be reinjected and percolated through the subsurface, thereby enhancing biodegradation rates by generating organics that are more easily biodegraded. Successful implementation of such an approach would considerably reduce both the time and cost of in-situ biotreatment. Pretreating groundwaters with sonication techniques would form VOCs that could be removed effectively by either bioremediation technologies or a dual vapor extraction technique (being developed by Stanford University under the VOC-Arid Program, now part of the Plumes Focus Area). Sonication could also be coupled with technologies aimed at mobilizing dense non-aqueous phase liquids (DNAPLs) in the subsurface, such as surfactant flooding. 


\section{INTRODUCTION/DESCRIPTION OF TECHNOLOGY}

An extensive discussion of the principles behind sonication was provided in the original research proposal for this program. The concept behind using sonication to "soften" halogenated organic compounds and polyaromatic hydrocarbons is relatively simple. By "softening", we mean partial degradation of VOCs and SVOCs. Previous biodegradation studies have demonstrated relatively long periods of time are required to biologically remediate many aquifers contaminated with halogenated compounds. However, many of the corresponding nonhalogenated organic compounds are relatively easily microbially degraded to innocuous products such as carbon dioxide $\left(\mathrm{CO}_{2}\right)$. By using the sonication step to quickly remove the bound chloride ion $\left(\mathrm{Cl}^{-}\right)$from a molecule, the by-product or remaining organic compound can be easily degraded under anaerobic or aerobic conditions.

This approach eliminates the costly proposition of using in-well sonication for a relatively long detention time to render the halogenated compounds innocuous to $\mathrm{HCl}$ and $\mathrm{CO}_{2}$. Using sonication to enhance the relatively slow step in microbial degradation (i.e., dehalogenation) will allow remediation to occur at a much faster rate. This technology can be used at sites where natural attenuation is not a realistic option. At facilities where the contamination is moving "beyond the fence", a line of treatment wells could be set-up to prevent halogenated compounds from moving off-site. The "by-products" can be degraded by natural attenuation.

The in-well sonication process utilizes in-situ ultrasonics/acoustics in a down-hole well for destruction/conversion of organic contaminants from groundwater, described in an Invention Disclosure filed by Peters and Wu [1995]. Treatment is accomplished by circulating groundwater through the ultrasonic reactor and reinjecting the treated water into the unsaturated (vadose) zone rather than lifting the treated water to the ground surface. (See the figure contained in Appendix I). The ultrasonically treated water, partially or completely free of contaminant concentrations, infiltrates back to the water table. This process is continued until the contaminant concentrations are sufficiently reduced. Addition of oxidants/catalysts into the process may further enhance the process efficiency and reduce the required sonication period. Use of an in-well ultrasonic reactor, potentially coupled with megasonics, which is more onedirectional in nature, may be required to treat more recalcitrant organic contaminants [Peters and $\mathrm{Wu}, 1995]$.

The in-well vapor stripping component of this combined sonication and stripping remedial technology is based on a special well design (see the figure contained in Appendix I) developed by Stanford University [Gorelick and Gvirtzman, 1993, 1995] that removes VOCs from groundwater without bringing the water to the surface for treatment. The well itself is screened at depth below the water table and allows groundwater contaminated with VOCs to enter the well. An upper screened interval is located above the water table and allows water depleted in VOCs to be returned to the aquifer. An eductor pipe is installed inside the well casing, creating a "well-within-a-well". Inside the inner well, an air line is introduced into which air is injected. The air is released beneath the water table, creating bubbles that rise. A simple separator plate (or well packer) is located within the inner well at an elevation above the water table. As the water/bubble mixture hits this separator plate, the water is forced laterally into the outer well and exits into the vadose zone through the upper screened interval. From there, the water freely infiltrates back to the water table using a series of infiltration galleries/trenches. The 
air bubbles, enriched in VOCs, are released into the outer well and are extracted to the ground surface under a vacuum.

In-well vapor stripping operates on two basic principles: groundwater recirculation and volatilization. Groundwater recirculation is accomplished using a dual-screened recirculation well. Air-lift pumping occurs when air is injected into the well. The density difference between the water outside the well and the water/bubble mixture within the inner well causes a lift to be created [François et al., 1996]. Water and air rise within the inner well, forcing additional water to flow from the aquifer into the well through the lower screened interval. The water and bubble mixture flows upward in the annular space around the air line. Because the water enters the well as the lower screened interval and returned to the water table, a groundwater circulation cell is developed in the vicinity of the well. The second operating principle is that of volatilization [Gvirtzman and Gorelick, 1992; Pinto, 1996]. When contaminated water enters the well at the lower screened interval, it encounters the injected air which has formed bubbles. The VOCs will volatilize and mass is transferred from the water to the gas phase. Given approximately 20 feet of contact distance between the contaminated water and the air bubbles, equilibrium partitioning occurs. The air within the well strips out the VOCs. During a demonstration conducted at Edwards Air Force Base demonstration, approximately $90 \%$ of the trichloroethylene (TCE) was stripped from the water with each pass through the well. This air is separated from water using the separator plate located above the upper screened interval and the VOC-enriched vapor is vacuumed off and treated by sorption onto granular activated carbon. The water exiting the well at the upper screened interval has then been depleted of VOCs and is returned to the aquifer where microbial degradation can occur, depending upon the type of compound, and during sequential passes through the treatment well, additional VOCs are stripped and removed. In-well vapor stripping has efficacy at any level of contaminant concentration and can be particularly effective when VOC concentrations are high.

The combined remedial system will take contaminated water and remove a significant portion of the SVOCs and VOCs in the well (the treatment well). The system operates by employing groundwater recirculation as described previously. Contaminated water enters the well and with each pass through the well contaminants are removed by both sonication and volatilization. A radial clean-up zone is created around the well. Previous work on recirculation wells [Philip and Walter, 1992; Kabala, 1993; Herrling et al., 1991; Gvirtzman and Gorelick, 1992] has shown that a single well can achieve a zone of cleanup that extends radially 2 to 3 times the aquifer thickness. Groundwater entering this zone under regional flow conditions will be recycled and cleaned. It is expected that with each pass through the well, in-well vapor stripping will remove approximately 90 to $99 \%$ of the VOCs, and sonication will remove $90+\%$. Any residual VOCs may be biodegraded as the water enters the unsaturated zone. In addition, the VOC vapors that are produced by the in-well vapor stripping system may be treated at the ground surface or may be degraded in-situ in the unsaturated zone through microbial activity.

\section{RELEVANCE TO EMSP GOALS}

This research work is consistent with the mission of providing the scientific understanding needed to develop methods for accelerating biodegradation processes for remediation of contaminated soils, sediments, and groundwater at DOE facilities. This project relates to in-situ chemical transformation, volatilization, and biodegradation; it deals with novel bioremediation reactions, alternative electron acceptor conditions, and modeling. Once 
sufficiently developed, the technique could be demonstrated at sites such as Hanford's 200 Area, Savannah River's A/M Area, the Paducah Gaseous Diffusion Plant's NE and NW Plumes, Argonne's 317/319 Area, and Lawrence Livermore's Main Site.

\section{BACKGROUND}

Boyd and Geiser [2000] have pointed out the need to develop integrated system technologies; cleanup under DOE's Environmental Management Cleanup Program ties multiple technologies in an integrated solution to solve specific site/facility problems. Due to the complexity of environmental problems at these facilities, there are no "silver bullets" to solve these problems; it is essential that several technologies be combined together in a synergistic fashion. By coupling technologies, it is possible to collapse cleanup schedules drastically, enabling return on investments exceeding 10:1, and allows cleanup and closure of sites much more rapidly [Boyd and Geiser, 2000]. The innovative technology in this research project couples in-well sonication, in-well vapor stripping, and biodegradation into an integrated process (see the figure contained in Appendix I). By partially destroying the SVOCs (e.g., opening up the benzene-ring structures), the ability to remove the resultant VOCs and biotreatment of the resultant organics is enhanced (over the case of biotreatment alone).

\section{Background -- Ultrasound}

The introduction of high power ultrasound (i.e., sound energy with frequencies in the range of $15 \mathrm{kHz}$ to $\sim 1 \mathrm{MHz}$ ) into liquid reaction mixtures is known to cause a variety of chemical transformations. In recent years, due to the growing need to eliminate undesirable chemical compounds, the utilization of high energy ultrasound for hazardous waste treatment has been explored with great interest [Hua and Hoffmann, 1996a,b; Hua et al., 1995a,b; Hoffmann et al., 1996; Kotronarou et al., 1991, 1992a,b; Kotronarou and Hoffmann, 1995].

Sonication of liquid media results in the formation of microbubbles that grow to a critical size and then implode. Temperatures at the collapsing bubble interface are about $5,000^{\circ} \mathrm{K}$ and pressures are near 500 atmospheres, but the bulk solution remains near ambient conditions. In these highly reactive conditions, hydroxyl radicals ( $\mathrm{OH}$ ) and hydrogen ions $(\mathrm{H})$ are generated; they are very effective at degrading organic compounds. If organic compounds are present in the water, they are rapidly destroyed, either directly or by reacting with the free radicals. The intensity of cavity implosion, and hence the nature of the reactions involved, can be controlled by process parameters such as the ultrasonic frequency, ultrasonic intensity per unit volume of liquid medium, static pressure, choice of ambient gas, and addition of oxidants (e.g., $\mathrm{H}_{2} \mathrm{O}_{2}, \mathrm{O}_{3}$ ).

The application of ultrasonic irradiation for treatment of hazardous chlorinated organic wastes started in the early 1980s. Argonne has been at the forefront of this research. To demonstrate the feasibility of the ultrasonic detoxification process and to obtain kinetic information about the process, two bench-scale batch-processing units, one pilot-scale batch/continuous-processing unit, and one continuous-flow unit were set up at Argonne. Research activities at Argonne have concentrated on the ultrasonic decomposition of hazardous organic compounds present in aqueous samples (including laboratory-prepared, laboratory-simulated, and real samples received from the field) from industrial waste streams and groundwaters. Results from these experiments indicated that ultrasonics or ultrasonics-enhanced advanced oxidation processes can convert the hazardous organic contaminants to non-toxic or 
less toxic, simpler organic compounds. For some simpler but toxic organic compounds (such as carbon tetrachloride, trichloroethylene, etc.), the introduced ultrasonic energy completely converts the compounds into non-hazardous compounds such as water, carbon dioxide, and hydrochloric acid. Of the process parameters investigated to date, the intensity of the ultrasonic-wave energy was found to have the largest effect on the destruction rate of the contaminant (which increases with the intensity). The results verified that the irradiation time required for a given degree of destruction can be further reduced by the addition of a small amount of chemical oxidant such as hydrogen peroxide. Some of these results have been published in the technical journals and conference proceedings.

Ultrasonic irradiation can easily be integrated with existing, conventional treatment systems, making it possible to simultaneously treat hazardous and non-hazardous waste streams. Successful development and deployment of this technology could completely change the treatment of wastes generated in the DOE complex.

\section{Physical and Chemical Principles -- Ultrasound}

Ultrasonic irradiation of liquid reaction mixtures induces electrohydraulic cavitation, which is a process during which the radii of preexisting gas cavities in the liquid oscillate in a periodically changing pressure field created by the ultrasonic waves. These oscillations eventually become unstable, forcing the violent implosion of the gas bubbles. The rapid implosion of a gaseous cavity is accompanied by adiabatic heating of the vapor phase of the bubble, yielding localized and transient high temperatures and pressures (while the bulk solution remains near ambient conditions). Temperatures on the order of $4,200^{\circ} \mathrm{K}$ and pressures of 975 bar have been estimated [Mason and Lorimer, 1988]. Experimental values of $\mathrm{P}=313$ atmospheres and $\mathrm{T}=3,360^{\circ} \mathrm{K}$ have been reported [Sehgal et al., 1977] for aqueous systems, while temperatures in excess of $5,000^{\circ} \mathrm{K}$ have been reported [Flint and Suslick, 1989, 1991; Suslick et al., 1986] for cavitation of organic and polymeric liquids. Recent experimental results on the phenomenon of sonoluminescence [Crum and Roy, 1994; Crum 1994] suggest that even more extreme temperatures and pressures are obtained during cavitational bubble collapse [Putterman, 1995]. Thus, the apparent chemical effects in liquid reaction media are either direct or indirect consequences of these extreme conditions.

Even though the basic physical and chemical consequences of cavitation are fairly-well understood, many fundamental questions about the cavitation site in aqueous solution remain unanswered. In particular, the dynamic temperature and pressure changes at the bubble interface and their effects on chemical reactions need further exploration. Since this region is likely to have transient temperatures and pressures in excess of $647^{\circ} \mathrm{K}$ and 221 bar for periods of microseconds to milliseconds, supercritical water (SCW) has been proposed that provides an additional phase for chemical reactions during ultrasonic irradiation in water [Hua et al., 1995b]. Supercritical water exists above the critical temperature, $\mathrm{T}_{c}$, of $647^{\circ} \mathrm{K}$ and the critical pressure, $\mathrm{P}_{c}$, of 221 bar and has physical characteristics intermediate between those of a gas and a liquid. The physicochemical properties of water such as viscosity, ion-activity product, density, and heat capacity change dramatically in the supercritical region. These changes favor substantial increases for rates of most chemical reactions.

Two distinct sites for chemical reactions exist during a single cavitation event [Hua et al., 1995b; Kotronarou et al., 1991]. They are the gas-phase in the center of a collapsing cavitation 
bubble and a thin shell of superheated liquid surrounding the vapor phase. The volume of the gaseous region is estimated to be larger than that of the thin liquid shell by a factor of $\sim 2 \times 10^{4}$.

During cavitation/bubble collapse, which occurs within $100 \mathrm{~ns}$, water undergoes thermal dissociation within the vapor phase to give hydroxyl radical and hydrogen atoms as follows:

$$
\mathrm{H}_{2} \mathrm{O} \rightarrow \mathrm{H}+\mathrm{OH}
$$

The concentration of $\bullet \mathrm{OH}$ at a bubble interface in water has been estimated to be $4 \times 10^{-3}$ M [Gutiérrez et al., 1991]. Many of the chemical effects of ultrasonically induced cavitation have been attributed to the secondary effects of $\bullet \mathrm{OH}$ and $\mathrm{H} \bullet$ production.

For treatment of carbon tetrachloride $\left(\mathrm{CCl}_{4}\right)$-contaminated waters, Wu et al. [1992a,b] speculated that the major reactions involved were bond-cleavage of water and of $\mathrm{CCl}_{4}$ in the cavitation hole. Destructions greater than $99 \%$ were achieved. First-order kinetics were observed within the experimental concentration ranges studied (up to $130 \mathrm{mg} / \mathrm{L}$ of $\mathrm{CCl}_{4}$ ). The residual $\mathrm{CCl}_{4}$ concentration decreased for increasing $\mathrm{pH}$ in the range of 3 to 9 (for the same applied sonication period). Better sonication efficiency was observed at higher initial $\mathrm{pH}$ values; however, this improvement diminished for $\mathrm{pH}>6$. In the experimental conditions employed in their study, the researchers concluded that temperature and $\mathrm{pH}$ had little effect on the $\mathrm{CCl}_{4}$ destruction rate; however, the destruction rate was significantly affected by the intensity of the ultrasonic energy. The destruction rate exhibited a linear relationship with the applied power intensity. Adding hydrogen peroxide as an oxidant had a negligible effect on the destruction rate (with or without ultrasonic irradiation), suggesting that the destruction of $\mathrm{CCl}_{4}$ in water under ultrasonic irradiation was dominated by the high temperature dissociation reactions within the collapsing cavities [Wu et al., 1992b].

Destruction of pesticides such as atrazine was shown to be effective using a Fenton's oxidation system, and was enhanced by the application of sonication [Peters and $\mathrm{Wu}, 1996$ ]. Removal efficiencies of atrazine exceeded 90\%, even for treatment times as low as 5 minutes. Sonication improved the removal of atrazine by at least $10 \%$ for treatment times of 10 minutes or less. Higher dosages of $\mathrm{Fe}^{+2}$ and $\mathrm{H}_{2} \mathrm{O}_{2}$ resulted in higher removals of atrazine from solution. They investigated four separate systems for their ability to remove atrazine from solution: (1) Fenton's oxidation conducted without application of UV light; (2) Fenton's oxidation conducted in the presence of UV light; (3) Fenton's oxidation conducted using sonication in the absence of UV light; and (4) Fenton's oxidation conducted using sonication in the presence of UV light. Of these four systems, the sonication-enhanced Fenton's oxidation resulted in the best treatment of the Fenton's oxidation systems studied. That system promoted the formation of hydroxyl radicals $(\bullet \mathrm{OH})$ to more effectively destroy the organic contaminants (e.g., atrazine). Their work showed that addition of oxidants such as $\mathrm{H}_{2} \mathrm{O}_{2}$ or Fenton's Reagent could enhance organic destruction using sonication.

Sonochemical reactions in water are characterized by the simultaneous occurrence of supercritical water reactions, direct pyrolyses, and radical reactions especially at high solute concentrations. Volatile solutes such as carbon tetrachloride [Hua and Hoffmann, 1996a] and 
hydrogen sulfide [Kotronarou et al., 1992b] undergo direct pyrolysis reactions within the gas phase on the collapsing bubbles or within the hot interfacial region as shown below:

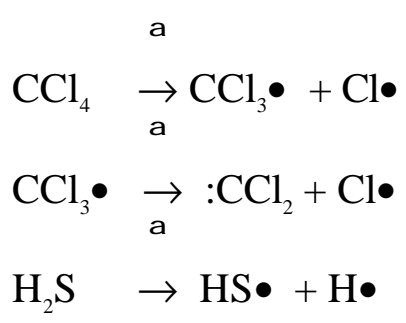

while low-volatility solutes such as thiophosphoric acid esters [Kotronarou et al., 1992a] and phenylate esters [Hua et al., 1995b; Kotronarou et al., 1992a] can react in transient supercritical phases generated within a collapsing bubble. In the case of ester hydrolysis, reaction rates are accelerated 102 to 104 times the corresponding rates under controlled kinetic conditions (i.e., same $\mathrm{pH}$, ionic strength, and controlled overall temperature). This effect can best be illustrated by the catalytic effect of ultrasonic irradiation on the rate of hydrolysis of parathion in

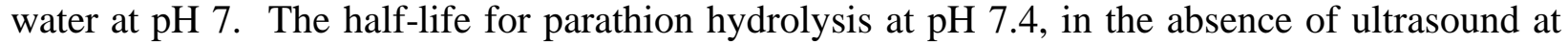
$25^{\circ} \mathrm{C}$ is 108 days. However, in the presence of ultrasound, the half-life is reduced to 20 minutes [Kotronarou et al., 1992a].

Pyrolysis (i.e., combustion) and supercritical water reactions in the interfacial region are predominant at high solute concentrations, while at low solute concentrations, free radicals are likely to predominate. Depending on its physical properties, a molecule can simultaneously or sequentially react in both the gas and interfacial liquid regions.

In the specific case of hydrogen sulfide gas dissolved in water, both pyrolysis in the vapor phase of the collapsing bubbles and hydroxyl radical attack in the quasi liquid interfacial region occur simultaneously as follows:

$$
\begin{aligned}
& \stackrel{\text { тм }}{\mathrm{H}_{2} \mathrm{~S}} \rightarrow \mathrm{HS} \bullet+\mathrm{H} \bullet \\
& \mathrm{H}_{2} \mathrm{~S}+\bullet \mathrm{OH} \rightarrow \mathrm{HS} \bullet+\mathrm{H} 2 \mathrm{O}
\end{aligned}
$$

Hua and Hoffmann [1996a] investigated the rapid sonolytic degradation of aqueous carbon tetrachloride $\left(\mathrm{CCl}_{4}\right)$ at an ultrasonic frequency of $20 \mathrm{kHz}$ and at an applied power of $130 \mathrm{~W}\left(108 \mathrm{~W} / \mathrm{cm}^{2}\right)$. The rate of disappearance of $\mathrm{CCl}_{4}$ was found to be first-order over a broad range of conditions, consistent with the results of $\mathrm{Wu}$ et al. [1992a,b]. The observed first-order degradation rate constant was $3.3 \times 10^{-3} \mathrm{~s}^{-1}$ when $\left[\mathrm{CCl}_{4}\right]_{\mathrm{i}}=195 \mathrm{mM} ; \mathrm{k}_{\mathrm{obs}}$ was observed to increase slightly to $3.9 \times 10^{-3} \mathrm{~s}^{-1}$ when $\left[\mathrm{CCl}_{4}\right]_{\mathrm{i}}$ was decreased by a factor of ten (i.e., $\left[\mathrm{CCl}_{4}\right]_{\mathrm{i}}=19.5 \mathrm{mM}$ ) [Hua and Hoffmann, 1996a]. Low concentrations of hexachloroethane, tetrachloroethylene, and hypochlorous acid $(\mathrm{HOCl})$ in the range of 0.01 to $0.1 \mathrm{mM}$, were detected as transient intermediates, while chloride ion and $\mathrm{CO}_{2}$ were found to be stable products.

The highly reactive intermediate, dichlorocarbene, was identified and quantified by means of trapping with 2,3-dimethylbutene. Evidence for involvement of the trichloromethyl radical was also obtained and was indirectly implied by the formation of hexachloroethane. The 
presence of ozone during sonolysis of $\mathrm{CCl}_{4}$ did not affect the degradation of carbon tetrachloride but was shown to inhibit the accumulation of hexachloroethane and tetrachloroethylene.

The following mechanism was proposed to account for the observed kinetics, reaction intermediates, and final products:

$$
\begin{aligned}
& \mathrm{CCl}_{4} \underset{\text { тм }}{\rightarrow} \bullet \mathrm{CCl}_{3}+\mathrm{Cl} \bullet \\
& \mathrm{CCl}_{3} \rightarrow: \mathrm{CCl}_{2}+\mathrm{Cl} \bullet
\end{aligned}
$$

Formation of dichlorocarbene, $: \mathrm{CCl}_{2}$ is also thought to occur by the simultaneous elimination of two chlorine atoms:

$$
\mathrm{CCl}_{4} \rightarrow: \mathrm{CCl}_{2}+\mathrm{Cl}_{2} \bullet
$$

A third mechanism for dichlorocarbene formation is disproportionation of the trichloromethyl radical that can be inferred from an analogous reaction between the trifluoromethyl radical and the hydrodifluoromethyl radical:

$$
\bullet \mathrm{CCl}_{3}+\bullet \mathrm{CCl}_{3} \rightarrow \mathrm{CCl}_{4}+: \mathrm{CCl}_{2}
$$

All three pathways are possible at the hot center of the imploding microbubble. The trichloromethyl radical can also couple to form hexachloroethane:

$$
\bullet \mathrm{CCl}_{3}+\bullet \mathrm{OH} \rightarrow \mathrm{HOCCl}_{3}
$$

In the presence of oxidizing species, the trichloromethyl radical can act as a scavenger of hydroxyl radicals:

$$
\bullet \mathrm{CCl}_{3}+\bullet \mathrm{OH} \rightarrow \mathrm{HOCCl}_{3}
$$

or molecular oxygen:

$$
\bullet \mathrm{CCl}_{3}+\bullet \mathrm{O}-\mathrm{O} \bullet \rightarrow \mathrm{O}-\mathrm{OCCl}_{3}
$$

Based on analogous gas-phase mechanisms, the reactive intermediate $\mathrm{HOCCl}_{3}$ appears to rapidly react to yield phosgene and other products as follows:

$$
\begin{aligned}
& \mathrm{HOCCl}_{3} \rightarrow \mathrm{HCl}+\mathrm{COCl}_{2} \\
& \mathrm{COCl}_{2}+\mathrm{H}_{2} \mathrm{O} \rightarrow \mathrm{CO}_{2}+2 \mathrm{HCl} \\
& -\mathrm{O}-\mathrm{OCCl}_{3}+\mathrm{H}_{2} \mathrm{O} \rightarrow \mathrm{HOCCl}_{3}+\mathrm{HO}_{2}
\end{aligned}
$$

Phosgene hydrolysis in water is rapid [Manogue and Pigford, 1960] under ambient conditions; and the rate constant is positively correlated with increasing temperature. Thus, the hydrolysis of this intermediate can be enhanced by the occurrence of supercritical water during cavitational microbubble collapse:

$$
\mathrm{COCl}_{2}+\mathrm{H}_{2} \mathrm{O} \rightarrow 2 \mathrm{HCl}+\mathrm{CO}_{2}
$$


The dichlorocarbene can be coupled for form tetrachloroethylene:

$$
2: \mathrm{CCl}_{2} \rightarrow \mathrm{C}_{2} \mathrm{Cl}_{4}
$$

or hydrolyze to carbon monoxide and hydrochloric acid:

$$
: \mathrm{CCl}_{2}+\mathrm{H}_{2} \mathrm{O} \rightarrow \mathrm{CO}+2 \mathrm{HCl}
$$

Chlorine atoms can combine to form molecular chlorine, which hydrolyses to hypochlorous acid and chloride ion:

$$
2 \cdot \mathrm{Cl} \rightarrow \mathrm{Cl}_{2} \rightarrow \mathrm{HOCl}+\mathrm{HCl}
$$

The formation of the reactive intermediate, dichlorocarbene, is confirmed by the selective trapping of the carbene with 2,3-dimethyl-2-butene to form 1,1-dichloro-2,2,3,3-tetramethylcyclopropane. In a similar fashion, the trichloromethyl radical is trapped by 2,3-dimethyl-2-butene to yield 2-methyl-2-trichloromethyl-1-butene. These trapped intermediates can be identified and quantified by gas chromatography/mass spectroscopy (GC/MS) techniques.

\section{In-Well Vapor Stripping}

In-well vapor stripping has been demonstrated at Edwards Air Force Base (AFB) for the removal of dissolved TCE from groundwater. The in-well vapor stripping component of this combined sonication and stripping remedial technology is based on a special well. The well itself is screened at two horizontal intervals [Gvirtzman and Gorelick, 1992, 1993; Gorelick and Gvirtzman, 1993, 1995]. A lower screened interval is located at depth below the water table and allows groundwater contaminated with VOCs to enter the well. An upper screened interval is located above the water table and allows water depleted in VOCs to be returned to the aquifer. An eductor pipe is installed inside the well casing creating a well-within-a-well. Inside the inner well, an air line is introduced into which air is injected. The air is released beneath the water table, creating bubbles that rise. A simple separator plate (or well packer) is located within the inner well at an elevation above the water table. As the water/bubble mixture hits this separator plate, the water is forced laterally into the outer well and exits into the vadose zone through the upper screened interval. From there, the water freely infiltrates back to the water table. The air bubbles, enriched in VOCs, are released into the outer well and are extracted to the ground surface under a vacuum.

As discussed previously, in-well vapor stripping operates on two basic principles. The first is that of groundwater recirculation and is accomplished using a dual-screened recirculation well. Air-lift pumping occurs when air is injected into the well. Due to the density difference between the water outside the well and the water/bubble mixture within the inner well, a lift is created [François et al., 1996]. Water and air rise within the inner well, forcing additional water to flow from the aquifer into the well through the lower screened interval. The water and bubble mixture flows upward in the annular space around the air line. Because the water enters the well as the lower screened interval and returned to the water table, a groundwater circulation cell is 
developed in the vicinity of the well. The second operating principle is that of volatilization [Gvirtzman and Gorelick, 1992; Pinto et al., 1996]. When contaminated water enters the well at the lower screened interval, it encounters the injected air which has formed bubbles. The VOCs will volatilize and mass is transferred from the water to the gas phase. Given approximately 20 feet of contact distance between the contaminated water and the air bubbles, equilibrium partitioning occurs. The air within the well strips out the VOCs. During the Edwards AFB demonstration, approximately $90 \%$ of the TCE was stripped from the water with each pass through the well. This air is separated from water using the separator plate located above the upper screened interval and the VOC-enriched vapor is vacuumed off and treated by sorption onto granular activated carbon. The water exiting the well at the upper screened interval has then been depleted of VOCs and is returned to the aquifer where microbial degradation can occur, depending upon the type of compound, and during sequential passes through the treatment well, additional VOCs are stripped and removed. In-well vapor stripping has efficacy at any level of contaminant concentration and can be particularly effective when VOC concentrations are high.

The combined remedial system will take contaminated water and remove a significant portion of the SVOCs and VOCs in the well (the treatment well). The system operates by employing groundwater recirculation as described previously. Contaminated water enters the well and with each pass through the well contaminants are removed by both sonication and volatilization. A radial clean-up zone is created around the well. Previous work on recirculation wells [Philip and Walter, 1992; Kabala, 1993; Herrling et al., 1991; Gvirtzman and Gorelick, 1992] has shown that a single well can achieve a zone of cleanup that extends radially 2 to 3 times the aquifer thickness. Groundwater entering this zone under regional flow conditions will be recycled and cleaned. It is expected that with each pass through the well, in-well vapor stripping will remove approximately 90 to $99 \%$ of the VOCs, and sonication will remove $90+\%$. Any residual VOCs may be biodegraded as the water enters the unsaturated zone. In addition, the VOC vapors that are produced by the in-well vapor stripping system may be treated at the ground surface or may be degraded in-situ in the unsaturated zone through microbial activity.

\section{$\underline{\text { In-Situ Biotreatment }}$}

Chlorinated solvents have been biodegraded in-situ by a variety of investigators [Mohn and Tiedje, 1992; Semprini et al., 1992; Criddle et al., 1990; Tatara et al., 1993]. Unfortunately, the rate of degradation is very slow. Weathers and Parkin [1995] have demonstrated that chlorinated solvent transformation was enhanced using methanogenic cell suspensions and iron filings (zero-valent metals). Although the exact mechanism of this activity is unknown, O'Hannesin [1993] demonstrated the loss of PCE and TCE (86\% and 90\%, respectively) and the near stoichiometric increase in dissolved chloride and detection of chlorination products. Matheson and Tratnyek [1994] reported non-stoichiometric sequential reduction of carbon tetrachloride $\left(\mathrm{CCl}_{4}\right)$ to chloroform and dichloromethane by iron in laboratory settings. Under anaerobic conditions, however, Helland et al. [1995] observed reduced carbon tetrachloride transformation rates by iron metal.

Kriegman-King and Reinhard [1992, 1994] have reported on the transformation of $\mathrm{CCl}_{4}$ in the presence of sulfide, pyrite, and certain clays. In some of their work, they demonstrated $\mathrm{CCl}_{4}$ dechlorination to $\mathrm{CHCl}_{3}$ by pyrite. This transformation was blocked by sulfide ion. 
The result of all this work is to encourage a physical/chemical method of removing the halogen groups and the resultant "softened" organics can then be biodegraded at relatively enhanced rates. This approach minimizes the rate limiting step of dechlorination by microbial mechanisms and enhances the relatively easy non-halogenated degradation of the remaining organic compounds.

\section{ADVANTAGES OF THE IN-WELL SONICATION/IN-WELL VAPOR STRIPPING/IN-SITU BIODEGRADATION APPROACH}

The research work is consistent with the mission of providing the scientific understanding needed to develop methods for accelerating biodegradation processes for remediation of contaminated soils, sediments, and groundwater at DOE facilities. This project relates to in-situ chemical transformation (e.g., softening of SVOCs), in-well vapor stripping, and biodegradation. The innovative technology couples in-well sonication, in-well vapor stripping, and biodegradation into an integrated process. By partially destroying the SVOCs (e.g., opening up the benzene-ring structures), the ability to remove the resultant VOCs and biotreatment of the resultant organics is enhanced (over the case of biotreatment alone). Advantages of this technique include:

- Remediation is performed in-situ (i.e., does not require handling or disposing of water at the ground surface);

- Treatment systems complement each other and their combination has the potential to drastically reduce or remove SVOCs and VOCs;

- System has the potential to add other innovative components (such as in-situ chemical treatments or surfactants);

- Ability to convert hard-to-degrade organics such as chlorinated organics and heavy organics (e.g., polyaromatic hydrocarbons) into more volatile organic compounds;

- Ability to destroy chlorinated organic compounds;

- Ability to remove residual VOCs and softened SVOCs through the combined action of in-well vapor stripping and biodegradation;

- Improved in-situ biotreatment of contaminated soils and groundwater; and

- Cost-effective and improved efficiency thereby shortening the time required to clean-up a contaminated site.

Results from this study have been presented at various technical conferences [Peters et al., 2000, 1999, 1998a,b]. Argonne National Laboratory has investigated the use of sonication alone, vapor stripping alone, and the combined in-well sonication/in-well vapor stripping system to treat chlorinated organic contaminants in groundwater [e.g., carbon tetrachloride $\left(\mathrm{CCl}_{4}\right)$, trichloroethylene (TCE), 1,1,1-trichloroethane (TCA), and 1,1,2,2-tetrachloroethylene (PCE)]. Pretreating groundwaters by use of sonication techniques forms volatile organic compounds (VOCs) that can be more efficiently removed by in-well vapor stripping and in-situ biodegradation. Figure 1 shows the results from batch treatment of groundwater containing $\sim 50 \mathrm{mg} / \mathrm{L}$ of the chlorinated organic compounds, using both sonication alone and sonication+vapor stripping. Figure 2 shows the residual TCE concentration following application of sonication alone and sonication+vapor stripping for continuous flow conditions; for reactor residence times ranging from 5 to 10 minutes, removals of $\mathrm{CCl}_{4}$ and TCA were $74 \%$ 
to $88 \%$ and $72 \%$ to $97 \%$, respectively, for a one-pass system. Sonication alone or vapor stripping alone results in removals ranging from $\sim 20 \%$ to $\sim 50 \%$; however, combining sonication with vapor stripping enhances removal of $\mathrm{CCl}_{4}, \mathrm{TCE}$, TCA, and PCE as compared to removal by either system alone (sonication or vapor stripping) by nearly an order of magnitude, and results in synergistic behavior enhancing removal efficiency. The combination of sonication with vapor stripping results in much better mixing, creation of much finer bubbles, thereby enhancing mass transfer from the liquid phase to gaseous phase, and enhancing the destruction of the chlorinated organic compounds during the microbubble implosions. As we move to higher ultrasonic frequencies and great applied power densities, plus incorporation of multiple frequencies and improved focusing and directionalizing of acoustic waves, we expect the system performance to be even better in the pilot-scale and field demonstration phases as compared to the laboratory data reported here.

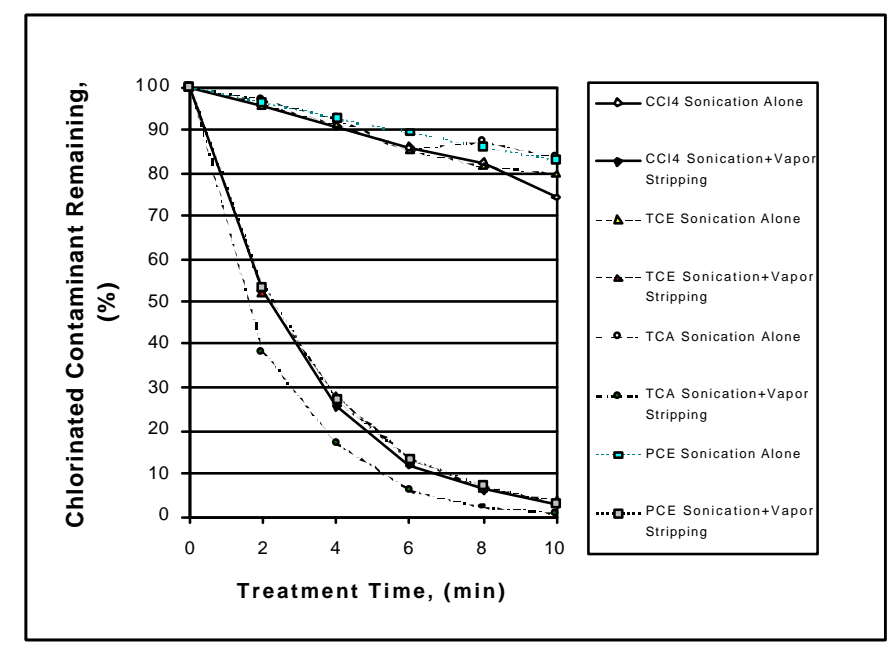

Fig. 1. Residual chlorinated organic compound remaining after batch sonication and sonication+vapor stripping treatment.

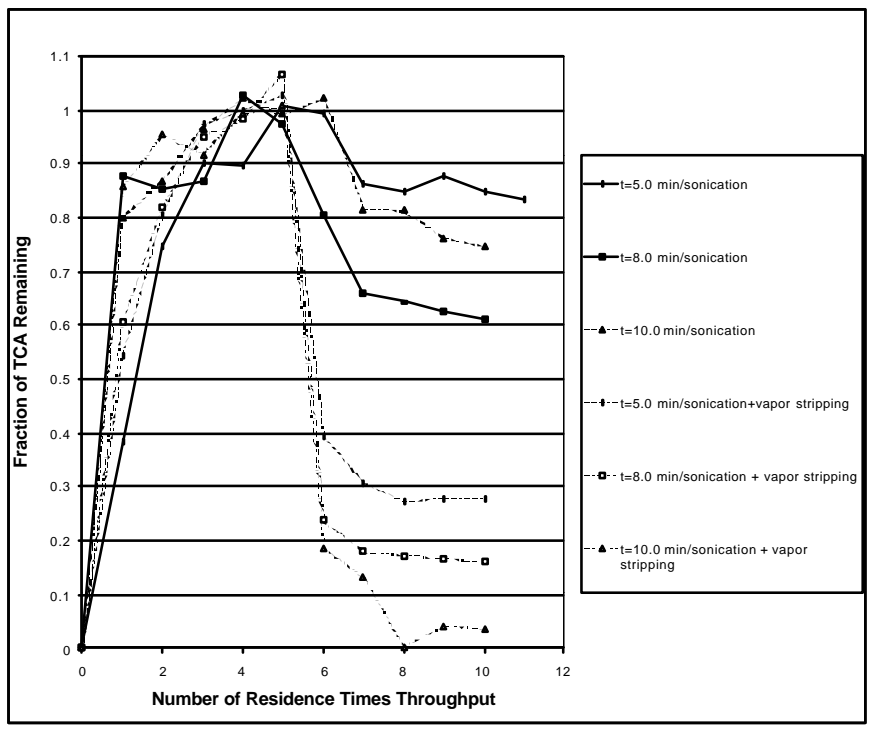

Fig. 2. Residual chlorinated organic compound remaining after continuous sonication and sonication+vapor stripping treatment.

\section{TECHNICAL ISSUES}

A number of issues need to be addressed to develop and demonstrate the in-well softening technology, as summarized below:

- Design of in-well system/couple with ultrasonics/megasonics;

- Identification of breakdown/daughter products and their volatilities;

- Biodegradability of parent and breakdown/daughter products;

- Measurement of $\bullet \mathrm{OH}, \mathrm{H} \bullet$, and other radicals, and investigation of their roles in the chemical reactions;

- Mass balance closure;

- Investigation of key parameters affecting process (e.g., dissolved gases, salt concentration, etc.);

- Fouling/scaling of process under hard water environments; 
- Zone of influence, treatment zone, and time requirements in subsurface (modeling); and

- Enhancements afforded with $\mathrm{H}_{2} \mathrm{O}_{2}$ or Fenton's Reagent

These issues were addressed in the various tasks described in this research project, in order to develop the technology for deployment.

The innovative technology couples in-well sonication, in-well vapor stripping, and biodegradation into an integrated process. By partially destroying the SVOCs (e.g., opening up the benzene-ring structures), the ability to remove the resultant VOCs and biotreatment of the resultant organics is enhanced (over the case of biotreatment alone).

\section{RESEARCH PROGRESS}

\section{Initial Quality Assurance/Quality Control Methods Development}

Considerable effort went into development of appropriate analytical procedures and methods associated with using volatile compounds. Analytical method development included selection and procurement of a Hewlett Packard 7694 Automatic Headspace Sampler for use with the Hewlett Packard 5890 Gas Chromatograph. Headspace analysis is well-suited for analysis of volatile and semivolatile organic compounds in water, and avoids the column degradation caused by liquid injection of water. The headspace sampling method includes ten minutes equilibration of samples at $70^{\circ} \mathrm{C}$ with shaking, programmed vial pressurization, venting, sample loop fill ( $1 \mathrm{~mL}$ loop volume), and 0.30 minute injection time. Equilibration time was selected by measuring area response for times ranging from 1 to 60 minutes. A 30 meter megabore fused capillary DB-624 column was selected based on its sensitivity and selectivity in analysis of chlorinated organic compounds. The HP 5890 chromatograph is equipped with both flame ionization and electron capture detectors. In the analytical range for this project $(0.1$ to $100 \mathrm{ppm}$ ), flame ionization provided adequate resolution and reproducible detection. The electron capture detector was found to be too sensitive for detection of major components, but is useful in examining sonicated samples for minor breakdown products. The GC temperature program was set for 1 minute at $90^{\circ} \mathrm{C}$, ramping $10^{\circ} /$ minute to $140^{\circ}$, then $25^{\circ} /$ minute to $200^{\circ}$, and held for 2 minutes at $200^{\circ} \mathrm{C}$. Standards were initially prepared in volumetric flasks. Due to analyte volatility, this was changed to injection by syringe through the vial septum of the chlorinated compounds into measured water mass. Planned sample size was $5 \mathrm{~mL}$ in $10 \mathrm{~mL}$ vials, however this was reduced to $1 \mathrm{~mL}$ in $10 \mathrm{~mL}$ vials to avoid overloading the column with analyte. Response of carbon tetrachloride standards held in sealed vials over a 0.25 to 48 hour time range was evaluated to determine how long samples could be stored prior to GC analysis. It was found that vials analyzed within three hours after sampling gave the most reproducible response. Vials showed a drop in response to approximately $80 \%$ at 15 hours, and to $20-40 \%$ at 25 hours. Since the hydrolysis rate for $\mathrm{CCl}_{4}$ in water is very low, there appears to be loss through the vial seal or septum. Therefore all subsequent samples and standards were analyzed as closely as possible to the actual sampling time, and all within three hours. Five analyte standards were prepared each day for the initial calibration curve, and check standards were performed late in the day, or when any questionable sample result was obtained. 


\section{Research Results}

The research results for the various tasks performed on this project summarized below:

\section{Task 1. Quantify representative VOC and SVOC contaminants at DOE facilities}

From the list of candidate contaminants, the contaminants $\mathrm{CCl}_{4}, \mathrm{TCE}, \mathrm{TCA}, \mathrm{PCE}$, and EDB were selected for this study.

Task 2. Conduct batch sonication experiments to determine preliminary optimal conditions for subsequent continuous-flow experiments

Under Task 2, the experiments were designed to investigate the degradation of halogenated organic compounds by ultrasonic irradiation of a solution. The compounds initially targeted for this study are carbon tetrachloride $\left(\mathrm{CCl}_{4}\right)$, trichloroethylene (TCE), tetrachloroethylene (PCE), 1,1,1-trichloroethane (TCA), and ethylenedibromide (EDB). For the sake of brevity of this report, selected results from the batch sonication system testing only $\mathrm{CCl}_{4}$, TCE, and TCA, are included below. Results of these two compounds are representative of the general trends observed. The effects of varying sonication time, ultrasonic power intensities, initial concentrations of target compounds, $\mathrm{pH}$, and hydrogen peroxide were examined. The results of these tests aided in the determination of the operation conditions for a continuous-flowing ultrasonic irradiation system in Task 4. Procedural effects were also examined to better understand potential interferences. These included temperature increase of the sample due to sonication, and loss of the target compound due to volatilization.

\section{Temperature Increase Due to Sonication}

Experiments performed to date were all started with an initial sample temperature of $20^{\circ} \mathrm{C}$. The sample was placed in a circulating constant temperature water bath to minimize temperature fluctuation during sonication. During the batch sonication experiments, sample temperatures increased $6^{\circ} \mathrm{C}$ to $8^{\circ} \mathrm{C}$ (from $\sim 20^{\circ} \mathrm{C}$ to $\sim 26^{\circ} \mathrm{C}-28^{\circ} \mathrm{C}$ ) over the 10 -minute period of sonication. No pattern was observed due to the presence of or concentration of the $\mathrm{CCl}_{4}$. A higher power intensity used will increase the sample temperature more rapidly than a lower

power intensity. Slight variations in these results are most likely due to the slight variation in the power output of the sonicator from run to run.

How this may effect the performance of sonication to break down the target compounds is questionable and probably insignificant. Higher temperatures could slightly decrease the effect of sonication on the compounds in the range of $20^{\circ} \mathrm{C}$ to $30^{\circ} \mathrm{C}$. Also, if the temperature was near the boiling point of solvent (water in this case) the extreme condition of cavitation would disappear and the target compounds would not be dissociated because the water vapor would fill the cavitation bubbles and cushion the implosion phenomena. 
Once potential procedural interferences were established to be minimal (described above), samples spiked with the target compounds were sonicated to determine the effectiveness of ultrasonics on decreasing the concentration of the compound in the sample solution. As described in the methods section, $500 \mathrm{~mL}$ samples were sonicated for 10 minutes and sampled at certain intervals during sonication. Results indicated that the rate of reduction is greater with a lower initial concentration.

First-order plots of the natural logarithm of $\mathrm{CCl}_{4}$ concentrations versus sonication time were generated for each experimental run. The experimental data fit the first-order reaction kinetic model. Degradation rate constants of $\mathrm{CCl}_{4}$ for the first-order model were obtained from the slopes of the linear regression of the plots according to the equation:

$$
-\frac{\mathrm{d}\left[\mathrm{CCl}_{4}\right]}{\mathrm{dt}}=\mathrm{k}\left[\mathrm{CCl}_{4}\right]
$$

\section{Varying Power Intensities of the Ultrasonic Irradiation}

The effect of varying the wattage introduced per probe tip surface area to the sample was also investigated. Three power intensities were investigated; $12.6,25.3$, and $35.8 \mathrm{~W} / \mathrm{cm}^{2}$. The samples were sonicated for 10 minutes. The results show a clear effect of the power intensity on the rate of reduction. With an increase in the wattage introduced to the sample there is an increase in the rate in which the $\mathrm{CCl}_{4}$ concentration is decreased. The same effect is exhibited for an initial $\mathrm{CCl}_{4}$ concentrations of 8 and $1.6 \mathrm{ppm}$, respectively.

\section{The Effect of Initial $\mathrm{pH}$ values}

The effect of the initial $\mathrm{pH}$ of the sample solution on the rate of contaminant reduction was investigated. Initial $\mathrm{pH}$ test values were between 3 and 9 . Samples spiked at $8 \mathrm{ppm}^{\mathrm{CCl}} \mathrm{Cl}_{4}$ were sonicated for 10 minutes at 25.3 or $35.8 \mathrm{~W} / \mathrm{cm}^{2}$. Initial $\mathrm{pH}$ values between 5 and 9 did not appear to influence the rate of reduction. However, an initial $\mathrm{pH}$ value of 3 showed a significant decrease in the reduction rate. This phenomenon agrees with results of others' studies.

\section{The Effect of Adding Hydrogen Peroxide}

Using hydrogen peroxide $\left(\mathrm{H}_{2} \mathrm{O}_{2}\right)[<0.1 \%]$ as an advanced oxidant to the sonication system resulted in negligible improvement over the ultrasonic system performance conducted in the absence of $\mathrm{H}_{2} \mathrm{O}_{2}$.

\section{Duplication of Experimental Results}

Most of the data generated in this project are based on one experiment per set of experimental conditions. However, a number of experiments were performed with three different sets of experimental conditions performed in duplicate. The slopes representing the rate of $\mathrm{CCl}_{4}$ decrease on the linear regression curves (of $\ln \mathrm{C} / \mathrm{C}_{\mathrm{o}}$ vs. reaction time) for each of the experiments proved to be extremely reproducible. In each case, the slopes were within $\sim 3 \%$ to $10 \%$ of the average slope. The data also indicate that with an increase in power intensity, the rate of decrease of the $\mathrm{CCl}_{4}$ kinetics increases. In addition, with a lower initial $\mathrm{CCl}_{4}$ concentration, the rate of decrease of $\mathrm{CCl}_{4}$ is greater. 


\section{Results from Batch Sonication and Batch Sonication/Vapor Stripping Experiments}

Sonication/vapor stripping experiments were performed in a reactor used to treat the chlorinated organic contaminants in groundwater employing sonication alone, vapor stripping alone, or combined sonication/vapor stripping. The reactor is a glass vessel with an ultimate capacity of 1.0-L; normally the reactor is operated using a sample volume of $\sim 500-\mathrm{mL}$. Batch experiments were performed separately on each of the chlorinated organic contaminants $\left(\mathrm{CCl}_{4}\right.$, TCE, TCA, and PCE). Initial contaminant concentrations ranged anywhere from $\sim 1$ to $\sim 100 \mathrm{mg} / \mathrm{L}$. The sonicator had an ultrasonic frequency of $20 \mathrm{kHz}$; the applied power intensity was 12.3-, 25.3-, and $35.8 \mathrm{~W} / \mathrm{cm}^{2}$. The batch reactions were operated normally for up to 10 minutes treatment time, with samples withdrawn for GC analysis every 2 minutes. The batch experiments were operated using either sonication alone, vapor stripping alone, or using the combined sonication/vapor stripping technique. Air injection rates used in these experiments were nominally 0- (sonication alone), 500-, 1000-, and 1500-mL/min. Several hundred batch experiments were performed during this study; selected representative results are presented for the sake of brevity.

Figure 3 shows the results of $\mathrm{CCl}_{4}$ removal using sonication alone and sonication+vapor stripping. The initial concentration of $\mathrm{CCl}_{4}$ was nominally $50 \mathrm{mg} / \mathrm{L}$. The applied power intensity was $12.3-, 25.3-$, and $35.8 \mathrm{~W} / \mathrm{cm}^{2}$. The air injection rate shown in this figure for the combined sonication+vapor stripping system was $500-\mathrm{mL} / \mathrm{min}$. Using sonication alone (for the entire range of power intensities), removal of $\mathrm{CCl}_{4}$ after 10 minutes ranged from $\sim 26 \%$ to $47 \%$, while removal of the combined sonication+vapor stripping system exceeded $99 \%$ for all three power intensities after 10 minutes treatment time. After 6 minutes treatment time, the combined system had $\mathrm{CCl}_{4}$ removals ranging from $\sim 88 \%$ to $98 \%$, well above that by sonication alone. Using nearly identical operating conditions, Figure 4 presents analogous results for the TCE system. Using sonication alone, removal of TCE after 10 minutes ranged from $19 \%$ to 38\% for the power intensities studied, while removal of TCE in the combined sonication+vapor stripping system ranged from $\sim 96 \%$ to $\sim 99 \%$. Even after 6 minutes processing time, the combined system had removal efficiencies ranging from $\sim 87 \%$ to $\sim 93 \%$, again considerably above that achieved by sonication alone. Figure 5 shows the first order rate constants for removal of $\mathrm{CCl}_{4}$ from groundwater via sonication alone, via vapor stripping alone (for an air injection rate of $500-\mathrm{mL} / \mathrm{min}$ ), and via the combined sonication/vapor stripping system. The rate constants via sonication are on the order of 0.03 to $0.06 \mathrm{~min}^{-1}$; this is lower than that by vapor stripping $\left(\mathrm{k} \sim 0.286 \mathrm{~min}^{-1}\right)$, while the rate constant for the combined system ranges from 0.35 to $0.65 \mathrm{~min}^{-1}$. This data indicates that the combined sonication/vapor stripping system operates in a synergistic manner; the rate constant for the combined system is considerably greater than the sum of the individual rate constants for sonication and vapor stripping separately. The data for TCE is similar in nature to that shown for $\mathrm{CCl}_{4}$. Figure 6 compares the removal efficiency of $\mathrm{CCl}_{4}$ and TCE as a function of the processing time using the combined sonication/vapor stripping system. The data indicates that higher removals are achieved for $\mathrm{CCl}_{4}$ compared to TCE for all processing times at comparable power intensities. This is not unexpected, as $\mathrm{CCl}_{4}$ has a higher Henrys' law constant than does TCE, and hence is easier to strip or remove from solution than is TCE. Figure 7 shows a comparison of the individual first order rate constants for $\mathrm{CCl}_{4}$ and TCE over the range of power intensities (12.3-. 25.3-, and 35.8-W/cm²). The rate constants for $\mathrm{CCl}_{4}$ 
are consistently higher than that for TCE, for all the treatment systems (sonication alone, vapor stripping alone, and the combined sonication/vapor stripping system). The data again indicate that the combined sonication/vapor stripping system operates in a synergistic manner; the rate constant for the combined system is considerably greater than the sum of the individual rate constants for sonication and vapor stripping separately, both for $\mathrm{CCl}_{4}$ and for TCE.

The next three sets of figures compare the removal of all of the various chlorinated organic contaminants $\left(\mathrm{CCl}_{4}, \mathrm{TCE}, \mathrm{TCA}\right.$, and PCE) at different power intensity levels. Figure 8 shows the normalized residual contaminant fraction remaining using sonication alone $(20-\mathrm{kHz}$, $12.3-\mathrm{W} / \mathrm{cm}^{2}$ ) and sonication+vapor stripping (using an air injection rate of $500-\mathrm{mL} / \mathrm{min}$ ). For all the chlorinated organic species, the fraction remaining ranges from $74 \%$ to $84 \%$, while the fraction of chlorinated organics remaining from the combined sonication/vapor stripping system is less than $4 \%$ in all cases after 10 minutes processing time. This again indicates a highly synergistic system. The results using vapor stripping alone are only marginally better than that achieved by sonication alone. Figure 9 shows results comparable to those in the previous figure, except that the power intensity has been increased to $25.3 \mathrm{~W} / \mathrm{cm}^{2}$. For all the chlorinated organic species, the fraction remaining ranges from $62 \%$ to $82 \%$, while the fraction of chlorinated organics remaining from the combined sonication/vapor stripping system is less than $3 \%$ in all cases after 10 minutes processing time. Increasing the power intensity still further, to $35.8-\mathrm{W} / \mathrm{cm}^{2}$ (see Figure 10), the fraction remaining ranges from $53 \%$ to $79 \%$, while the fraction of chlorinated organics remaining from the combined sonication/vapor stripping system is less than $2 \%$ in all cases after 10 minutes processing time. Even after 6 minutes processing time, the removal of all of the chlorinated organic compounds in the combined sonication/vapor stripping system exceeds 90\%. In Figures 8 to 10, removals of the chlorinated organic compounds follow the order involving their Henrys' law constant $\left(\mathrm{CCl}_{4}>\mathrm{TCE}>\mathrm{TCA}>\mathrm{PCE}\right)$.

Figure 11 shows a comparison of the various fractional residual concentrations of each of the chlorinated organic species as a function of the batch processing time for the various applied power intensities via sonication treatment only; as the power intensity is increased, the removal of each of the chlorinated organic species also increases. Figure 12 shows a comparison of the various fractional residual concentrations of each of the chlorinated organic species as a function of the batch processing time for the various applied power intensities in the combined sonication/vapor stripping system (using an air injection rate of $500-\mathrm{mL} / \mathrm{min}$ ); as the power intensity is increased, the removal of each of the chlorinated organic species also increases. The decrease in concentration of the various chlorinated organic species tends to follow an exponential decay; hence the first-order kinetics are a reasonable description of the system kinetics. Figure 13 presents the first-order rate constants for removal of TCE from groundwater using sonication alone plotted as a function of the applied power intensity for various nominal initial contaminant concentrations. The first-order rate constants vary linearly with the applied power intensity. Likewise, the first-order rate constants are observed to vary slightly with the initial contaminant concentration; this phenomenon has also been observed by other researchers [Hua and Hoffmann, 1996a; Wu et al., 1992a]. 


\section{Comparison of Trichloroethylene Removal by Sonication + Vapor Stripping to Sonication Alone}

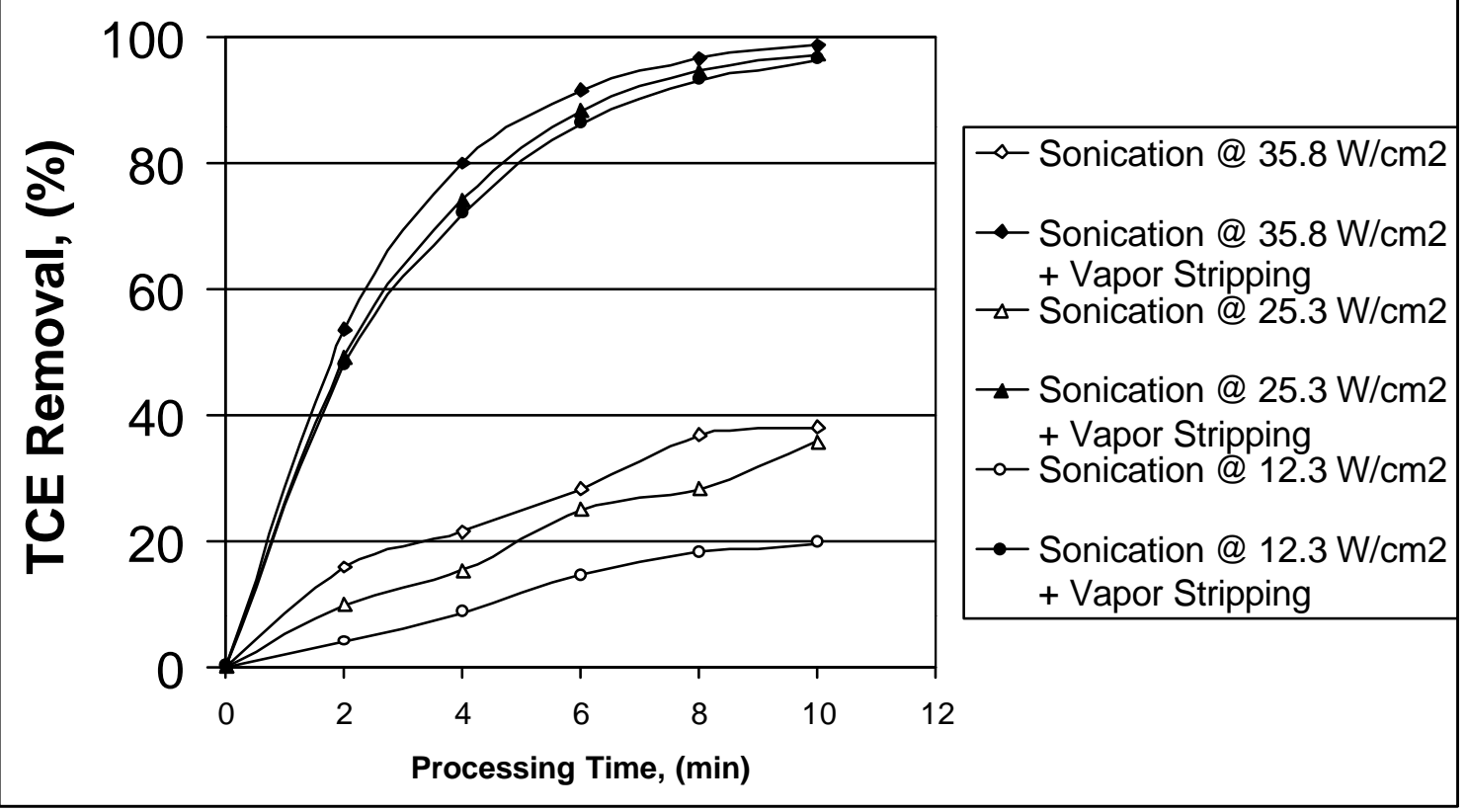

Figure 3. Comparison of $\mathrm{CCl}_{4}$ removal by sonication+vapor stripping (air injection rate $\sim-500-\mathrm{mL} / \mathrm{min})$ to sonication alone $(20 \mathrm{kHz})$. 


\section{Comparison of Trichloroethylene Removal by Sonication + Vapor Stripping to Sonication Alone}

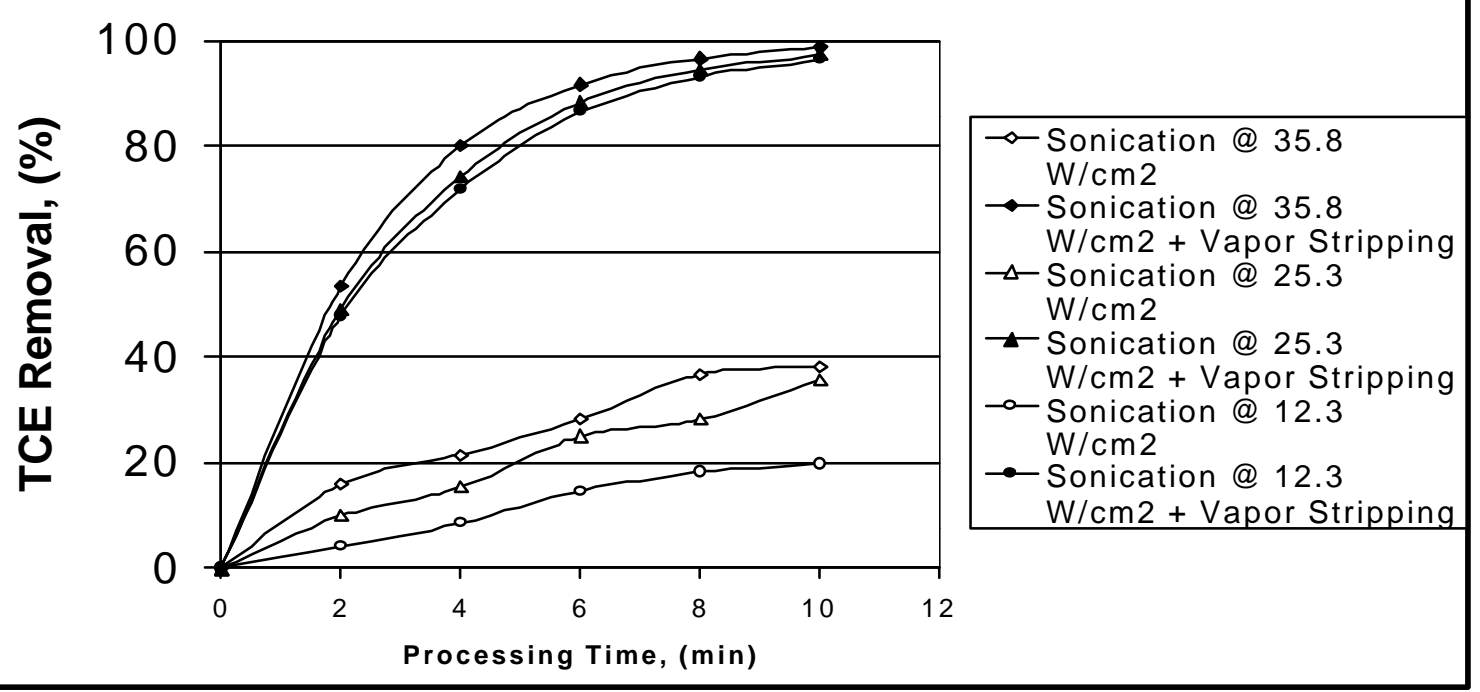

Figure 4. Comparison of TCE removal by sonication+vapor stripping (air injection rate $\sim 500-\mathrm{mL} / \mathrm{min})$ to sonication alone $(20 \mathrm{kHz})$. 


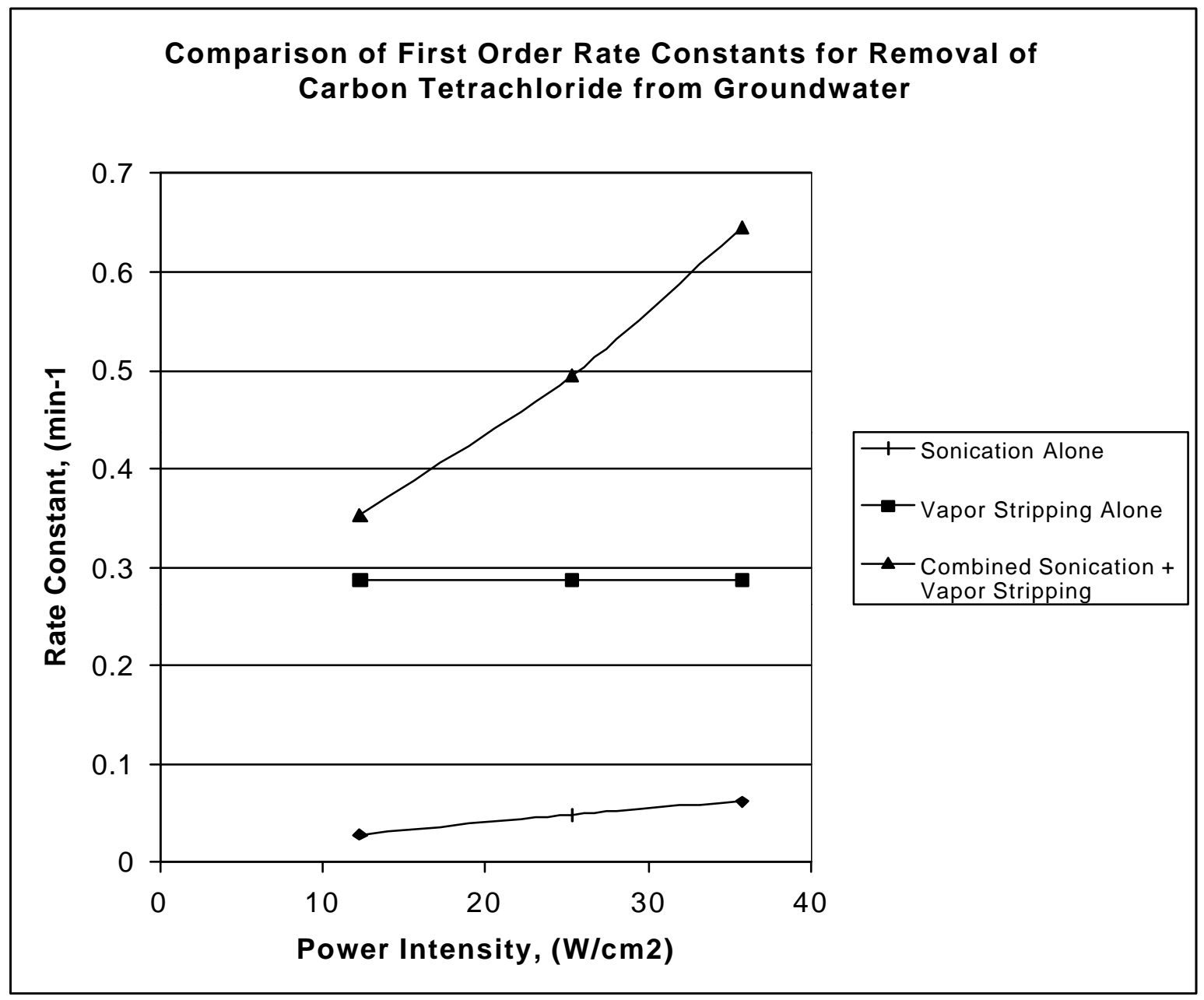

Figure 5. Comparison of first-order rate constants for removal of $\mathrm{CCl}_{4}$ from groundwater using sonication, vapor stripping, and combined sonication/vapor stripping. 


\section{Removal Efflclency of Carbon Tetrachlorldeand} Trlchloroethylene as a Functlon of ProcessIng TIme UsIng Comblned SonlcatlonNapor Strlpplng

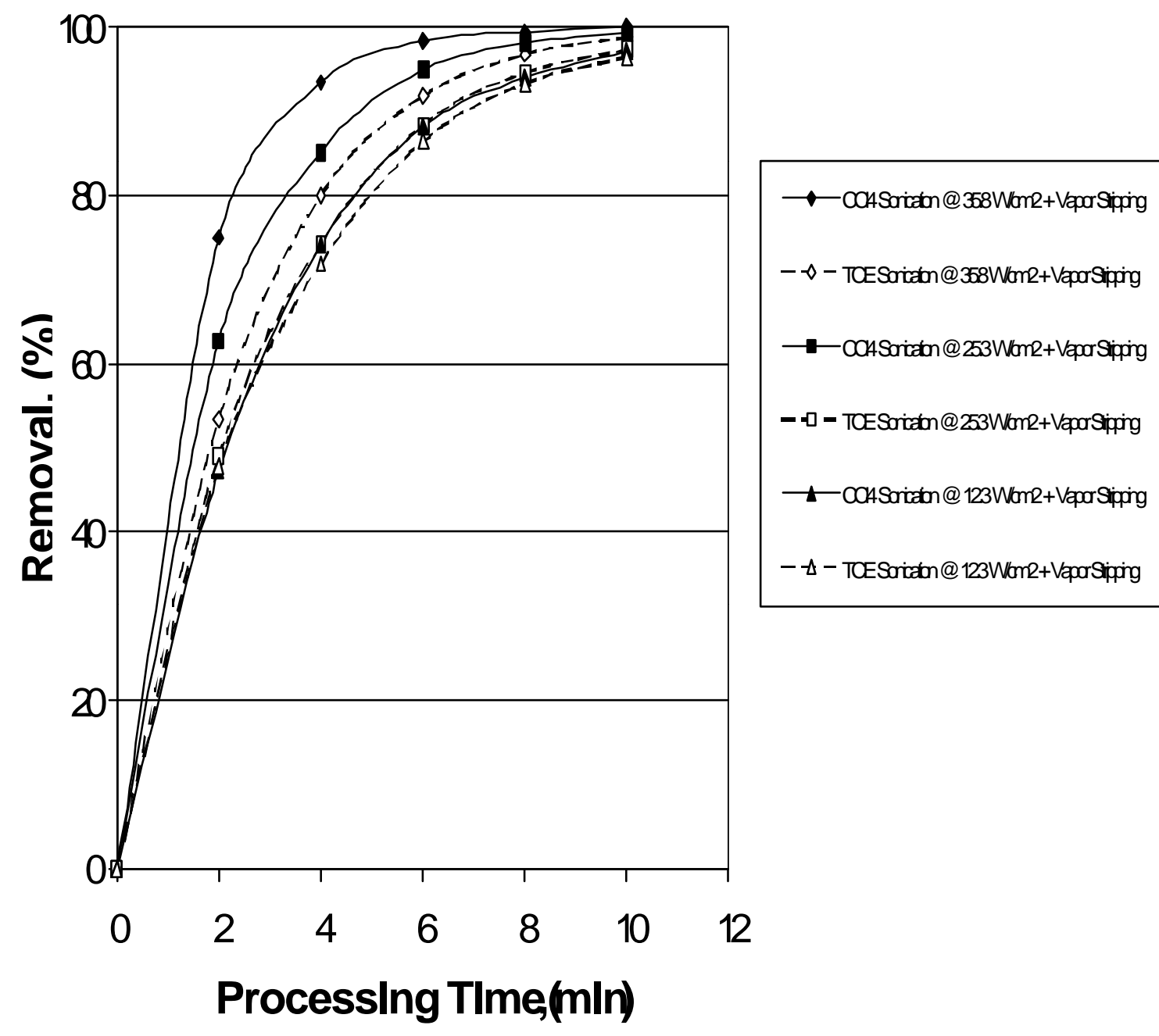

Figure 6. Removal efficiency of $\mathrm{CCl}_{4}$ and TCE as a function of the batch treatment time using combined sonication/vapor stripping techniques. 


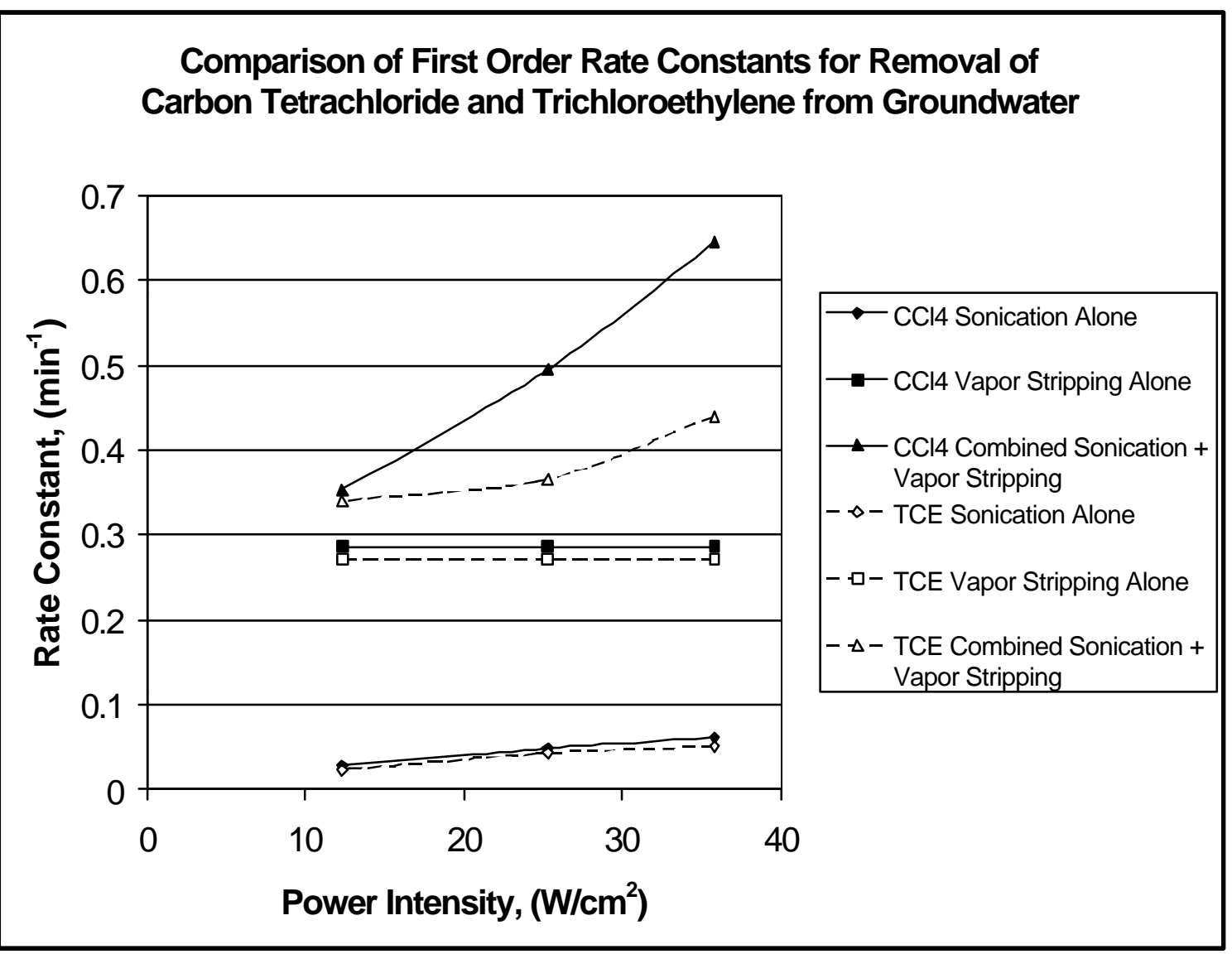

Figure 7. Comparison of first-order rate constants for removal of $\mathrm{CCl}_{4}$ and TCE from groundwater using sonication, vapor stripping, and combined sonication/vapor stripping. 


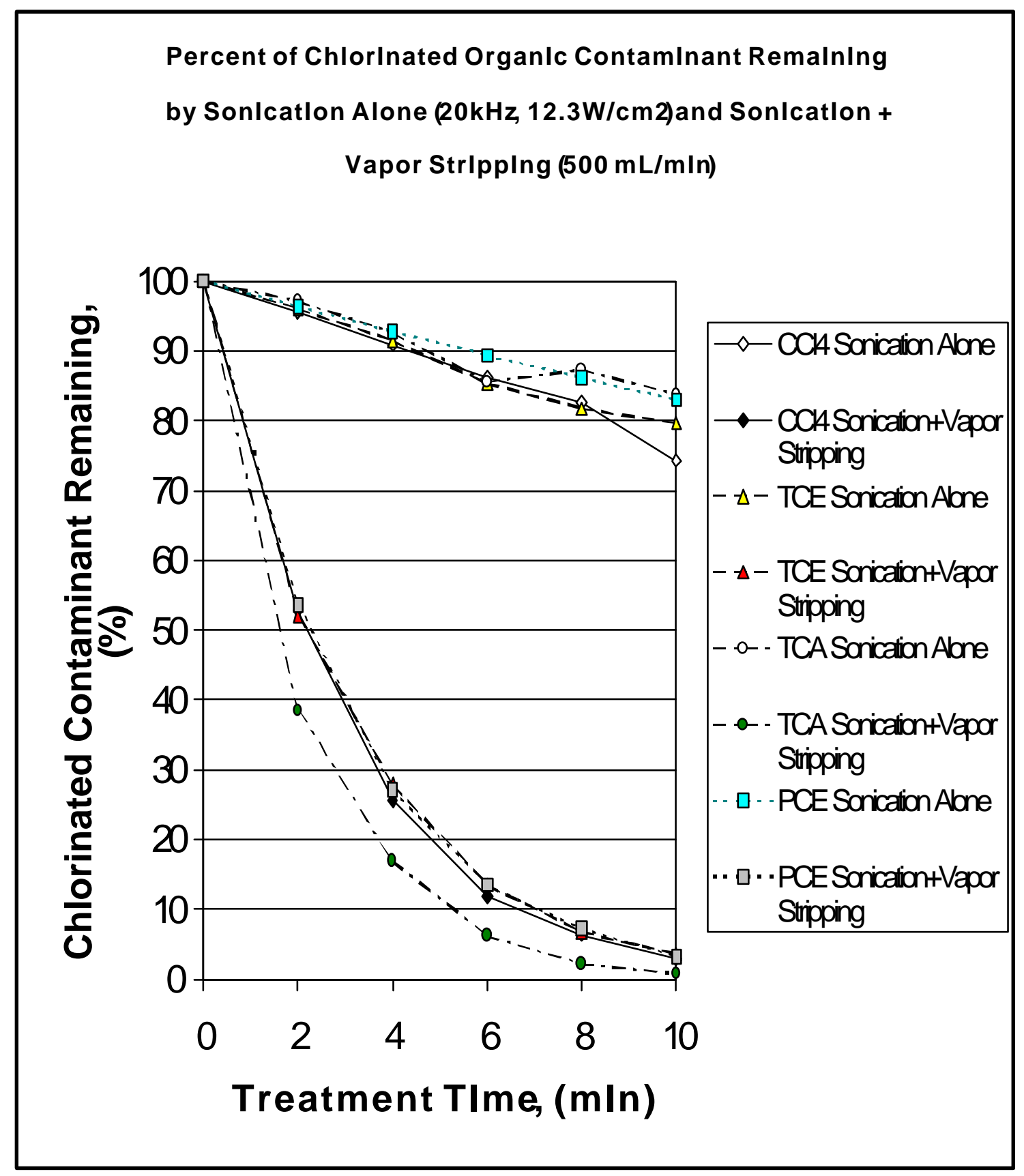

Figure 8. Fraction of chlorinated contaminant remaining in groundwater for various batch treatment times via sonication alone $\left(20 \mathrm{kHz}, 12.3 \mathrm{~W} / \mathrm{cm}^{2}\right)$ and via sonication+vapor stripping (air injection rate $\sim 500 \mathrm{~mL} / \mathrm{min}$ ). 


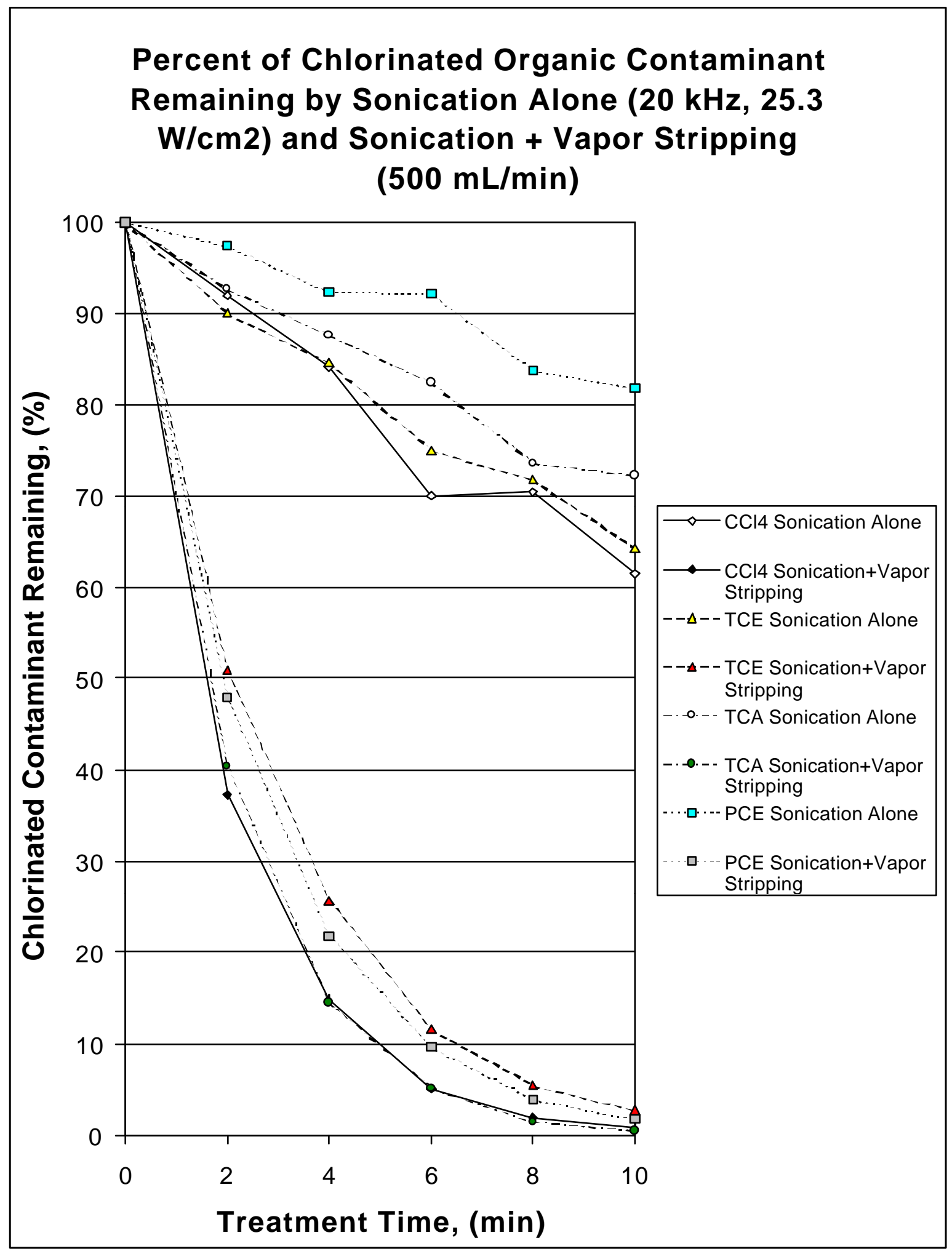

Figure 9. Fraction of chlorinated contaminant remaining in groundwater for various batch treatment times via sonication alone $\left(20 \mathrm{kHz}, 25.3 \mathrm{~W} / \mathrm{cm}^{2}\right)$ and via sonication+vapor stripping (air injection rate $\sim 500 \mathrm{~mL} / \mathrm{min}$ ). 


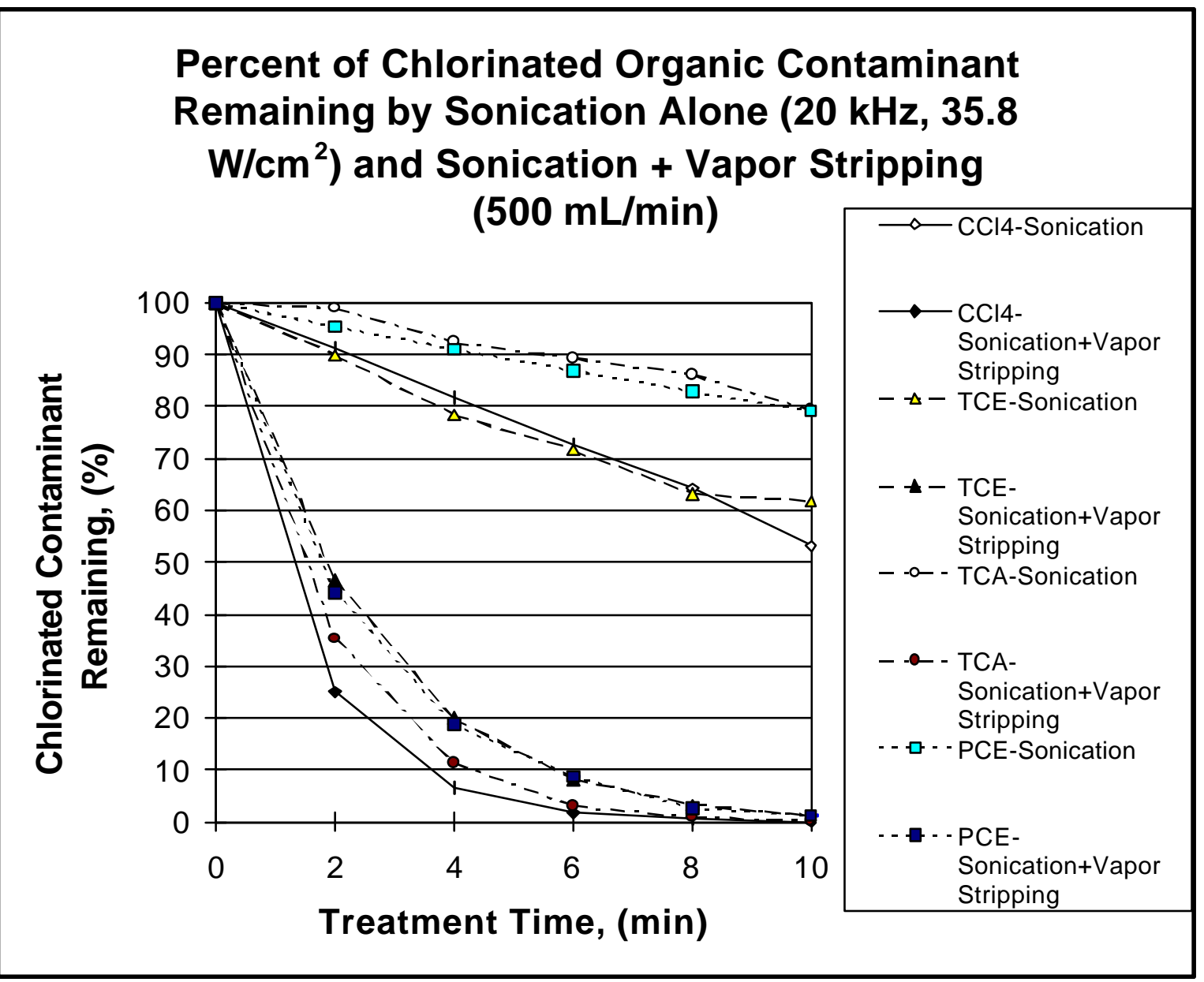

Figure 10. Fraction of chlorinated contaminant remaining in groundwater for various batch treatment times via sonication alone $\left(20 \mathrm{kHz}, 35.8 \mathrm{~W} / \mathrm{cm}^{2}\right)$ and via sonication+vapor stripping (air injection rate $\sim 500 \mathrm{~mL} / \mathrm{min}$ ). 


\section{Comparlson of Residual Concentratlor of Chlorlnated Organlc Compounds Uslng Sonlcatlon Alone at Varlous Power IntensItles}

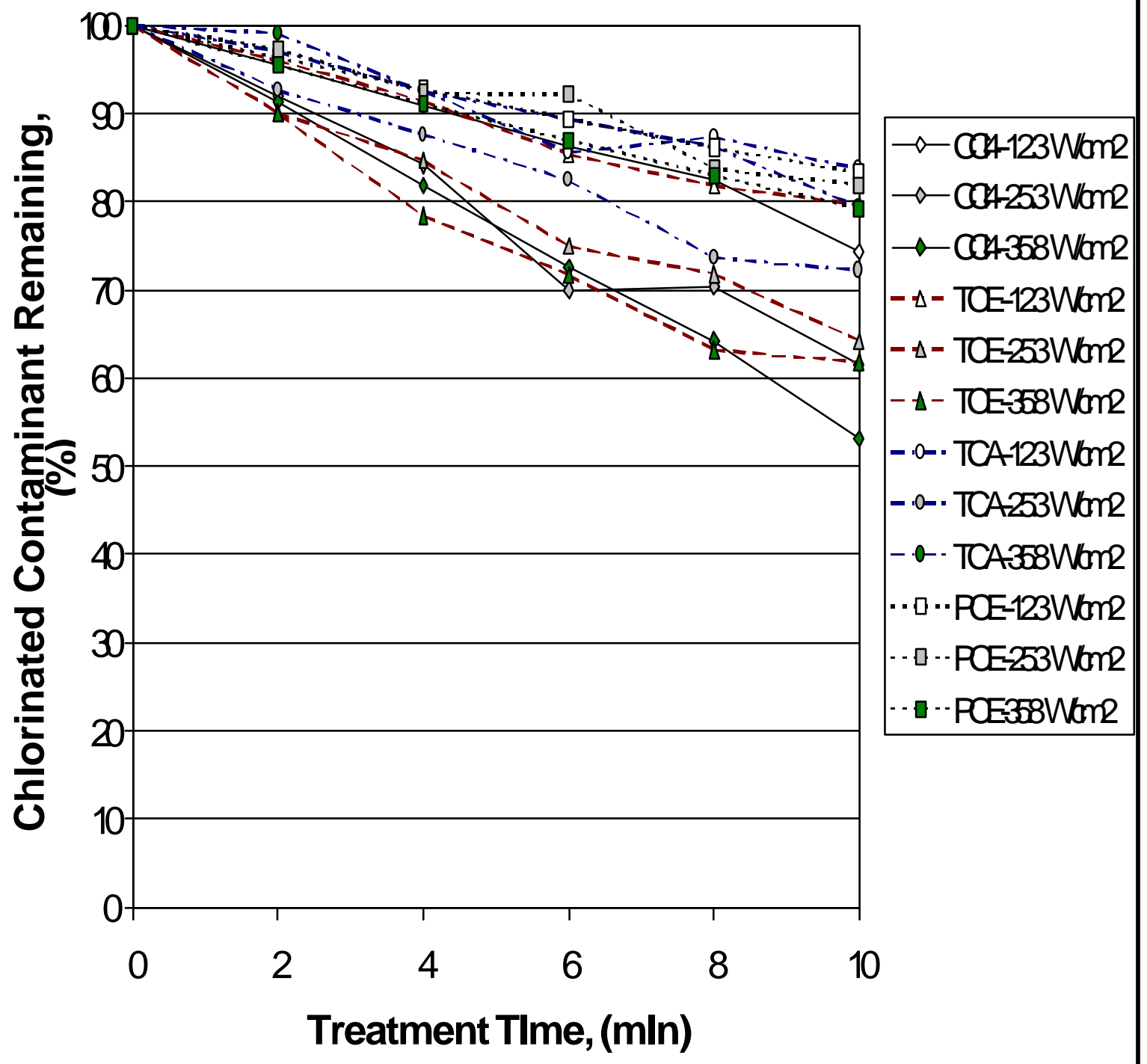

Figure 11. Fraction of chlorinated contaminant remaining in groundwater for various batch treatment times via sonication alone $(20 \mathrm{kHz})$ for various applied power intensities (12.3-, 25.3-, and 35.8-W/ $\left./ \mathrm{cm}^{2}\right)$. 


\section{Compaison of PercentPesidal Chained

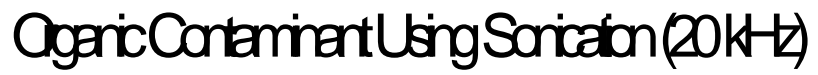 +VaporSipping(500mLtrin) atVaiousPowerhtensies}

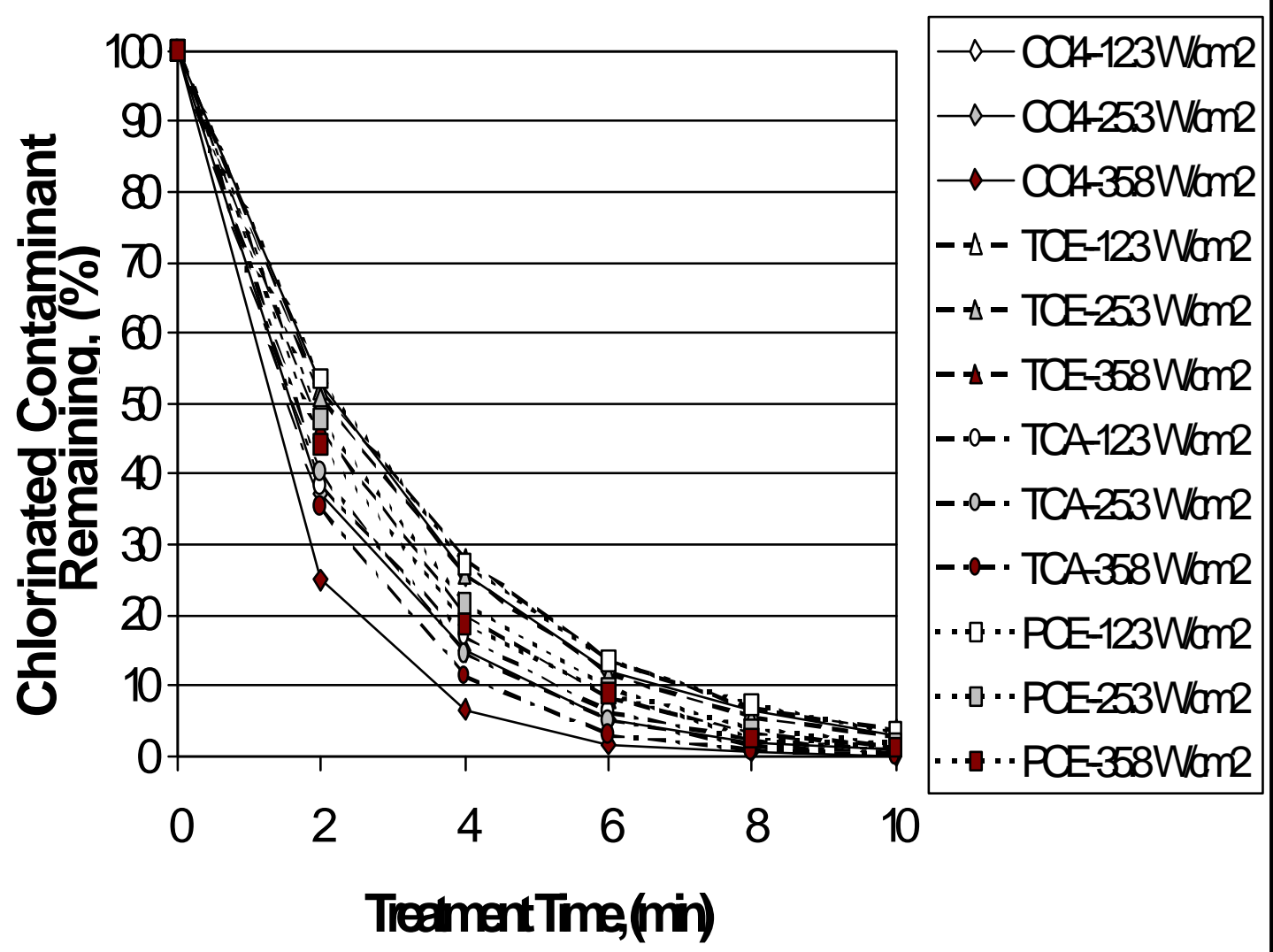

Figure 12. Fraction of chlorinated contaminant remaining in groundwater for various batch treatment times via combined sonication $(20 \mathrm{kHz}) /$ vapor stripping (air injection rate $\sim 500-\mathrm{mL} / \mathrm{min}$ ) for various applied power intensities (12.3-, 25.3-, and $\left.35.8-\mathrm{W} / \mathrm{cm}^{2}\right)$. 


\section{First-Order Rate Constant as a Function of Applied Power Intensity for Sonication Alone of Trichloroethane}

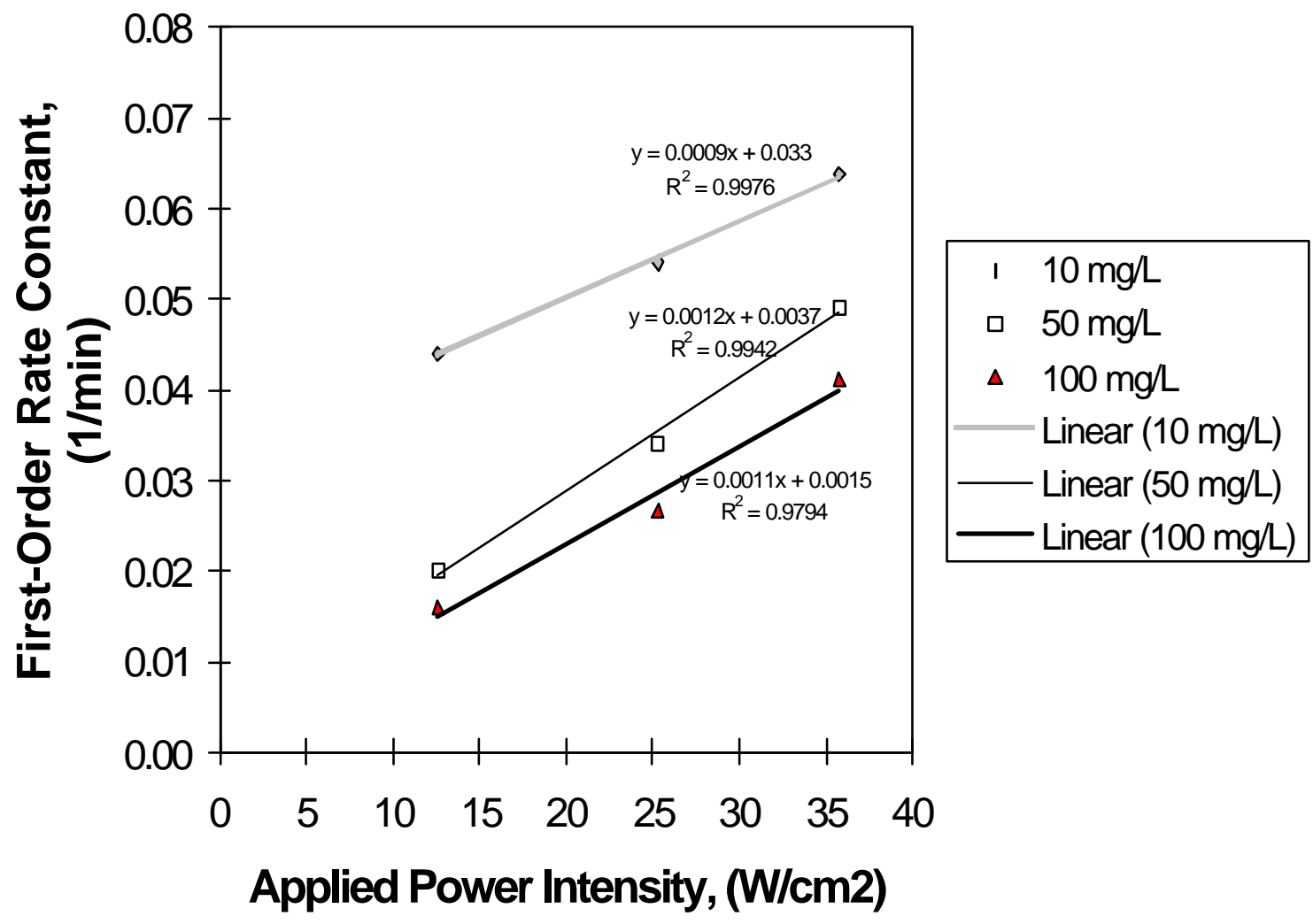

Figure 13. First-order rate constants for removal of TCA from groundwater using sonication alone $(20 \mathrm{kHz})$ for various applied power intensities and various initial TCA concentrations.

The results from these batch experiments are summarized in several tables that are discussed below. Table 1 compares the first-order rate constants by acoustic cavitation (sonication) for removal of $\mathrm{CCl}_{4}$ and TCE from groundwater. The rate constants $\left(\mathrm{min}^{-1}\right)$ are listed for a variety of nominal initial concentrations and applied ultrasonic power intensities. There are several things worth noting. First, generally the first order rate constant is higher for $\mathrm{CCl}_{4}$ than for TCE. This is not unexpected, given that $\mathrm{CCl}_{4}$ has a higher Henrys' law constant than does TCE. Secondly, as the power intensity is increased, the rate constant also increases in a linear fashion. Thirdly, as the initial concentration decreases, the rate constant increases (i.e., the removal efficiency by sonication increases as the contaminant concentration decreases). 
The first-order rate constants are observed to vary slightly with the initial contaminant concentration; this phenomenon has also been observed by other researchers [Hua and Hoffmann, 1996a; Wu et al., 1992a].

Table 1. Comparison of First-Order Rate Constants $\left(\mathrm{min}^{-1}\right)$ by Acoustic Cavitation for Removal of $\mathrm{CCl}_{4}$ and TCE from Groundwater.

\begin{tabular}{|c|c|c|c|c|c|c|}
\hline $\begin{array}{c}\text { Nominal } \\
\begin{array}{c}\text { Concentration, } \\
(\mathrm{mg} / \mathrm{L})\end{array}\end{array}$ & \multicolumn{2}{|c|}{$12.3 \mathrm{~W} / \mathrm{cm}^{2}$} & \multicolumn{2}{|c|}{$25.3 \mathrm{~W} / \mathrm{cm}^{2}$} & \multicolumn{2}{|c|}{$35.8 \mathrm{~W} / \mathrm{cm}^{2}$} \\
\cline { 2 - 7 } & $\mathrm{CCl}_{4}$ & $\mathrm{TCE}$ & $\mathrm{CCl}_{4}$ & $\mathrm{TCE}$ & $\mathrm{CCl}_{4}$ & $\mathrm{TCE}$ \\
\hline 1.6 & 0.0345 & 0.0347 & 0.0574 & 0.0426 & 0.0788 & 0.0551 \\
8.0 & 0.0308 & 0.0221 & 0.0489 & 0.0304 & 0.0673 & 0.0403 \\
50 & 0.0282 & 0.0235 & 0.0488 & 0.0431 & 0.0619 & 0.0508 \\
70 & 0.0193 & 0.0130 & 0.0376 & 0.0210 & 0.0577 & 0.0426 \\
\hline
\end{tabular}

Table 2 below compares the first-order rate constants obtained for removal of $\mathrm{CCl}_{4}$ and TCE from groundwater using vapor stripping. Three different air injection flow rates were employed: 500-, 1000-, and 1500-mL/min. Table 1 cited above contains the first-order rate constants for an air flow rate of $0-\mathrm{mL} / \mathrm{min}$ (i.e., using sonication alone). The first-order rate constant by vapor stripping with $500-\mathrm{ml} / \mathrm{min}$ is significantly higher than the case with $0 \mathrm{~mL} / \mathrm{min}$ (> 5x larger). For both $\mathrm{CCl}_{4}$ and TCE, as the air injection flow rate is increased, the first-order rate constant also increases, but in a nonlinear fashion; for example, when the air flow rate is doubled from 500 - to $1000-\mathrm{mL} / \mathrm{min}$, the first-order rate constant does not double. As the air injection rate is further increased, the effect of the first-order rate constant is less pronounced. The first-order rate constants are higher for $\mathrm{CCl}_{4}$ than for TCE, as expected due to the higher Henrys' law constant for $\mathrm{CCl}_{4}$ as compared to TCE. Additionally, as the initial concentration is increased, the first-order rate constant generally increases.

Table 2. Comparison of First-Order Rate Constants for Removal of $\mathrm{CCl}_{4}$ and $\mathrm{TCE}$ from Groundwater Using Vapor Stripping Techniques

\begin{tabular}{|c|c|c|c|c|c|c|}
\hline \multirow{2}{*}{$\begin{array}{c}\text { Initial } \\
\text { Concentration, } \\
(\mathrm{mg} / \mathrm{L})\end{array}$} & \multicolumn{3}{|c|}{$\mathrm{CCl}_{4}$} & \multicolumn{3}{c|}{$\mathrm{TCE}$} \\
\cline { 2 - 7 } & \multicolumn{3}{|c|}{ Air Flow Rate, $(\mathrm{mL} / \mathrm{min})$} & \multicolumn{2}{c|}{ Air Flow Rate, $(\mathrm{mL} / \mathrm{min})$} \\
\cline { 2 - 7 } & 500 & 1000 & 1500 & 500 & 1000 & 1500 \\
\cline { 2 - 7 } & $\mathrm{k},\left(\mathrm{min}^{-1}\right)$ & $\mathrm{k},\left(\mathrm{min}^{-1}\right)$ & $\mathrm{k},\left(\mathrm{min}^{-1}\right)$ & $\mathrm{k},\left(\mathrm{min}^{-1}\right)$ & $\mathrm{k},\left(\mathrm{min}^{-1}\right)$ & $\mathrm{k},\left(\mathrm{min}^{-1}\right)$ \\
\hline 10 & 0.2944 & 0.7126 & 0.5509 & 0.1538 & 0.5158 & 0.4501 \\
50 & 0.2863 & 0.4110 & 0.6291 & 0.2426 & 0.4008 & 0.5458 \\
100 & 0.3865 & 0.6583 & 0.8453 & 0.2044 & 0.4115 & 0.5559 \\
\hline
\end{tabular}


Tables 3 and 4 compare the first-order rate constants for removal of $\mathrm{CCl}_{4}$ and TCE from groundwater, respectively, using sonication alone, vapor stripping alone (for an air injection flow rate of $500-\mathrm{mL} / \mathrm{min}$ ), and by combined sonication/vapor stripping. These tables also list the first-order rate constants at three different applied power intensities. The first-order rate constant for the combined sonication/vapor stripping system is consistently the largest value. The effect is more pronounced as the applied power intensity is increased. It is also worth noting that the combination of sonication coupled with vapor stripping operates in a synergistic fashion; the rate constant of the combined system is much greater than the addition of individual treatments (sonication and vapor stripping). This is likely the result of much greater mixing being associated with sonication of the gas bubbles, resulting in much smaller (finer sized) bubbles being used in solution; this causes a more effective mass transfer of the organic components into the gas phase, and hence provides much greater removals (and hence larger first-order rate constants).

Table 3. Comparison of First Order Rate Constants for Removal of Carbon Tetrachloride $\left(\mathrm{CCl}_{4}\right)$ from Groundwater.

Sonication Frequency: $20 \mathrm{kHz}$

Nominal Initial $\mathrm{CCl}_{4}$ Concentration: $50 \mathrm{mg} / \mathrm{L}$ Applied Air Flow Rate: 500 mL/min

\begin{tabular}{|c|c|c|c|}
\hline $\begin{array}{c}\text { Applied Power Intensity } \\
\text { for Sonication, }\left(\mathrm{W} / \mathrm{cm}^{2}\right)\end{array}$ & $\mathrm{k}_{\text {sonication }},\left(\mathrm{min}^{-1}\right)$ & $\mathrm{k}_{\text {vapor stripping }},\left(\mathrm{min}^{-1}\right)$ & $\mathrm{k}_{\text {sonication+vapor stripping }},\left(\mathrm{min}^{-1}\right)$ \\
\hline 12.3 & 0.0282 & 0.2863 & 0.3531 \\
25.3 & 0.0488 & 0.2863 & 0.4947 \\
35.8 & 0.0619 & 0.2863 & 0.6452 \\
\hline
\end{tabular}

Table 4. Comparison of First Order Rate Constants for Removal of Trichloroethylene (TCE) from Groundwater.

Sonication Frequency: $20 \mathrm{kHz}$

Nominal Initial TCE Concentration: $50 \mathrm{mg} / \mathrm{L}$

Applied Air Flow Rate: 500 mL/min

\begin{tabular}{|c|c|c|c|}
\hline $\begin{array}{c}\text { Applied Power Intensity } \\
\text { for Sonication, }\left(\mathrm{W} / \mathrm{cm}^{2}\right)\end{array}$ & $\mathrm{k}_{\text {sonication }}\left(\mathrm{min}^{-1}\right)$ & $\mathrm{k}_{\text {vapor stripping }}\left(\min ^{-1}\right)$ & $\mathrm{k}_{\text {sonication+vapor stripping, }},\left(\min ^{-1}\right)$ \\
\hline 12.3 & 0.0235 & 0.2724 & 0.3403 \\
25.3 & 0.0431 & 0.2724 & 0.3662 \\
35.8 & 0.0508 & 0.2724 & 0.4402 \\
\hline
\end{tabular}

Table 5 summarizes the first-order rate constants for the four major chlorinated organic contaminants studied $\left(\mathrm{CCl}_{4}, \mathrm{TCE}, \mathrm{TCA}\right.$, and PCE) for a variety of sonication conditions (applied power intensities of 12.3-, 25.3-, and 35.8-W/ $\mathrm{cm}^{2}$ ) and air injection rates (500- and $1000-\mathrm{mL} / \mathrm{min})$. First-order rate constants are listed for removal of the various contaminants using sonication alone, vapor stripping alone, and the combined sonication/vapor stripping 
system. The first-order rate constants are observed to be considerably larger for the combined system, as compared to using either sonication or vapor stripping alone. A plausible explanation for this behavior was described above. It is also worth noting that the same trends are observed for TCA and PCE as were reported previously for the $\mathrm{CCl}_{4}$ and TCE systems.

Table 5. First-Order Rate Constants for Removal/Destruction of Chlorinated Organic Compounds from Groundwater Using Sonication Alone, Vapor Stripping Alone, and Combined Sonication/Vapor Stripping in Continuous Flow Operations.

\begin{tabular}{|c|c|c|c|c|c|c|c|c|c|c|c|}
\hline \multirow{3}{*}{ Compound } & \multicolumn{3}{|c|}{ Sonication Alone } & \multicolumn{2}{|c|}{$\begin{array}{c}\text { Vapor } \\
\text { Stripping } \\
\text { Alone }\end{array}$} & \multicolumn{6}{|c|}{ Combined Sonication/Vapor Stripping } \\
\hline & \multicolumn{3}{|c|}{$\begin{array}{l}\text { Power Intensity } \\
\quad\left(\mathrm{W} / \mathrm{cm}^{2}\right)\end{array}$} & \multicolumn{2}{|c|}{$\begin{array}{l}\text { Air Injection } \\
\text { Flow Rate, } \\
\text { (mL/min) }\end{array}$} & \multicolumn{6}{|c|}{$\begin{array}{c}\text { Air Injection Rate }(\mathrm{mL} / \mathrm{min}) \text { and Ultrasonic } \\
\text { Power Intensity }\left(\mathrm{W} / \mathrm{cm}^{2}\right)\end{array}$} \\
\hline & 12.3 & 25.3 & 35.8 & 500 & 1000 & $\begin{array}{l}500 / \\
12.3 \\
\end{array}$ & $\begin{array}{l}500 / \\
25.3 \\
\end{array}$ & $\begin{array}{l}500 / \\
35.8\end{array}$ & $\begin{array}{c}1000 / \\
12.3 \\
\end{array}$ & $\begin{array}{l}1000 / \\
25.3\end{array}$ & $\begin{array}{l}1000 / \\
35.8 \\
\end{array}$ \\
\hline $\mathrm{CCl}_{4}$ & 0.028 & 0.049 & 0.062 & 0.286 & 0.411 & 0.353 & 0.487 & 0.645 & 0.729 & 0.870 & 0.866 \\
\hline TCE & 0.019 & 0.022 & 0.024 & 0.243 & 0.401 & 0.356 & 0.356 & 0.440 & 0.516 & 0.583 & 0.633 \\
\hline TCA & 0.020 & 0.034 & 0.049 & 0.228 & 0.531 & 0.341 & 0.549 & 0.640 & 0.691 & 0.864 & 0.904 \\
\hline PCE & 0.019 & 0.021 & 0.022 & 0.282 & 0.454 & 0.483 & 0.411 & 0.447 & 0.492 & 0.412 & 0.494 \\
\hline
\end{tabular}

It should be noted that while vapor stripping does a decent job in removing the chlorinated compounds from solution, it merely transfers the contaminant from the liquid phase to the gaseous phase; it does not destroy the organic contaminant. Using a vapor stripping system alone would require that a vapor treatment system (such as a granular activated carbon adsorber or a thermal oxidizer) be installed to treat the gaseous phase containing the transferred chlorinated solvent contaminant. The sonication and the combined sonication/vapor stripping system are much more effective in destroying the chlorinated solvent contaminants. As evidenced in the results presented for Task 5, the majority of the contaminants are destroyed (typically, greater than 99\%), with only trace amounts of byproducts formed.

Task 3. Perform batch experiments for measuring hydroxyl/hydrogen radicals in solution

In research conducted at Caltech, the sonolytic production of hydrogen peroxide $\left(\mathrm{H}_{2} \mathrm{O}_{2}\right)$ and hydroxyl radicals $(\bullet \mathrm{OH})$ were investigated using ultrasonic frequencies of $20,40,80$, and $500 \mathrm{kHz}$, respectively, in the presence of four different saturating gases $\left(\mathrm{Kr}, \mathrm{Ar}, \mathrm{He}\right.$, and $\left.\mathrm{O}_{2}\right)$ at each frequency [Hua and Hoffmann, 1997]. The temperature of the sonicated solutions were maintained at 25 to $30^{\circ} \mathrm{C}$ using a refrigerated water bath. $\mathrm{H}_{2} \mathrm{O}_{2}$ formation was measured with a $\mathrm{KI}$ dosimeter, and the formation of $\bullet \mathrm{OH}$ was monitored by trapping with terephthalic acid. Both the applied frequency and the physicochemical properties of the saturating gases influence the sonochemical rates of production of $\bullet \mathrm{OH}$ and $\mathrm{H}_{2} \mathrm{O}_{2}$. At $20 \mathrm{kHz}$, the rate constants for the production of $\mathrm{H}_{2} \mathrm{O}_{2}$ vary over an order of magnitude as a function of the nature of the dissolved gas $\left(0.0508\right.$ and $\left.1.31 \mu \mathrm{M}^{-1}\right)$ [Hua and Hoffmann, 1997]. Similar trends were observed for the production of $\bullet \mathrm{OH}$ at the same frequencies and under an identical set of saturating gases. The

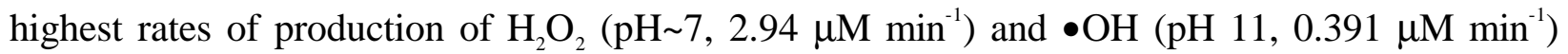


were observed during sonolysis of $\mathrm{Kr}$-saturated solutions at $500 \mathrm{kHz}$. Sonolysis of He-saturated solutions at $20 \mathrm{kHz}$ resulted in the lowest rates of production of $\mathrm{H}_{2} \mathrm{O}_{2}\left(0.0508 \mu \mathrm{M} \mathrm{min}\right.$ min $\left.^{-1}\right)$ and

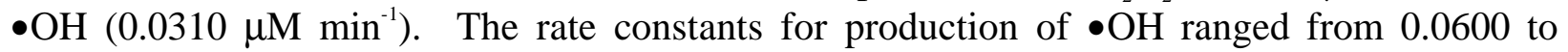
$2.68 \mu \mathrm{M}$ min-1 using $\mathrm{O}_{2}$ as the saturating gas, for ultrasonic frequencies ranging from 20 to $513 \mathrm{kHz}$. Decreasing differences among the saturating gases at higher frequencies were attributed to changes in bubble dynamics and thermodynamics as the resonant bubble radius decreases from $177 \mu \mathrm{m}$ at $20 \mathrm{kHz}$ to $7 \mu \mathrm{m}$ at $500 \mathrm{kHz}$ [Hua and Hoffmann, 1997].

Task 4. Conduct continuous-flow experiments for degradation of SVOCs and identification or quantification of by-products

Based on the promising results from the batch sonication/vapor stripping experiments, experiments were performed in a continuous flow mode. Results are presented for the cases involving $\mathrm{CCl}_{4}$ and TCA as the chlorinated organic contaminant, although similar results were also obtained for the other chlorinated organic species (TCE and PCE). For these experiments, the ultrasonic frequency was $20 \mathrm{kHz}$, with an applied power intensity of $35.8 \mathrm{~W} / \mathrm{cm}^{2}$. The initial concentration of the chlorinated organic contaminant was nominally $50 \mathrm{mg} / \mathrm{L}$. The residence time within the reactor was set at 5, 8, and 10 minutes. The reactor volume was $500-\mathrm{mL}$. Figure 14 shows the results of the residual concentration of TCA after a function of the number of residence times throughput through the reactor (well). Initially, the reactor was filled with artificial groundwater containing no contaminant; at the beginning of the run, the reactor was fed with two feed streams (one containing the uncontaminated groundwater; the other containing a saturated feed stream of the organic contaminant). The ratio of these two feed streams was determined by mass balance calculations to provide a nominal initial concentration of $\sim 50 \mathrm{mg} / \mathrm{L}$. In accordance with chemical reactor design, the reactor operated as a continuous stirred tank reactor. It takes about $3+$ residence times to reach a "pseudo-steady-state" condition. This was observed in our experiments; after about 4 or 5 residence times throughput of both the artificial groundwater and the saturated contaminant feed stream, the concentration of the contaminant within the reactor had reached a steady-state condition. Afterwards, the sonicator was turned on, and the reactor effluent was analyzed for its residual TCA concentration. Similar experiments were performed in which both sonication and vapor stripping (at an air flow rate of $500 \mathrm{~mL} / \mathrm{min}$ ) were performed simultaneously. The results are shown in Figure 14. For the residence times ranging from 5 to 10 minutes, TCA removal by sonication alone ranged from $14.6 \%$ to $36.6 \%$, while TCA removal by the combined sonication/vapor stripping system for the same set of residence times, ranged from $72.3 \%$ to $97.3 \%$, showing a substantial enhancement of the combined system over that by sonication alone. Analogous results are presented in Figure 15 for the $\mathrm{CCl}_{4}$ system, operating under nearly identical operating conditions. For the residence times ranging from 5 to 10 minutes, $\mathrm{CCl}_{4}$ removal by sonication alone ranged from $17.1 \%$ to $17.9 \%$, while $\mathrm{CCl}_{4}$ removal by the combined sonication/vapor stripping system for the same set of residence times, ranged from $74.0 \%$ to $87.9 \%$, again showing a substantial enhancement of the combined system over that by sonication alone.

Experiments were also performed using vapor stripping alone. The set up for these experiments were similar to that described above, in which a steady state concentration of the contaminant was achieved $(\sim 50 \mathrm{mg} / \mathrm{L})$ prior to performing vapor stripping. Results from the vapor stripping experiments (with residence times ranging from 5 to 10 minutes) are shown for the cases involving TCA and $\mathrm{CCl}_{4}$ in Figures 16 and 17, respectively. For the residence times 
ranging from 5 to 10 minutes, TCA removal by vapor stripping alone ranged from $55.6 \%$ to $75.4 \%$, while TCA removal by the combined sonication/vapor stripping system for the same set of residence times, ranged from $72.3 \%$ to $97.3 \%$, showing a significant enhancement of the combined system over that by vapor stripping alone. Similarly, for the residence times ranging from 5 to 10 minutes, $\mathrm{CCl}_{4}$ removal by vapor stripping alone ranged from $68.4 \%$ to $80.3 \%$, while $\mathrm{CCl}_{4}$ removal by the combined sonication/vapor stripping system for the same set of residence times, ranged from $74.0 \%$ to $87.9 \%$, again showing an enhancement of the combined system over that by vapor stripping alone. Although the vapor stripping alone results in improved residual concentrations of TCA and $\mathrm{CCl}_{4}$ (comparing to Figures 14 and 15), the residual concentration of TCA and $\mathrm{CCl}_{4}$ are significantly higher than that achieved with the combined system. In all cases, the combined system at any particular residence time resulted in improved performance over the individual cases involving sonication alone and vapor stripping alone. It should be noted that while vapor stripping does a decent job in removing the chlorinated compounds from solution, it merely transfers the contaminant from the liquid phase to the gaseous phase; it does not destroy the organic contaminant. The sonication and the combined sonication/vapor stripping system are much more effective in destroying the chlorinated solvent contaminants.

One other interesting feature of these continuous flow experiments is the observation that the first-order rate constants are nearly identical between the batch experiments and the continuous flow experiments, as shown in Figure 18 for the cases of TCA and $\mathrm{CCl}_{4}$. Therefore, the batch experiments provide a quick estimate of the first-order rate constant for operation in the continuous flow mode.

As we move to higher ultrasonic frequencies and great applied power densities, plus incorporation of multiple frequencies and improved focusing and directionalizing of acoustic waves, we expect the system performance to be even better in the pilot-scale and field demonstration phases as compared to the laboratory data reported here. 


\section{Comparison of Fraction TCA Remaining Using Sonication + Vapor Stripping to Sonication Alone $\left(20 \mathrm{kHz} ; 35.8 \mathrm{~W} / \mathrm{cm}^{2}\right)$}

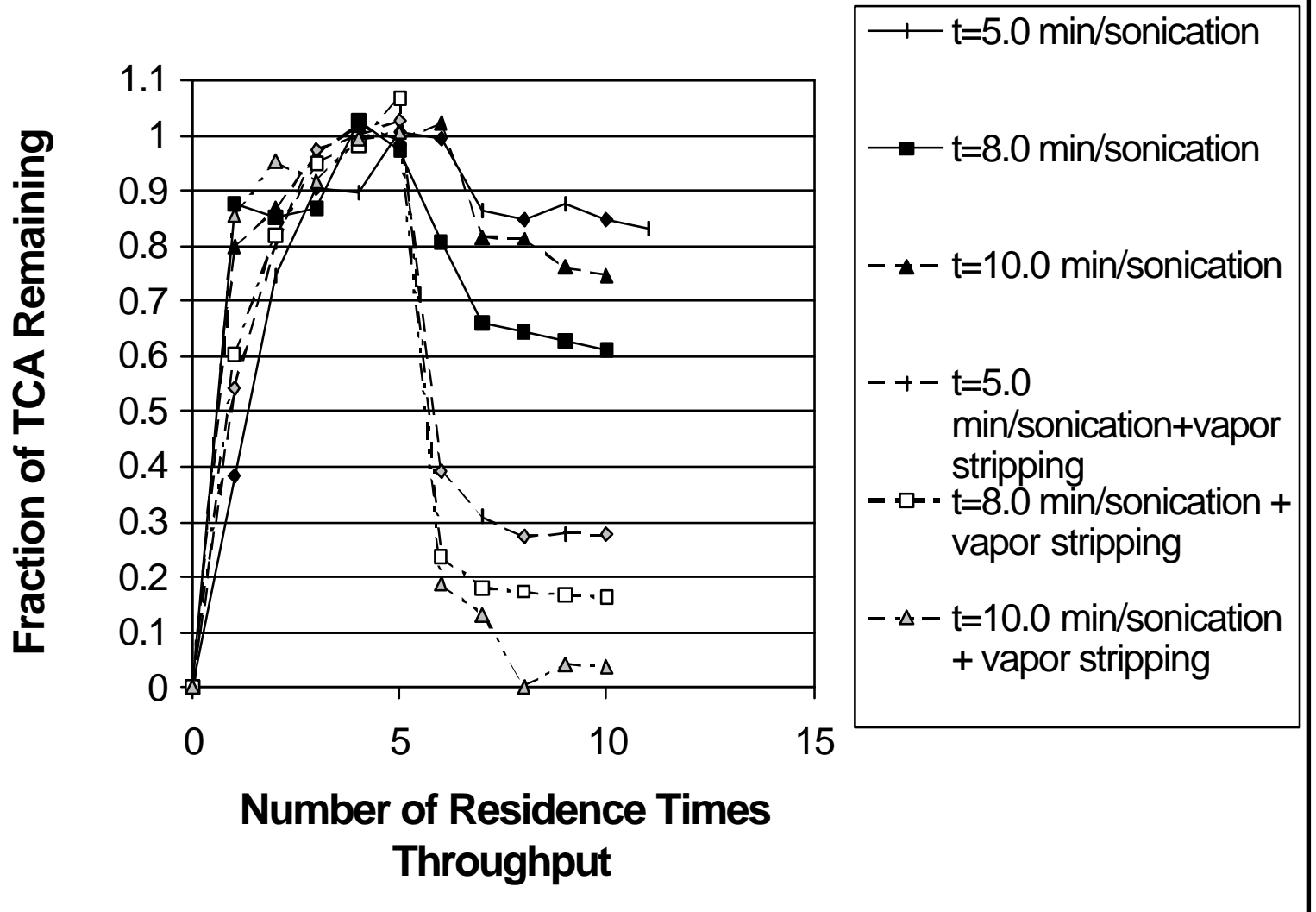

Figure 14. Comparison of fraction TCA remaining using sonication+vapor stripping $\left(500-\mathrm{mL} / \mathrm{min}\right.$ air injection rate) to sonication alone $\left(20 \mathrm{kHz}, 35.8 \mathrm{~W} / \mathrm{cm}^{2}\right)$. 


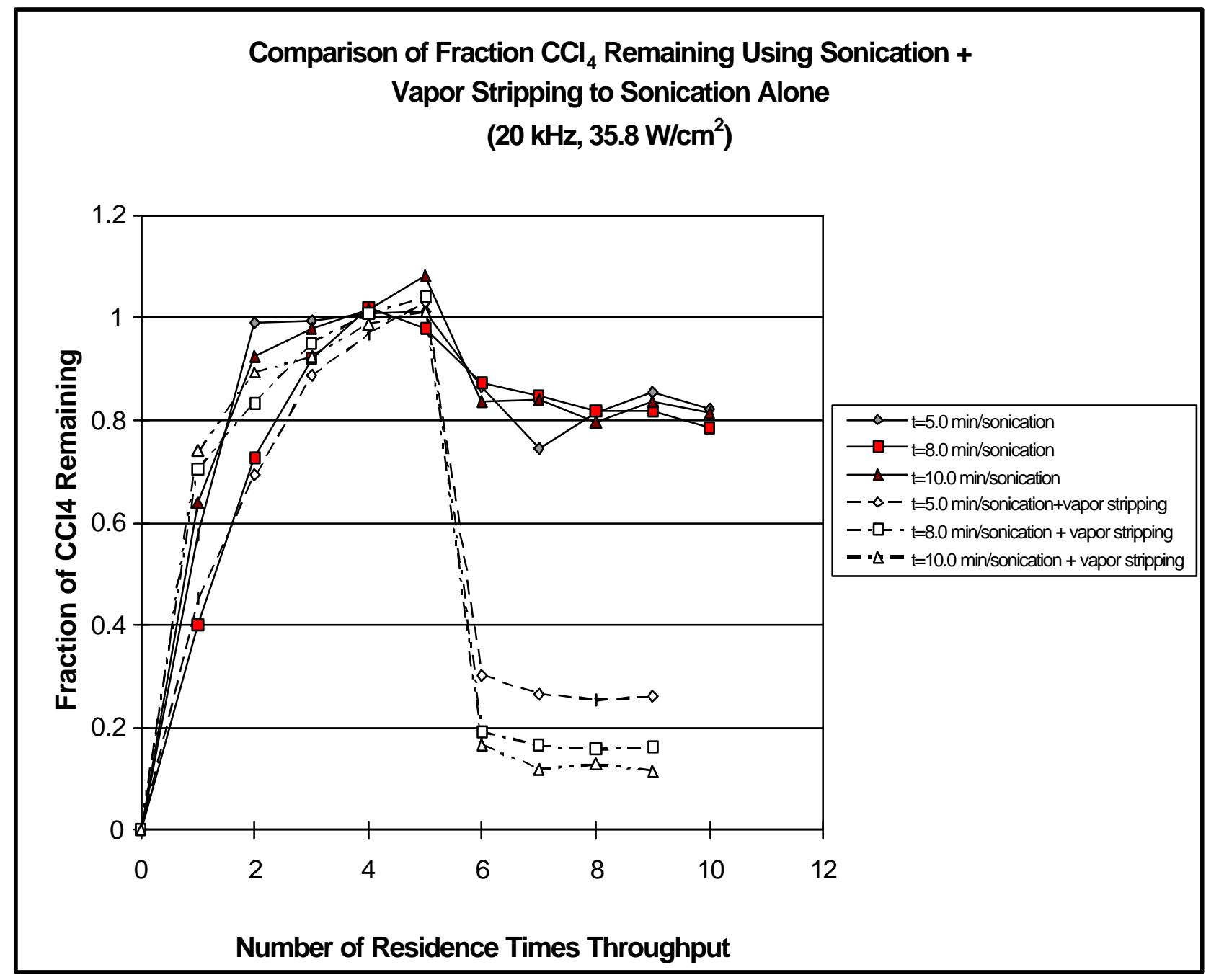

Figure 15. Comparison of fraction $\mathrm{CCl}_{4}$ remaining using sonication+vapor stripping $(500-\mathrm{mL} / \mathrm{min}$ air injection rate) to sonication alone $\left(20 \mathrm{kHz}, 35.8 \mathrm{~W} / \mathrm{cm}^{2}\right)$. 


\section{Comparison of Concentration of TCA Remaining Using Sonication $\left(20-\mathrm{kHz}, 35.8 \mathrm{~W} / \mathrm{cm}^{2}\right)+$ Vapor Stripping to Vapor Stripping Alone (500-mL/min)}

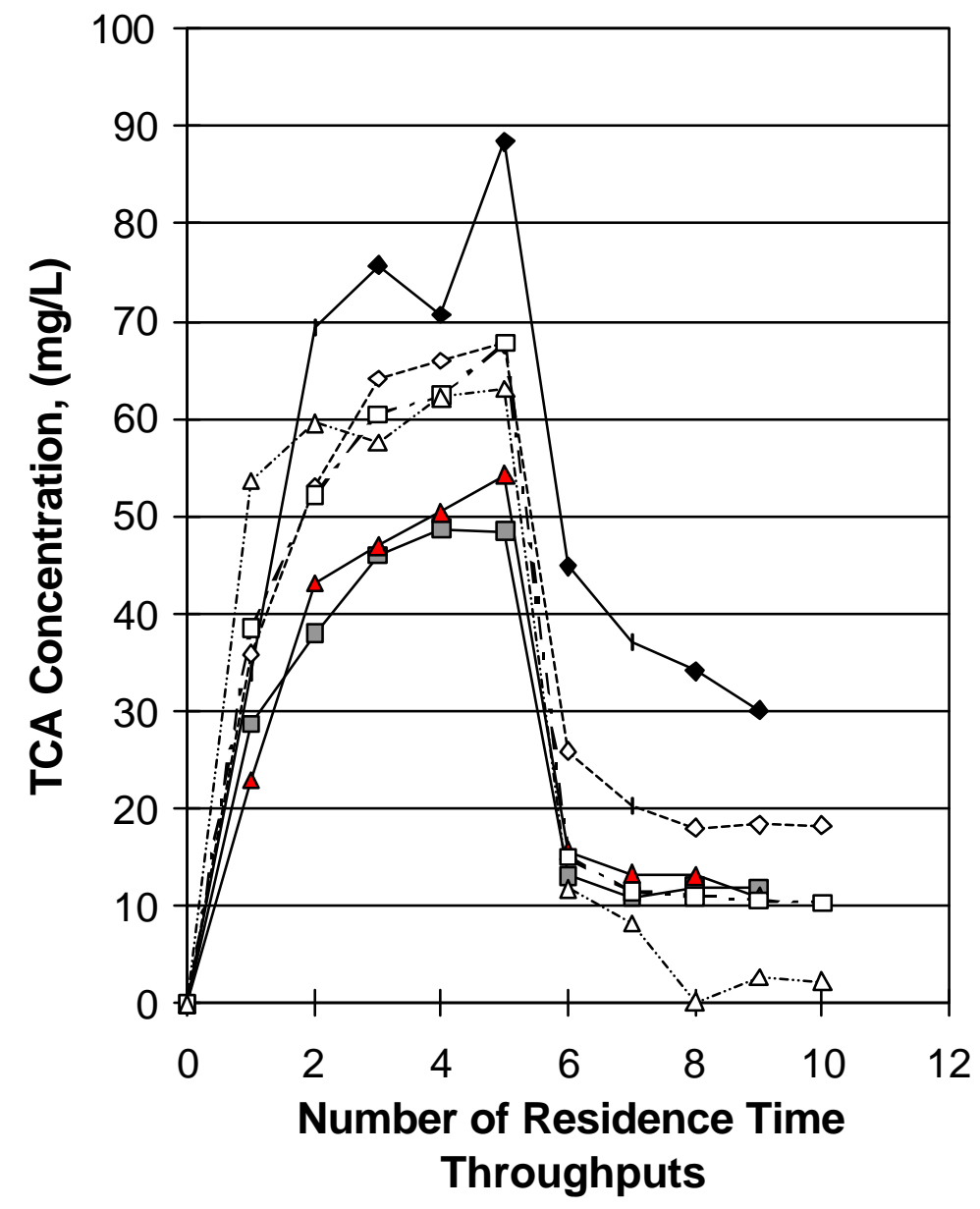

$\longrightarrow \mathrm{t}=5.0 \mathrm{~min} / \mathrm{vapor}$ stripping

$\square-\mathrm{t}=8.0 \mathrm{~min} / \mathrm{vapor}$ stripping

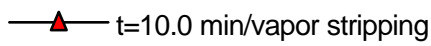

-------- t=5.0 min/sonication+vapor stripping

- $\square-\mathrm{t}=8.0 \mathrm{~min} /$ sonication + vapor stripping

$\cdots \cdots \cdot-\cdots-1=10.0 \mathrm{~min} /$ sonication + vapor stripping

Figure 16. Comparison of fraction TCA remaining using sonication $\left(20 \mathrm{kHz} ; 35.8 \mathrm{~W} / \mathrm{cm}^{2}\right)+$ vapor stripping to vapor stripping alone (500-mL air injection rate). 


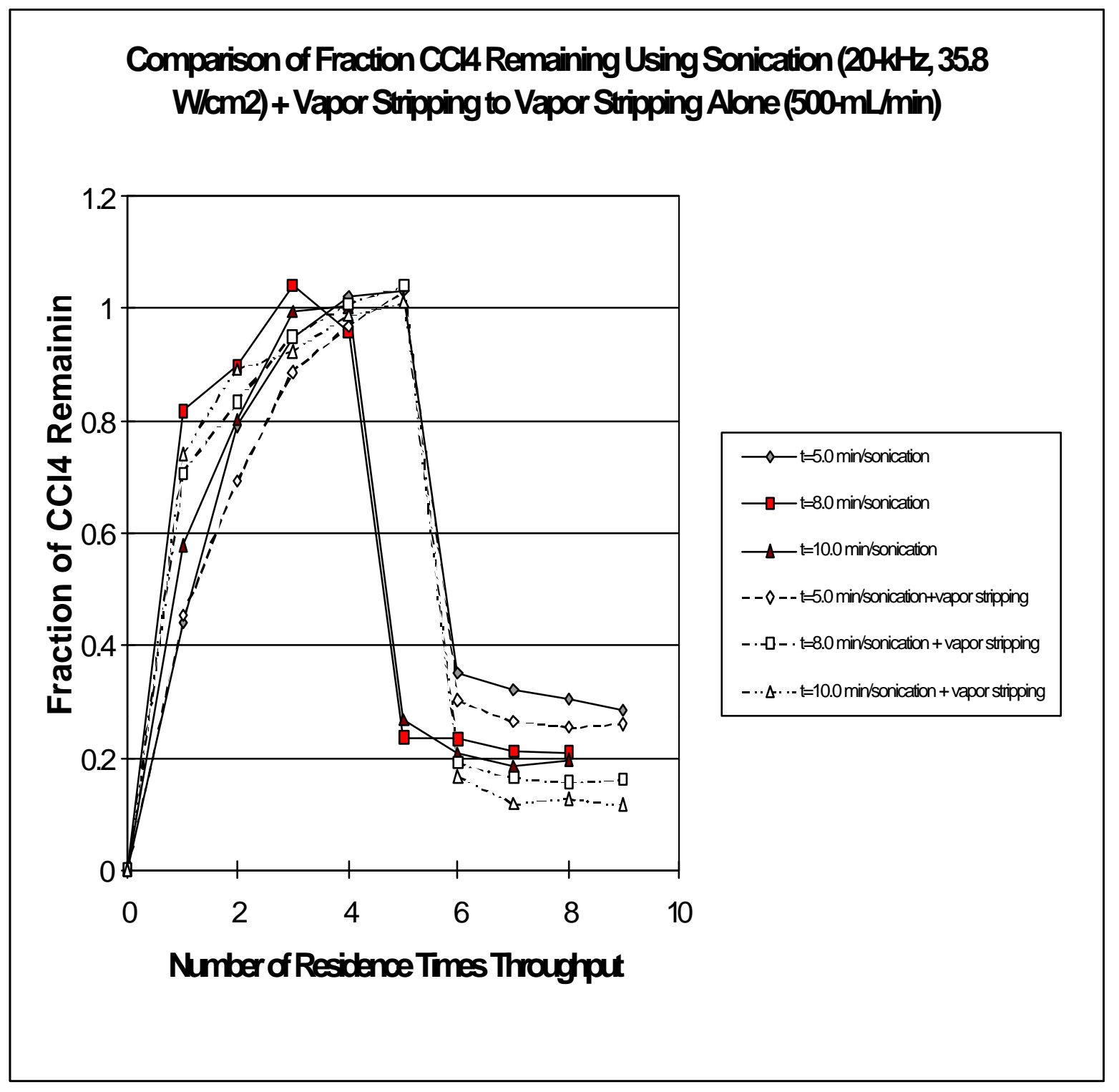

Figure 17. Comparison of fraction $\mathrm{CCl}_{4}$ remaining using sonication $\left(20 \mathrm{kHz} ; 35.8 \mathrm{~W} / \mathrm{cm}^{2}\right)+$ vapor stripping to vapor stripping alone $(500-\mathrm{mL}$ air injection rate). 


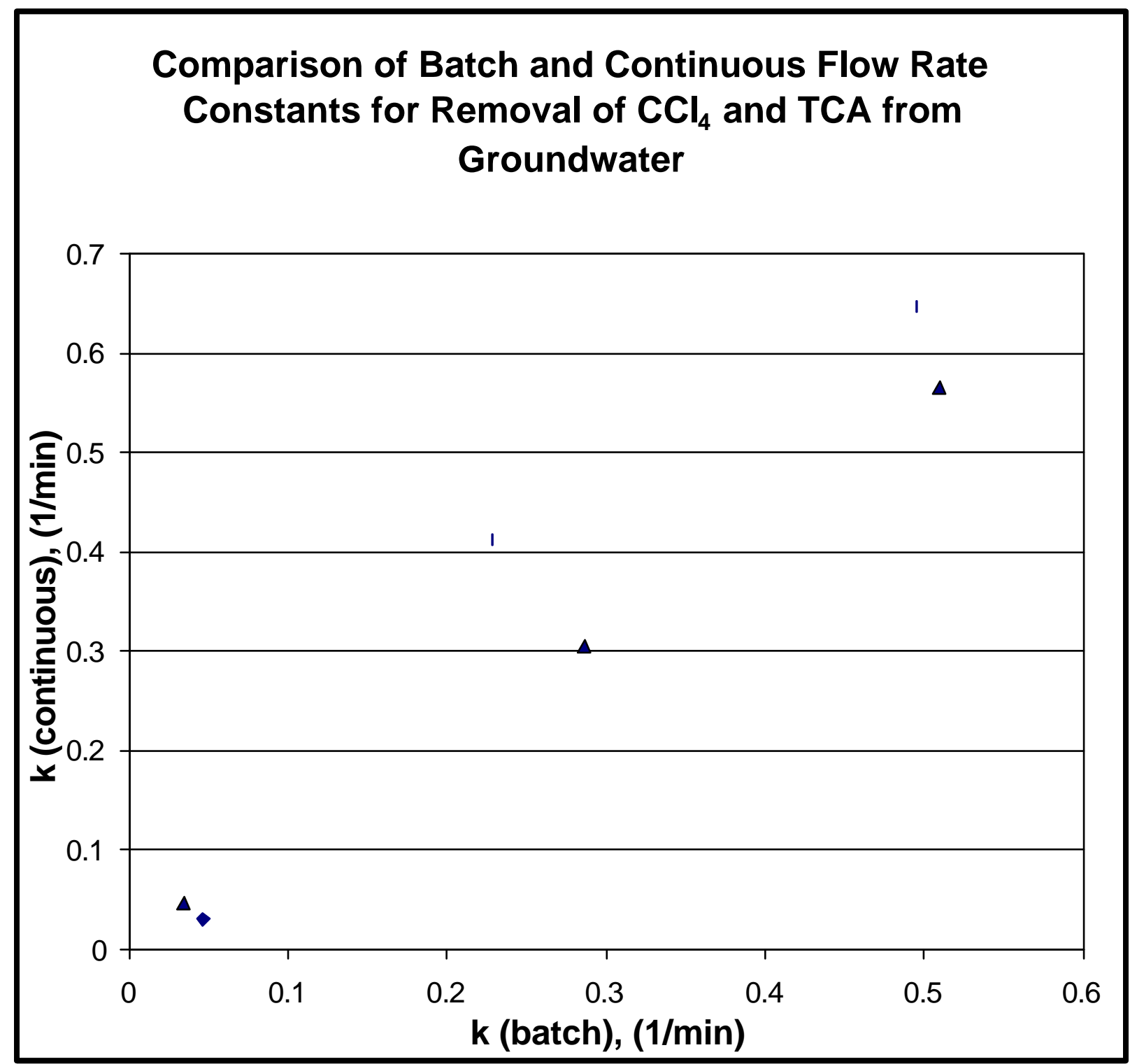

Figure 18. Comparison of batch and continuous flow rate constants for removal for $\mathrm{CCl}_{4}$ and TCA from groundwater using combined in-well sonication/in-well vapor stripping. 
Task 5. Investigate the chemical reaction mechanism to improve system performance

Degradation Products/Kinetic Modeling. Hua and Hoffmann [1996a] observed that the extent of $\mathrm{CCl}_{4}$ degradation was greater than $99 \%$ after 90 minutes of sonication treatment. The initial concentration was held constant in their experiments at $0.20 " 0.05 \mathrm{mM}(\sim 300 \mathrm{mg} / \mathrm{L})$. Loss of $\mathrm{CCl}_{4}$ due to volatilization was found to be less than $2 \%$ in separately run control experiments conducted in the absence of sonication [Hung and Hoffmann, 1999]. The $\mathrm{pH}$ after sonolytic degradation of $\mathrm{CCl}_{4}$ were near 3.5; the principal products observed were $\mathrm{OCl}, \mathrm{Cl}^{-}$, $\mathrm{C}_{2} \mathrm{Cl}_{4}$, and $\mathrm{C}_{2} \mathrm{Cl}_{6}$ [Hung and Hoffmann, 1999]. The distribution of products and chemical intermediates after 90 minutes of ultrasonic treatment is summarized in Table 6 below.

Table 6. Final Distribution of Chlorine Atoms in a Sonicated Solution of $\mathrm{CCl}_{4}$ after 90 Minutes of Sonolysis [Hua and Hoffmann, 1996a].

\begin{tabular}{lll}
\hline & & Concentration, $(\mu \mathrm{M})$ \\
\cline { 3 - 3 } Species & Initial & Final \\
\hline $\mathrm{CCl}_{4}$ & 400 & 4.0 \\
$\mathrm{C}_{2} \mathrm{Cl}_{4}$ & $\mathrm{ND}$ & $3.1 \times 10^{-3}$ \\
$\mathrm{C}_{2} \mathrm{Cl}_{6}$ & $\mathrm{ND}$ & $8.4 \times 10^{-2}$ \\
$\mathrm{Cl}$ & $\mathrm{ND}$ & 1100 \\
$\mathrm{HOCl}$ & $\mathrm{ND}$ & 130 \\
\hline
\end{tabular}

*ND: Not detected.

In more recent work, Hung and Hoffmann [1999] monitored the degradation products of $\mathrm{CCl}_{4}$ and $\mathrm{CHCl}_{3}$ degradation under sonolysis. Using a $0.2 \mathrm{mM}$ solution of $\mathrm{CCl}_{4}$, the highest concentrations of $\mathrm{C}_{2} \mathrm{Cl}_{4}$ and $\mathrm{C}_{2} \mathrm{Cl}_{6}$ observed were $80 \mathrm{nM}$ and $25 \mathrm{nM}$, respectively, accounting for $\sim 0.04 \%$ of $\mathrm{CCl}_{4}$ appearing as $\mathrm{C}_{2} \mathrm{Cl}_{4}$ and $<0.0125 \%$ of $\mathrm{CCl}_{4}$ appearing as $\mathrm{C}_{2} \mathrm{Cl}_{6}$, respectively. The extent of degradation of $\mathrm{CCl}_{4}$ exceeded $99 \%$ after 90 minutes of sonolysis [Hung and Hoffmann, 1999]. Hung and Hoffmann [1999] noted that $\mathrm{C}_{2} \mathrm{Cl}_{6}$ and $\mathrm{C}_{2} \mathrm{Cl}_{4}$, produced as intermediates during the sonolytic degradation of $\mathrm{CCl}_{4}$, are also readily degraded during aqueous-phase sonication.

In other studies, sonolysis of $10 \mathrm{mg} / \mathrm{L}$ of TCE produced $\mathrm{Cl}, \mathrm{H}_{2}$, and $\mathrm{CO}$ as major products, and small amounts of $\mathrm{CO}_{2}, \mathrm{CH}_{4}, \mathrm{C}_{2} \mathrm{H}_{6}$, and dichloroethylene (detected by GC-MS) [Inazu et al., 1993]. Sonication of high concentrations of TCE resulted in a higher number of intermediate compounds [Inazu et al., 1993]. During sonolysis of high TCE aqueous concentrations ( $\sim 40 \mathrm{mg} / \mathrm{L})$, Drijvers et al. [1996] reported formation of chlorinated products such as $\mathrm{C}_{2} \mathrm{HCl}, \mathrm{C}_{2} \mathrm{Cl}_{6}, \mathrm{C}_{4} \mathrm{Cl}_{2}, \mathrm{C}_{2} \mathrm{Cl}_{4}, \mathrm{C}_{4} \mathrm{Cl}_{4}, \mathrm{C}_{4} \mathrm{HCl}_{5}$, and $\mathrm{C}_{4} \mathrm{Cl}_{6}$ in trace amounts. Sonication of aqueous chloroform with phenol present produced chlorophenols, and with benzene present produced phenol, chlorobenzene, and chlorophenols [Kruus et al., 1998]. Bhatnagar and Cheung [1994] reported no chlorinated organic by-products being observed from sonolysis of C1 and C2 chlorinated compounds.

The sonication of $\mathrm{CCl}_{4}$ follows simple pseudo-first order reaction kinetics [Hua and Hoffmann, 1996a]. Slopes of standard linear regressions of the observed ln $\left.\left(\left[\mathrm{CCl}_{4}\right]_{1} / \mathrm{CCl}_{4}\right]_{0}\right)$ versus time data correspond to the observed first-order rate constants. Hung and Hoffmann 
[1999] conducted sonication experiments for degradation of $\mathrm{CCl}_{4}$ using various ultrasonic frequencies (see Tables 7 and 8 below); results from their studies are summarized below.

Table 7. Results of Calorimetry Measurements [Hung and Hoffmann, 1999]

\begin{tabular}{lcc}
\hline $\begin{array}{c}\text { Frequency, } \\
(\mathrm{kHz})\end{array}$ & $\begin{array}{c}\text { Power Output, } \\
(\mathrm{W})\end{array}$ & $\begin{array}{l}\text { Power Density, } \\
\left(\mathrm{W} / \mathrm{cm}^{3}\right)\end{array}$ \\
\hline 200 & 62 & 0.65 \\
50 & 48 & 0.10 \\
$205,358,618,1078$ & 35 & 0.06 \\
\hline
\end{tabular}

Table 8. Normalized Rate Constants for the Sonolytic Degradation of $\mathrm{CCl}_{4}$ in Water at $\mathrm{pH}_{\circ} \sim 7, \mathrm{pH}_{\infty} \sim 3.5$, and $\mathrm{T} \sim 286^{\circ} \mathrm{K}$ with $\left[\mathrm{CCl}_{4}\right]_{0} \sim 0.2 \mathrm{mM}$ [Hung and Hoffmann, 1999].

\begin{tabular}{lcccccc}
\hline Frequency, $(\mathrm{kHz})$ & 205 & 358 & 618 & 1078 & 20 & 500 \\
$\mathrm{k}_{\mathrm{ICC} \mid \mathrm{H}]},\left(\mathrm{min}^{-1}\right)$ & 0.044 & 0.049 & 0.055 & 0.039 & 0.025 & 0.070 \\
\hline
\end{tabular}

Hua and Hoffmann [1996a] have proposed the following mechanism for the sonolytic degradation of $\mathrm{CCl}_{4}$ in water (Note: ))) refers to sonolysis):

$$
\begin{aligned}
& \mathrm{CCl}_{4} \stackrel{\prime \prime \prime}{\rightarrow} \cdot \mathrm{Cl}+\cdot \mathrm{CCl}_{3} \\
& \mathrm{CCl}_{4} \stackrel{\prime \prime}{\rightarrow} \mathrm{Cl}_{2}+: \mathrm{CCl}_{2} \\
& \cdot \mathrm{CCl}_{3} \rightarrow \bullet \mathrm{Cl}^{-} \mathrm{CCl}_{2} \\
& \cdot \mathrm{CCl}_{3}+\bullet \mathrm{CCl}_{3} \rightarrow \mathrm{CCl}_{4}+: \mathrm{CCl}_{2} \\
& \cdot \mathrm{CCl}_{3}+\bullet \mathrm{CCl}_{3} \rightarrow \mathrm{C}_{2} \mathrm{Cl}_{6}
\end{aligned}
$$

Dichlorocarbene formed in Equation $\{3\}$ self-reacts to form tetrachloroethylene

$$
: \mathrm{CCl}_{2}+: \mathrm{CCl}_{2} \rightarrow \mathrm{C}_{2} \mathrm{Cl}_{4}
$$

or it can react with water to form carbon monoxide and hydrochloric acid

$$
: \mathrm{CCl}_{2}+\mathrm{H}_{2} \mathrm{O} \rightarrow 2 \mathrm{HCl}+\mathrm{CO}
$$

$\mathrm{C}_{2} \mathrm{Cl}_{6}$ and $\mathrm{C}_{2} \mathrm{Cl}_{4}$ are produced as intermediates during the sonolytic degradation of $\mathrm{CCl}_{4}$; these intermediates are also readily degraded during aqueous-phase sonication [Hung and Hoffmann, 1999]. Additional information related to the chemical mechanisms during sonolytic treatment of chlorinated organics has been described by Hoffmann and his researchers [Hung and Hoffmann, 1999; Hua and Hoffmann, 1996a]. 
Task 6. Perform batch or continuous-flow experiments to determine the effects of oxidants $\underline{\mathrm{H}}_{2} \underline{\mathrm{O}}_{2}$, Fenton's Reagent, etc.) on SVOC degradation and the biodegradability of the resultant product

Using hydrogen peroxide $\left(\mathrm{H}_{2} \mathrm{O}_{2}\right)[<0.1 \%]$ as the sole advanced oxidant to the sonication system resulted in negligible improvement over the ultrasonic system performance conducted in the absence of $\mathrm{H}_{2} \mathrm{O}_{2}$.

Task 7. Identify and quantify corrosion potential and salt formation

Six metal coupons (using either carbon steel 1018 or stainless steel 304) were placed on a polyethylene device that held the coupons in solution around the sonicator transducer probe. The reactor was operated using sonication alone $\left(20 \mathrm{kHz}, 35.8 \mathrm{~W} / \mathrm{cm}^{2}\right)$ over the course of a day; in several of the experiments, elevated chloride concentrations were employed (up to $0.3 \%$ ). The sonication system was operated continuously; the coupons were removed periodically from the sonication vessel at 1.0-, 2.0-, 3.0-, 4.0-, 6.0-, and 8.0-hours. After the sonication treatment, the coupons were rinsed in deionized water and then acetone, and then allowed to air dry. Weight loss measurements were made using an Ohaus analytical balance.

The metal thickness loss $(\mathrm{T})$ was calculated using the following equation:

$$
\mathrm{T}=\frac{\left(\mathrm{W}_{1}-\mathrm{W}_{2}\right)(393.7)}{\mathrm{Ad}}
$$

where: $\quad \mathrm{T}=$ Metal thickness loss, (mils)

$\mathrm{W}_{1}=$ Initial coupon weight, $(\mathrm{g})$

$\mathrm{W}_{2}=$ Final coupon weight, $(\mathrm{g})$

$\mathrm{A}=$ Coupon surface area, $\left(\mathrm{cm}^{2}\right)$

$\mathrm{d}=$ Metal/alloy density, $\left(\mathrm{g} / \mathrm{cm}^{3}\right)$

The density of carbon steel 1018 and stainless steel 304 is 7.87 and $7.94 \mathrm{~g} / \mathrm{cm}^{3}$, respectively.

The corrosion rate $(\mathrm{R})$ was calculated using the following equation:

$$
\mathrm{R}=\frac{\left(\mathrm{W}_{1}-\mathrm{W}_{2}\right)(393.7)(365)}{\mathrm{Ad} \mathrm{D}}
$$

where: $\mathrm{R}=$ Corrosion rate, (mils/year)

$\mathrm{W}_{1}=$ Initial coupon weight, $(\mathrm{g})$

$\mathrm{W}_{2}=$ Final coupon weight, $(\mathrm{g})$

$\mathrm{A}=$ Coupon surface area, $\left(\mathrm{cm}^{2}\right)$

$\mathrm{d}=$ Metal/alloy density, $\left(\mathrm{g} / \mathrm{cm}^{3}\right)$

$\mathrm{D}=$ Exposure time, (days)

Results from these corrosion experiments are summarized in Table 9. In the first experiment, carbon steel 1018 coupons were subjected to continuous sonication conditions $\left(20-\mathrm{kHz}, 35.8-\mathrm{W} / \mathrm{cm}^{2}\right)$ in a solution containing $\sim 20 \mathrm{mg} / \mathrm{L} \mathrm{CCl}_{4}$ and $0.3 \%$ sodium chloride $(\mathrm{NaCl})$. In the second experiment, stainless steel 304 coupons were subjected to continuous sonication 
conditions $\left(20-\mathrm{kHz}, 35.8-\mathrm{W} / \mathrm{cm}^{2}\right)$ in a solution containing $20 \mathrm{mg} / \mathrm{L} \mathrm{CCl}$ and $0.3 \% \mathrm{NaCl}$. In the third experiment, carbon steel 1018 coupons were subjected to continuous sonication conditions $\left(20-\mathrm{kHz}, 35.8-\mathrm{W} / \mathrm{cm}^{2}\right)$ in a solution containing $\sim 20 \mathrm{mg} / \mathrm{L} \mathrm{CCl}_{4}$ (without any $\mathrm{NaCl}$ present). The mean metal thickness loss for the three experiments were 0.00707, 0.00029, and 0.00631-mils, respectively, for Experiments 1, 2, and 3. The mean corrosion rates for these same three experiments were $121.3,0.92$, and 132.7 mils/year, respectively.

Table 9. Summary of Metal Thickness Loss and Corrosion Rate for Continuous Sonication $\left(20-\mathrm{kHz}, 35.8-\mathrm{W} / \mathrm{cm}^{2}\right)$ of Metal Coupons Placed in Solution Containing Chlorinated Compounds.

\begin{tabular}{|c|c|c|c|c|c|c|}
\hline $\begin{array}{c}\text { Experiment } \\
\text { No. }\end{array}$ & $\begin{array}{l}\text { Treatment } \\
\text { Conditions } \\
\end{array}$ & $\begin{array}{c}\text { Corrosion } \\
\text { Coupon }\end{array}$ & $\begin{array}{l}\text { Treatment } \\
\text { Time, } \\
\text { (min) }\end{array}$ & $\begin{array}{l}\text { Coupon } \\
\text { Weight } \\
\text { Loss, (g) }\end{array}$ & $\begin{array}{c}\text { Metal } \\
\text { Thickness } \\
\text { Loss (T), } \\
\text { (mils) }\end{array}$ & $\begin{array}{c}\text { Corrosion } \\
\text { Rate (R), } \\
\text { (mils/year) }\end{array}$ \\
\hline 1 & $\begin{array}{c}\text { Continuous } \\
\text { Sonication }(20- \\
\mathrm{kHz}, 35.8- \\
\left.\mathrm{W} / \mathrm{cm}^{2}\right) \\
\text { in presence of } \\
\sim 20 \\
\mathrm{mg} / \mathrm{L} \mathrm{CCl}_{4} \text { and } \\
0.3 \% \mathrm{NaCl}^{2}\end{array}$ & $\begin{array}{c}\text { carbon } \\
\text { steel } 1018\end{array}$ & $\begin{array}{l}60 \\
120 \\
180 \\
\\
240 \\
\\
360 \\
480\end{array}$ & $\begin{array}{l}0.0051 \\
0.0149 \\
0.0263 \\
0.0419 \\
\\
0.0761 \\
0.1733\end{array}$ & $\begin{array}{l}0.00641 \\
0.01871 \\
0.03303 \\
0.05262 \\
0.09558 \\
0.21766\end{array}$ & $\begin{array}{c}56.11 \\
81.97 \\
96.45 \\
115.25 \\
\\
139.54 \\
238.33\end{array}$ \\
\hline 2 & $\begin{array}{c}\text { Continuous } \\
\text { Sonication }(20- \\
\mathrm{kHz}, 35.8- \\
\left.\mathrm{W} / \mathrm{cm}^{2}\right) \\
\text { in presence of } \\
\sim 20 \\
\mathrm{mg} / \mathrm{L} \mathrm{CCl} \text { and } \\
0.3 \% \mathrm{NaCl}\end{array}$ & $\begin{array}{l}\text { stainless } \\
\text { steel } 304\end{array}$ & $\begin{array}{l}60 \\
120 \\
180 \\
240 \\
\\
360 \\
480 \\
\end{array}$ & $\begin{array}{l}0.0001 \\
0.0002 \\
0.0007 \\
0.0002 \\
0.0000 \\
0.0002\end{array}$ & $\begin{array}{c}0.00012 \\
0.00025 \\
0.00087 \\
0.00025 \\
0 \\
0.00025\end{array}$ & $\begin{array}{c}1.091 \\
1.091 \\
2.545 \\
0.545 \\
\\
0 \\
0.273\end{array}$ \\
\hline 3 & $\begin{array}{c}\text { Continuous } \\
\text { Sonication (20- } \\
\mathrm{kHz}, 35.8- \\
\left.\mathrm{W} / \mathrm{cm}^{2}\right) \\
\text { in presence of } \\
\sim 20 \\
\mathrm{mg} / \mathrm{L} \mathrm{CCl}_{4} \text { (no } \\
\mathrm{NaCl} \text { present) }\end{array}$ & $\begin{array}{c}\text { carbon } \\
\text { steel } 1018\end{array}$ & $\begin{array}{l}60 \\
120 \\
180 \\
240 \\
\\
360 \\
480\end{array}$ & $\begin{array}{l}0.0106 \\
0.0204 \\
0.0375 \\
0.1799 \\
0.0998 \\
0.0830\end{array}$ & $\begin{array}{l}0.01331 \\
0.02562 \\
0.04710 \\
0.22595 \\
0.12534 \\
0.10424\end{array}$ & $\begin{array}{l}116.62 \\
112.22 \\
137.53 \\
494.82 \\
183.00 \\
114.15\end{array}$ \\
\hline
\end{tabular}


The corrosion rates for carbon steel are quite high, typically being in the range of $\sim 120$ to 139 mils/year. Observation under a microscope indicated no evidence of localized, pitting corrosion; rather, general corrosion was observed. However, these high corrosion rates indicated a potential for localized corrosion to occur. It needs to be pointed out, however, that these experiments were short in duration ( $~ 8$ hours total treatment time) and that the sonicator was operated continuously at $20-\mathrm{kHz}, 35.8-\mathrm{W} / \mathrm{cm}^{2}$. In actual operation in the field, the sonication/vapor stripping system would be operated intermittently, not continuously. Additionally, as the corrosion layer (rust) forms within the well, the corrosion layer will shield the well casing underneath the corrosion layer. Thus, the corrosion rate will likely decrease significantly over longer time periods of operation, due to the increased resistance to mass transfer in forming the corrosion products. Therefore, it is the personal opinion of the Principal Investigator that the corrosion rate will not be a significant problem in the actual field operation of the sonication/vapor stripping system in wells fabricated of carbon steel.

The corrosion rate using stainless steel 304 is extremely low ( $<1$ mil/year); corrosion rates below 5 mils/year are considered to have good resistance to corrosion. The corrosion rate for the stainless steel is more than 2 orders-of-magnitude less than that experienced for carbon steel. Where possible, stainless steel well casings should be used in conjunction with the sonication/vapor stripping technology.

Task 8. Determine the volatility and biodegradability of the treated waters (and compare to untreated waters)

\section{Treatment}

Research was performed on each of the chlorinated organic species studied $\left(\mathrm{CCl}_{4}, \mathrm{TCE}\right.$, TCA, and PCE) to determine the volatility/stability of each chlorinated organic species using head space analysis [Quinn et al., 1998a,b]. The chlorinated organic species were found to be stable [negligible loss (i.e., <5\%)] for time periods as summarized below:

\begin{tabular}{cc}
\hline Chlorinated Organic Compound & Stability Period, (hr) \\
\hline $\mathrm{CCl}_{4}$ & 3.0 \\
$\mathrm{TCE}$ & 1.3 \\
$\mathrm{TCA}$ & $\sim 1.5$ \\
$\mathrm{PCE}$ & 0.9
\end{tabular}

These results are consistent with work of other researchers in this field. Hua and Hoffmann [1996] stirred a solution of $\mathrm{CCl}_{4}$ and maintained it at a temperature of $25^{\circ} \mathrm{C}$; liquid samples were sequentially withdrawn and analyzed. None of the dissolved $\mathrm{CCl}_{4}$ appeared to be lost from the solution over a period of 90 minutes. Even with a small headspace in their reactor, loss of $\mathrm{CCl}_{4}$ due to volatilization during sonolysis was negligible [Hua and Hoffmann, 1996a]. Loss of $\mathrm{CCl}_{4}$ due to vapor stripping was found to be less than $2 \%$ in separate run control experiments conducted in the absence of ultrasonic irradiation [Hung and Hoffmann, 1999]. Performing control experiments conducted in the absence of ultrasonic irradiation, Suri et al. [1999] observed negligible loss of TCE over a 25 -minute period at $45^{\circ} \mathrm{C}$. Under ultrasonic irradiation, two experiments were conducted with 0 - and 10-mL headspace, respectively; comparison of 
their results indicated that loss of TCE by volatilization was negligible $(<2 \%)$ over a 20 -minute period [Suri et al., 1999]. Bhatnagar and Cheung [1994], Francony and Petrier [1996], and Hua and Hoffmann [1996a] have also reported negligible loss of TCE during sonolysis.

Carbon tetrachloride $\left(\mathrm{CCl}_{4}\right)$ was selected as the model compound for this study. The objective of this experiment was to study the ability of common soil bacterial consortium to biodegrade the "softened" $\mathrm{CCl}_{4}$ after sonication treatment. This first biodegradation experiment was conducted under aerobic conditions. The $\mathrm{CCl}_{4}$ at an initial concentration of $30 \mathrm{mg} / \mathrm{L}$ was sonicated for $10 \mathrm{~min}$. at $20 \mathrm{kHz}$. The sonicated and unsonicated $\mathrm{CCl}_{4}$ were used for the biodegradation studies.

\section{Microorganisms:}

An aerobic bacterial consortium isolated from a garden soil was used in this experiment. The purpose of choosing this common soil bacteria was that the in-well sonication method will partially degrade (soften) the target compound, in this case $\mathrm{CCl}_{4}$, which in turn will be easily amenable to bacterial degradation. We have specific chlorinated solvents degrading bacteria in our culture collection; however, this specific chlorinated solvent degraders were not used for this study because in this experiment, the effects of sonication on $\mathrm{CCl}_{4}$ and its amenability to bacterial degradation were being tested. The soil bacterial consortium was pregrown and a late logarithmic culture was used as inoculum for the experiment.

\section{Growth Conditions:}

The bacterial consortium was grown in a basic mineral salt medium containing the following components:

\begin{tabular}{lc}
\hline Components & $(\mathrm{g} / \mathrm{L})$ \\
\hline $\mathrm{K}_{2} \mathrm{HPO}_{4}$ & 1.0 \\
$\mathrm{KH}_{2} \mathrm{PO}_{4}$ & 0.5 \\
$\mathrm{MgSO}_{4}$ & 0.1 \\
$\mathrm{NaCl}$ & 0.1 \\
$\left(\mathrm{NH}_{4}\right)_{2} \mathrm{SO}_{4}$ & 0.2 \\
Yeast extract & 0.01 \\
\hline
\end{tabular}

The bacterial medium was prepared and distributed in $10-\mathrm{mL}$ quantities into $150-\mathrm{mL}$ culture bottles with airtight seal. A $50-\mathrm{mL}$ quantity of the sonicated or unsonicated $\mathrm{CCl}_{4}$ was added to each culture bottle. A $1 \%$ pregrown inoculum was added to the culture bottles. The experiment was conducted in triplicates with triplicate abiotic controls. All culture bottles were incubated in a gyratory shaker kept at $100 \mathrm{rpm}$ at ambient temperature $\left(20-22^{\circ} \mathrm{C}\right)$. Samples were drawn periodically from the culture bottles to measure bacterial growth and for the analysis of $\mathrm{CCl}_{4}$ and its breakdown products. 


\section{Analysis:}

Bacterial growth: Bacterial growth was monitored by observing the turbidity of the culture with a Spectronic 20 spectrophotometer (Milton Roy, Rochester, NY) kept at the wavelength of $600 \mathrm{~nm}$.

GC Analysis: Analytical method development included selection and procurement of a Hewlett Packard 7694 Automatic Headspace Sampler for use with the Hewlett Packard 5890 Gas Chromatograph. Headspace analysis is well-suited for analysis of volatile and semivolatile organic compounds in water, and avoids the column degradation caused by liquid injection of water. The headspace sampling method includes ten minutes equilibration of samples at $70^{\circ} \mathrm{C}$ with shaking, programmed vial pressurization, venting, sample loop fill (1 mL loop volume), and 0.30 minute injection time. Equilibration time was selected by measuring area response for times ranging from 1 to 60 minutes. A 30 meter megabore fused capillary DB-624 column was selected based on its sensitivity and selectivity in analysis of chlorinated organic compounds. The HP 5890 chromatograph is equipped with both flame ionization and electron capture detectors. In the analytical range for this project $(0.1$ to $100 \mathrm{ppm})$, flame ionization provided adequate resolution and reproducible detection. The electron capture detector was found to be too sensitive for detection of major components, but is useful in examining sonicated samples for minor breakdown products. The GC temperature program was set for 1 minute at $90^{\circ} \mathrm{C}$, ramping $10^{\circ}$ minute to $140^{\circ}$, then $25^{\circ}$ /minute to $200^{\circ}$, and held for 2 minutes at $200^{\circ} \mathrm{C}$. Standards were initially prepared in volumetric flasks. Due to analyte volatility, this was changed to injection by syringe through the vial septum of the chlorinated compounds into measured water mass. Planned sample size was $5 \mathrm{~mL}$ in $10 \mathrm{~mL}$ vials, however this was reduced to $1 \mathrm{~mL}$ in $10 \mathrm{~mL}$ vials to avoid overloading the column with analyte. Response of carbon tetrachloride standards held in sealed vials over a 0.25 to 48 hour time range was evaluated to determine how long samples could be stored prior to GC analysis. It was found that vials analyzed within three hours after sampling gave the most reproducible response. Vials showed a drop in response to approximately $80 \%$ at 15 hours, and to $20-40 \%$ at 25 hours. Since the hydrolysis rate for $\mathrm{CCl}_{4}$ in water is very low, there appears to be loss through the vial seal or septum. Therefore all subsequent samples and standards were analyzed as closely as possible to the actual sampling time, and all within three hours. Five analyte standards were prepared each day for the initial calibration curve, and check standards were performed late in the day, or when any questionable sample result was obtained.

Experimental Scheme:

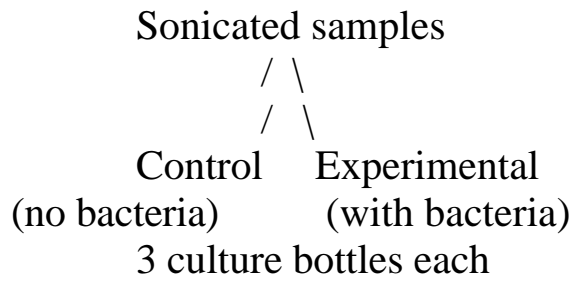

Sonicated samples

/ I

Control

(with bacteria)

3 culture bottles each
Unsonicated samples

11

11

Control Experimental

(no bacteria) (with bacteria)

3 culture bottles each 


\section{Results:}

Bacterial Growth: Figure 19 shows the growth of the bacteria in the sonicated and unsonicated $\mathrm{CCl}_{4}$ samples. Data were the average of triplicate culture bottles. The bacterial growth was minimal at the beginning (first 4 days) as the bacterial culture gets adapted to the compound $\mathrm{CCl}_{4}$, after day 4, the bacteria grew slowly. The bacterial growth was better in the sonicated samples compared to unsonicated samples. This indicates that there is some "softening" of $\mathrm{CCl}_{4}$ due to sonication, which bacteria were able to use as carbon source and break it down further. In the abiotic controls, there was no growth.

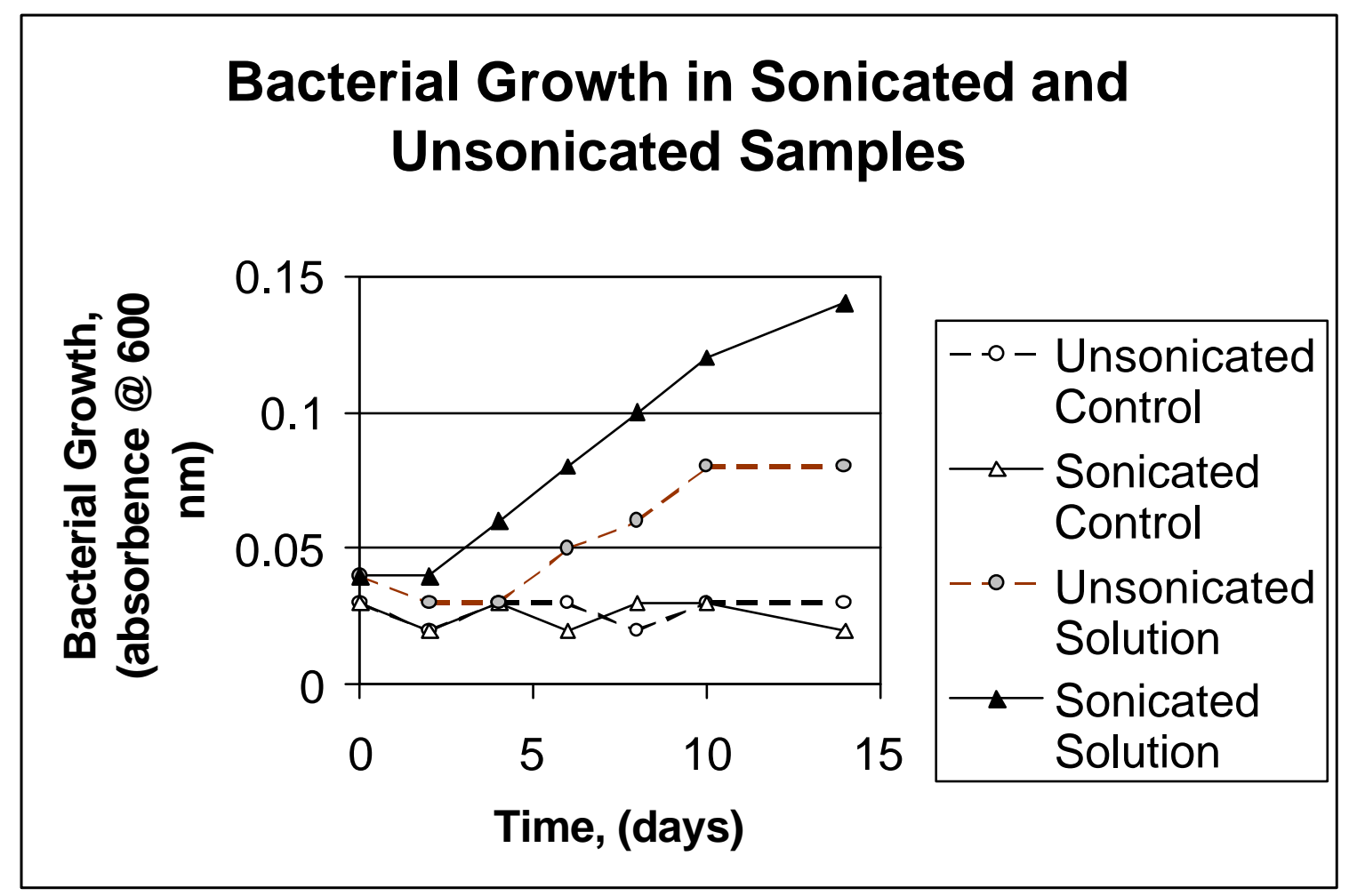

Figure 19. Bacterial Growth in Sonicated and Unsonicated Samples

This experiment showed that the sonicated sample supported bacterial growth compared to unsonicated sample and this indirectly shows that the "softened" $\mathrm{CCl}_{4}$ is being degraded by the common soil bacteria.

The biotransformation of trichloroethylene (TCE) under various electron acceptor conditions was investigated using enrichment cultures developed from the anaerobic digester sludge of the Thibodaux sewage treatment plant (near Nicholls State University). The results indicated that TCE was biotransformed under sulfate-reducing, methanogenic, nitrate-reducing, iron-reducing, and fermenting conditions. However, the rates of TCE removal varied among the conditions studied. The fastest removal of TCE (100\% removal in 9 days) was observed under 
mixed electron acceptor conditions, followed in order by methanogenic, fermenting, iron-reducing, sulfate-reducing, and nitrate-reducing conditions. Under mixed electron acceptor conditions, the TCE was converted to ethene, which was further metabolized. Under sulfate- and nitrate-reducing conditions, the major metabolites produced from TCE metabolism were cis-and trans-dichloroethylene (DCE). Under methanogenic, iron-reducing, and fermenting conditions, cis- and trans-DCE and ethene were produced from TCE metabolism.

Similar results were obtained for the biotransformation of carbon tetrachloride $\left(\mathrm{CCl}_{4}\right)$. Under mixed electron acceptor conditions, $\mathrm{CCl}_{4}$ removal was the fastest (100\% removal in 11 days), and this was followed in order by methanogenic, fermenting, iron-reducing, and sulfate-reducing conditions. Under nitrate-reducing conditions, $\mathrm{CCl}_{4}$ removal was minimal ( 8\% removal in 45 days). This study showed that nitrate-reducing conditions did not favor the biodegradation of $\mathrm{CCl}_{4}$. On the other hand, under mixed electron acceptor conditions, both TCE and $\mathrm{CCl}_{4}$ were removed efficiently. This study showed evidence for chlorinated solvents removal in a mixed microbial system similar to any contaminated field site, where heterogeneous microbial populations exist.

In the future, similar experiments may be conducted using field samples collected from sites contaminated with dense non-aqueous phase liquids (DNAPLs) such as TCE, $\mathrm{CCl}_{4}, \mathrm{TCA}$, and PCE. In natural conditions, heterogeneous microbial populations exist and by increasing the growth of mixed microbial populations under mixed electron acceptor conditions, the biodegradation of DNAPLs can be accelerated. After optimizing the conditions in the laboratory, we intend to conduct a field test at a contaminated site, specifically, the Savannah River Site, and monitor the removal of various DNAPLs under mixed electron acceptor conditions. From preliminary discussions with the Savannah River Site (SRS), they have expressed a great deal of interest in the technology for treatment and containment of TCE-DNAPL plumes at their facility.

In addition, experiments will be conducted on the effect of in-well acoustic cavitation ("softening") of DNAPLs on bioremediation. The experimental system will evaluate the ability of various microorganisms present in the contaminated sites under a variety of electron acceptor conditions for their ability to degrade the in-well softened DNAPLs. The microbial ecology after in-well softening of DNAPL-contaminated sites will also be examined. We intend to study various microbial populations before and after the in-well sonication/in-well vapor stripping treatment and follow any microbial succession by studying the microbial population shift due to the acoustic cavitation treatment.

Concentration of $\mathrm{CCl}_{4}$ : The first two analysis of the head space of the culture bottles did not show any difference between sonicated and unsonicated samples in terms of parent compound concentration and its breakdown products from day 0 to day 7 .

Our hypothesis is that a wide variety of electron acceptor conditions can and will provide a wide variety of enzyme activities and associated microbial activities to remove chlorinated solvents. Aerobic and anaerobic bacteria present in the contaminated site can affect the rate of degradation of contaminants depending on the local environment. Under appropriate conditions microorganisms can biotransform, dechlorinate, and eventually degrade the chlorinated organic solvents. The presence or absence of certain electron acceptors will determine the redox potential in the environment. The redox potential in turn will control the range and distribution 
of microorganisms. Aerobic and anaerobic metabolism of organic compounds usually requires electron acceptors like organic compounds (fermentation conditions), oxygen, sulfate, nitrate, iron, and carbon dioxide. The effects of various electron acceptor conditions on the metabolism of pre-treated (sonicated) chlorinated solvents will be investigated.

\section{Future Work on Biodegradation Studies:}

\section{Experimental Approach}

Collection of Samples and Analyses:

In the future, samples from the SVOC-contaminated site will be collected and analyzed for physical and chemical characteristics of the sample such as $\mathrm{pH}$, redox potential, total organic carbon, ammonia, and phosphorous. Initial experiments will be conducted in shake flasks and anaerobic bottles that will determine the effect of microbial metabolism on the metabolites produced from the in-well softening of SVOCs.

Selection of Microbial System for the Study:

In the future, samples from the SVOC-contaminated sites will be collected and screened for various microbial population viz., aerobic heterotrophic bacteria and the following anaerobic bacteria such as sulfate reducing, nitrate reducing, iron reducing and methanogenic bacteria under various electron accepting conditions. The best conditions will be selected in terms of maximum organic contaminants degradation.

Once the microbial system has been selected for the bioremediation of organic contaminants, further studies will be carried out on the influence environmental factors on the bacterial growth and the application value of these bacteria in terms of bioremediation of softened organic solvents. The system of electron acceptor conditions is important for the removal of organics present in anaerobic sites.

Laboratory Enrichment Studies:

\section{Aerobic bacteria}

The aerobic heterotrophic bacteria present in the contaminated site will be enriched as described before [Boopathy et al., 1994]. The heterotrophic medium consisting of the following components will be prepared: $\mathrm{K}_{2} \mathrm{HPO}_{4}(1.0 \mathrm{~g} / \mathrm{L}), \mathrm{KH}_{2} \mathrm{PO}_{4}(0.5 \mathrm{~g} / \mathrm{L}), \mathrm{MgSO}_{4}(0.10 \mathrm{~g} / \mathrm{L}), \mathrm{NaCl}$ $(0.1 \mathrm{~g} / \mathrm{L}),\left(\mathrm{NH}_{4}\right)_{2} \mathrm{SO}_{4}(0.2 \mathrm{~g} / \mathrm{L})$, yeast extract $(0.01 \mathrm{~g} / \mathrm{L})$, and sonicated and unsonicated sample $(90 \mathrm{~mL})$. The medium $(100 \mathrm{~mL})$ has been distributed in several $200 \mathrm{~mL}$ culture bottles with screw cap and mineret lock for periodic headspace sampling (gas phase). A portion of the contaminated soil $(1 \mathrm{~g})$ were added to these culture bottles as bacterial source. The culture bottles were incubated at room temperature $\left(20-22^{\circ} \mathrm{C}\right)$ in a gyratory shaker kept at $150 \mathrm{rpm}$. The enrichment cultures were transferred to fresh media periodically. After five transfers, the enrichment culture were tested for its effectiveness in removing organic contaminants. Bacterial growth was monitored by measuring the culture turbidity at $600 \mathrm{~nm}$ using a Spectronic 20 spectrophotometer. The dissolved oxygen (D.O) was monitored using a D.O probe available in our laboratory. Experiments were conducted in triplicates with triplicate abiotic controls to 
compare the results. A similar parallel experiment was conducted without the media but only with sonicated and unsonicated samples.

\section{Anaerobic bacteria:}

Under all the anaerobic conditions described below, one set of experiment will be conducted with the enriched media to enrich the selective bacterial population and another set of experiment have been conducted only with sonicated and unsonicated samples.

\section{Sulfate reducing bacteria $(S R B)$ :}

The anaerobic techniques described by Balch and Wolfe [1976] and Daniels et al. [1986] were used throughout the study. Anaerobic culture bottles with butyl rubber stoppers and aluminum crimps were used. The enrichment medium for the experiment was described earlier by Boopathy et al. [1993]. The medium consists of the following components (in $\mathrm{mM}$ ): $\mathrm{KCl}$ (4.1), $\mathrm{NH}_{4} \mathrm{Cl}$ (16.8), $\mathrm{CaCl}_{2}$ (0.61), $\mathrm{K}_{2} \mathrm{HPO}_{4}$ (1.45), $\mathrm{KH}_{2} \mathrm{PO}_{4}$ (1.85), $\mathrm{NaCl}(0.60), \mathrm{MgCl}_{2}(0.1)$, $\mathrm{Na}_{2} \mathrm{CO}_{3}$ (1.5), $\mathrm{Na}_{2} \mathrm{~S}$ (1.0), rasazurin (0.003), pyruvate (30.0), sodium sulfate (20.0), and sonicated and unsonicated sample $(90 \mathrm{~mL})$. The $\mathrm{pH}$ of the medium was adjusted to 6.8. After preparation, medium was distributed into anaerobic culture bottles and was made anaerobic as described previously by Balch and Wolfe [1976] using a gassing manifold system available in our laboratory. The gas phase was $100 \% \mathrm{~N}_{2}$ and the culture bottles were kept at the pressure of 20 psi $\mathrm{N}_{2}$.

In the future, soil samples will be collected from the intermittently anaerobic vadose zone (which has significant anaerobic bacterial populations) of the contaminated site. Samples will be kept in sterile containers and transported to the laboratory. A portion of the soil sample $(1 \mathrm{~g})$ will be added to the anaerobic culture bottles containing sulfate reducing media in $100 \mathrm{~mL}$ amounts. The culture bottles will be incubated at room temperature $\left(20-22^{\circ} \mathrm{C}\right)$ in a gyratory shaker kept at $150 \mathrm{rpm}$. The cultures showing substantial growth will be transferred to fresh medium. After five more transfers, experiments will be conducted on the sixth transfer enrichment cultures. In this enrichment cultures, bacterial growth will be monitored by observing the culture turbidity. The experiment will be conducted in triplicate with abiotic controls.

\section{Nitrate reducing bacteria:}

The culture conditions described for SRB enrichment study will be followed except for a few changes in the media composition. The nitrate reducing medium contain all the components described in the SRB medium, but, in the place of pyruvate, sodium acetate $(40 \mathrm{mM})$ was added. Sodium nitrate $(20 \mathrm{mM})$ replaced sodium sulfate as electron acceptor. In this experiment, we monitor bacterial growth. The experiment was conducted in triplicates with abiotic controls.

\section{Iron reducing Bacteria:}

The culture conditions for iron reducing conditions were similar to that of nitrate reducing conditions described above except that $20 \mathrm{mM}$ Fe (III) served as electron acceptor in place of nitrate. The soluble iron was added to the medium as iron-citrate complex as described by Coates et al. [1996]. The study was conducted in triplicates with abiotic controls. 


\section{Methanogenic Bacteria:}

All the culture conditions and experimental procedure described for SRB enrichment study were followed except that the medium contained $40 \mathrm{mM}$ sodium acetate instead of pyruvate as carbon source and the medium did not contain sodium sulfate. The headspace contained $\mathrm{H}_{2}-\mathrm{CO}_{2}$ (80:20) instead of $\mathrm{N}_{2}$. Bacterial growth was monitored. The experiment was conducted in triplicates with abiotic controls.

\section{Fermenting Bacteria:}

In the future, fermenting bacteria present in the contaminated site will be enriched by supplementing simple sugars such as molasses in the media. The mineral salts present in the SRB medium will be used without the addition of pyruvate and sulfate. The medium will be supplemented with $0.3 \%$ (v/v) molasses as carbon source and will be incubated under anaerobic conditions with $100 \%$ N2 in the headspace. Similar experimental protocols described above for SRB will be followed.

\section{$\underline{\text { Analyses }}$}

\section{Bacterial growth}

The bacterial growth in the culture samples were monitored by measuring the culture turbidity at $600 \mathrm{~nm}$ using a Spectronic 20 spectrophotometer.

\section{Dissolved oxygen (D.O)}

The D.O in the sample was monitored by using an oxygen analyzer (Gilson Oxygraph model Oxy-5, Gilson Electronics, Middleton, WI). The instrument was calibrated with deionized water saturated with oxygen.

$\underline{\mathrm{pH}}$

The $\mathrm{pH}$ in the sample was measured by using a $\mathrm{pH}$ meter (Accumet $\mathrm{pH}$ meter).

\section{Nitrogen, Ammonia and Phosphorus}

Nitrogen, ammonia, and phosphorus were analyzed by colorimetric methods using Hach water analysis reagent kits (Hach Company, Loveland, CO).

\section{$\underline{\text { VOC and SVOC }}$}

The VOC and SVOC analyses were analyzed using GC techniques.

The higher the vapor pressure of the chlorinated organic compound, the more volatile the compound. Carbon tetrachloride $\left(\mathrm{CCl}_{4}\right)$ and trichloroethane (TCA) have vapor pressures of $\sim 100 \mathrm{~mm} \mathrm{Hg}$ at ambient temperatures; they are the most volatile of the parent halogenated organic compounds, the other parent compounds (TCE, PCE, and EDB) are much less volatile. Hexachloroethane is not very volatile $(\sim 1 \mathrm{~mm} \mathrm{Hg})$ for the potential degradation products, while 
phosgene (if formed) has a relatively high vapor pressure $(\sim 1200 \mathrm{~mm} \mathrm{Hg})$, indicating that phosgene could be quite readily stripped out of solution, whereas hexachloroethane, is not readily stripped from solution.

Degradation rates were obtained from Howard et al. [1991]. Their data indicate that unacclimated biodegradation half-lives can range from $~ 168$ days up to 4.5 years. Similarly, the half-lives of the halogenated organic compounds in soil range from 168 days up to 1 year. This material indicates the need to make the organic contaminants both bioavailable, and potentially partially degraded so that biodegradation activities can be enhanced.

Task 9. Develop computer simulation model to describe combined in-well sonication/in-well vapor stripping, and biodegradation

A numerical model has been developed at Stanford University to simulate the influences of the processes of in-well sonication, in-well vapor stripping, and biodegradation on the groundwater as they occur in the subsurface. Given the complexity of the flow and multi-process treatment system, the representation of removal processes in the model was represented as simply as possible. The model was based on MT3D, an existing groundwater contaminant transport code, which will be modified. The model accounts for flow induced by a single recirculating well and the changes to water as dissolved VOCs are removed by the selected in-situ treatment. In addition to the contaminant removal processes mentioned above, other important physical and chemical processes that can be accounted for in the model are advection, dispersion, molecular diffusion, and equilibrium adsorption-desorption of contaminants to and from aquifer solids.

The success of contaminant transport modeling effort is strongly dependent on the availability of adequate input data. The first phase of model use was in association with the laboratory-scale aquifer system to be constructed at ANL. This brief statement refers only to the laboratory system and the measurements that are needed for successful modeling. For the laboratory-scale system, several key parameters and state variables must be measured. Assuming that the laboratory system consists of homogeneous sand, that the contaminant under study is a single dissolved VOC, and that all significant changes in concentration occur in the treatment well or in the aquifer (saturated zone), the model will require the following input parameters:

- $\quad$ For flow, the following measurements are needed: porosity, effective porosity, hydraulic conductivity, bulk density, particle density, particle grain-size distribution analysis, the location of the treatment well and the specifics of its design (screened intervals, diameter), flow rate of air through the well, flow rate of water through the well. Depending on the exact experiment, boundary conditions are needed for the heads in feed tanks around the edge depending on whether there is an induced natural gradient or not. During the experiment, the primary state variable that must be measured is hydraulic heads in three dimensions (3D). This should be done using multi-level mini-piezometers. Observation of the capillary fringe may also be important if it represents a relatively large volume of water in the laboratory system. 
- For contaminant transport, the following measurements are needed: contaminant properties such as sorption isotherms, kinetic isotherms, Henry's law constants, aqueous diffusion coefficients, and gas diffusion rate constants. A tracer test using a non-reactive substance, such as chloride, should be conducted prior to loading the tank with VOC. The analysis of this test helps determine the dispersion coefficient needed for simulation of VOC transport through the aquifer. If possible, other non-reactive tracers should be introduced once the recirculating flow system is operational. These tracers should be introduced at various locations in the tank and measured at each monitoring well and at various locations and depths in the feed tanks. This will help us better understand the flow system mechanics and local flow velocities. The state variable of interest is concentration that must be measured in 3D over time using multi-level monitoring wells. Initial concentrations, boundary concentrations, and concentrations during the tracer test must be measured. Other laboratory measurements required to characterize the contaminant removal processes include: the biodegradation rate in the aquifer, the air-water flow ratio for vapor stripping, the single-pass stripping percentage (assuming that the laboratory system will be too small for the water-bubble mixture to reach equilibrium), the single pass removal percentage for in-well sonication as a function of dissolved VOC concentration, and the degradation product function due to sonication. Each VOC will be modeled sequentially. That is, first the parent VOC will be considered over the entire time frame of the experiment, and then based on the degradation product function due to sonication, the daughter product(s) will be modeled over the entire time frame of the experiment. Concentrations in the treatment well at the bottom well screen and the top well screen must be measured. VOC off-gas from the vapor-stripping well must be measured over time. Granular activated carbon (GAC) usage must be measured. Soil VOC gas concentrations, humidity of the injected and retrieved vapor, the temperature of the water, and the temperature of the injected and retrieved air must be measured as well. A suite of basic water quality measurements must be obtained (e.g. major anions, cations, pH, dissolved oxygen, etc.) before and after each laboratory experiment. Some of the above parameters will require column experimental work to be conducted. If there are any interference effects due to combining contaminants, these must be investigated.

The main output of the model involves predicted heads and contaminant concentrations throughout the aquifer over time. Using reasonable estimates of parameter values, the model can be used to gain a quantitative understanding of how the entire system works. Given preliminary estimates of parameters, the model can be used to assist in the design of laboratory experiments. For example, we can simulate the concentration removal over time in the system and thereby get some idea of where and when to monitor concentrations. Once the experiments were performed, the model was used to analyze the resulting data, and the process components of the model were modified to better represent the true system. This calibration stage involved matching simulated to observed heads and concentrations. Once the laboratory-scale system was understood and was able to be modeled, a similar process will be followed to help design the field system. That is, the model can be used to design the field-scale system, calibrate it to field data, and analyze 
system performance in 3D over time. In the field, this will be particularly valuable as measurements will be relatively sparse.

Numerical modeling of the combined in-well sonication/in-well vapor stripping system was performed on the basis of hypothetical parameter values. In the modeling, the contaminant of concern was assumed to be trichloroethylene (TCE). The hydraulic conductivity, porosity, and retardation values are typical for a clean sand aquifer. For a laboratory pilot system, the treatment well was assumed to be placed at the tank and water was withdrawn through the bottom $0.7-\mathrm{m}$ of the well. The treated water was reinjected into the unsaturated zone. Simulations were performed for two different flow rates. The lower flow rate of $0.063 \mathrm{~m}^{3} /$ day was equivalent to treating half of the total pore volume per day, and the higher flow rate of $1.26 \mathrm{~m}^{3} /$ day corresponded to the treatment of the entire pore volume each day. Hypothetical values for the destruction of TCE used in the simulation were $20 \%, 50 \%$, and $80 \%$ destruction of TCE for each pass. (Results from the continuous flow studies have indicated that for residence times of 5 to 10 minutes, the removal efficiency of TCE using the combined acoustic cavitation $\left(20-\mathrm{kHz}, \sim 36 \mathrm{~W} / \mathrm{cm}^{2}\right) /$ vapor stripping $(\sim 500 \mathrm{~mL} / \mathrm{min}$ air injection rate) system ranges from $\sim 70 \%$ to $>95 \%$ for a single pass through the system). For the purposes of the simulations, it was assumed that the sonication rate was independent of concentration, although Hua and Hoffmann [1996a] have noted a weak influence of initial concentration on the first-order rate constant for the sonolytic degradation of $\mathrm{CCl}_{4}$; this phenomena was also observed by Wu et al. [1992a], and has been observed in our current studies. In this numerical modeling activity, the removal per pass by vapor stripping was assumed to be $80 \%$ (Note: discussions with scientific personnel at the Savannah River Site have indicated that the removal per pass by vapor stripping in their vapor stripping wells is $50 \%$ or less per pass). The initial contaminant distribution for the simulation was $5 \mathrm{mg} / \mathrm{L}$ of TCE in the aqueous phase distributed uniformly in the saturated zone. The parameter values used in the simulations are summarized in the table below:

\begin{tabular}{|l|l|}
\hline Tank dimensions & $\begin{array}{l}\text { Length }=3.0 \mathrm{~m} \\
\text { Width }=1.0 \mathrm{~m} \\
\text { Height }=2.0 \mathrm{~m}\end{array}$ \\
\hline Saturated thickness & $1.4 \mathrm{~m}(70 \%$ of height $)$ \\
\hline Well location & Center of cell $(\mathrm{x}=1.5 \mathrm{~m} ; \mathrm{y}=0.5 \mathrm{~m})$ \\
\hline Screened interval & Bottom $0.7 \mathrm{~m}$ of cell \\
\hline Flow rate & $\begin{array}{l}\text { High case: } 1.26 \mathrm{~m}^{3} / \text { day } \\
\text { Low case: } 0.63 \mathrm{~m}^{3} / \text { day }\end{array}$ \\
\hline Sonication removal per pass & $\begin{array}{l}\text { High case: } 80 \% \\
\text { Middle case: } 50 \% \\
\text { Low case: } 20 \%\end{array}$ \\
\hline $\begin{array}{l}\text { Vapor stripping removal per } \\
\text { pass }\end{array}$ & $80 \%$ \\
\hline Hydraulic conductivity & 10 m/sec \\
\hline Effective porosity & 0.3 \\
\hline Retardation factor & 1.3 \\
\hline Initial contaminant distribution & $5 \mathrm{mg} / \mathrm{L} \mathrm{TCE}$ uniformly distributed through saturated zone \\
\hline Dispersivities & $\begin{array}{l}\text { Longitudinal: } 0.1 \mathrm{~m} \\
\text { Transverse: } 0.1 \mathrm{~m}\end{array}$ \\
\hline Discretization & $\Delta \mathrm{x}=\Delta \mathrm{y}=\Delta \mathrm{z}=0.1 \mathrm{~m}$ \\
\hline
\end{tabular}


A total of six simulations were performed (one for each combination of flow rate and sonication removal rate).

In the simulations, the combined removal per pass due to sonication and vapor stripping was $84 \%, 90 \%$, or $94 \%$, depending on the sonication removal assumed. Three-dimensional plots of contaminant concentrations over time were developed, employing a pumping rate of $1.26 \mathrm{~m}^{3} /$ day and a sonication removal of $50 \%$ per pass. The simulations indicated that the contaminant is removed quite rapidly (This indeed has been shown in our experimental results for the combined in-well sonication/in-well vapor stripping system), although higher concentration regions persist in the corners of the tank. Concentration histories at the well intake for each of the six simulations were developed. As expected, concentrations drop more rapidly at the higher pumping rate -- a $90 \%$ reduction in contaminant concentration is achieved in about 4 days at the high pumping rate and in 8 days at the lower pumping rate.

The results of this numerical modeling study indicate that for these choices of parameter values and monitoring locations, it would be difficult to determine the effects of sonication based on TCE concentration in the combined sonication/vapor stripping simulation (due to the high removal of TCE assumed for the vapor stripping component). The results from these simulations indicate that the effect of the combined sonication/vapor stripping technology is very promising; the effect of sonication is very likely even more noticeable for relatively nonvolatile compounds for which vapor stripping is not highly effective.

Task 10. Perform large-scale experiments with a laboratory in-well sonication/in-well vapor stripping/bioremediation system.

Due to the time and expense required to perform the other tasks, this task was not performed in a pilot-scale system. The system was intended to be scaled up to handle 100 to 200 gallons of artificial groundwater spiked with the contaminant(s) of concern in a high bay at Argonne National Laboratory. However, a smaller-scale system capable of handling up to 10 gallons was planned for construction and operation in a walk-in hood of the research laboratory of the PI. In the interim, continuous flow studies were conducted to investigate the synergistic/antagonistic effects involved with treating multiple chlorinated organic compounds simultaneously. In continuous flow studies with reactor residence times ranging from 5 to 10 minutes, removal of the individual chlorinated organic compounds by sonication alone typically ranges from 20 to $40 \%$, by vapor stripping alone ranges from $\sim 20 \%$ to $\sim 60+\%$, and by the combined sonication/vapor stripping system ranges from $70+\%$ to $>95 \%$.

Task 11. Perform systems analysis and economic analysis for system scale-up for a field demonstration.

This task was not performed at a level sufficient relating to a full-scale field demonstration. However, the power requirements for a sonolytic system and the combined sonication/vapor stripping system were determined for a ultrasonic power intensity of $35.8 \mathrm{~W} / \mathrm{cm}^{2}$ treating water containing $50 \mathrm{mg} / \mathrm{L}$ of $\mathrm{CCl}_{4}$ or TCE. For batch treatment, the electrical energy per unit mass is calculated using the equation listed below:

$$
\mathrm{EE} / \mathrm{M}=\left(10^{6} \mathrm{xPxt}\right) /\left[60 \mathrm{xVx}\left(\mathrm{C}_{\mathrm{i}}-\mathrm{C}_{\mathrm{f}}\right)\right]
$$


where: $\quad \mathrm{EE} / \mathrm{M}=$ electrical energy per unit mass of contaminant removed $(\mathrm{kWh} / \mathrm{kg})$

Sonication Power Capacity $=600 \mathrm{~W}$

Power Intensity $=35.8 \mathrm{~W} / \mathrm{cm}^{2}($ or $17 \%)$

$\mathrm{P}=600 \mathrm{~W} \times 0.17=102 \mathrm{~W}=0.103 \mathrm{~kW}$

$\mathrm{t}=$ Treatment time $(\min )=10 \mathrm{~min}$.

$\mathrm{V}=$ Total volume of the solution $(\mathrm{L})=0.5 \mathrm{~L}$

$\mathrm{C}_{\mathrm{i}}=$ Initial contaminant concentration $(\mathrm{ppm})=50 \mathrm{mg} / \mathrm{L}$

$\mathrm{C}_{\mathrm{f}}=$ Final contaminant concentration $(\mathrm{ppm})$

$\mathrm{C}_{\mathrm{f}}$ can be calculated using the first-order equations from the batch sonication, vapor stripping, and the combined sonication/vapor stripping experiments. Results from these power requirement calculations for the above set of conditions are shown in Figure 20. These results show that the combined in-well sonication/in-well vapor stripping system is considerably less energy intensive than using sonication alone; the power requirement for a given removal efficiency of $\mathrm{CCl}_{4}$ or TCE is nearly an order of magnitude lower for the combined in-well sonication/in-well vapor stripping system than by sonication alone.

For tasks 11 to 13 (systems/r stripping technology at a selected DOE facility), these tasks will be pursued under a continuation grant proposal. We feel the science of this in-well sonication/in-well vapor stripping technology has been sufficiently demonstrated and the fundamentals understood at the lab-scale to merit taking the technology to the field by performing a pilot-scale investigation (in a pilot-scale system to be constructeconomic analysis, fabricate field equipment, and demonstrate the in-well sonication/in-well vapoed in a high-bay facility at Argonne National Laboratory, capable of treating up to 200 gallons in an experimental run). We have had preliminary discussions with the Savannah River Site; the Subsurface Contaminant Focus Area (SCFA) has indicated a keen interest in this technology for treating chlorinated organic DNAPL plumes at the Savannah River Site. For example, the staff at the Savannah River Site are interested in using this approach to treat a TCE plume that is about 0.6-miles long. This approach could drastically shorten the time for clean and decrease the cleanup costs involved in remediating this site.

\section{ANNUAL SONICATION WORKSHOP}

Argonne National Laboratory has taken the lead to hold an annual workshop for projects in the field of sonication which are funded by DOE's EMSP Program. The first annual workshop was held at Argonne on October 25, 1996. These workshops brings together researchers to discuss results from their research projects, from the following organizations: University of Illinois, Purdue University, University of Washington, Syracuse University, and the University of California at Davis, in addition to Argonne. Another workshop was held during the latter part of October 1997. There are six sonication projects funded by EMSP:

(1) Argonne National Laboratory: "Use of Sonication for In-Well Softening of Semivolatile Organic Compounds"; PIs: Robert W. Peters and John Manning.

(2) Purdue University: "An Investigation of Homogeneous and Heterogeneous Sonochemistry for Destruction of Hazardous Waste"; PI: Inez Hua. 


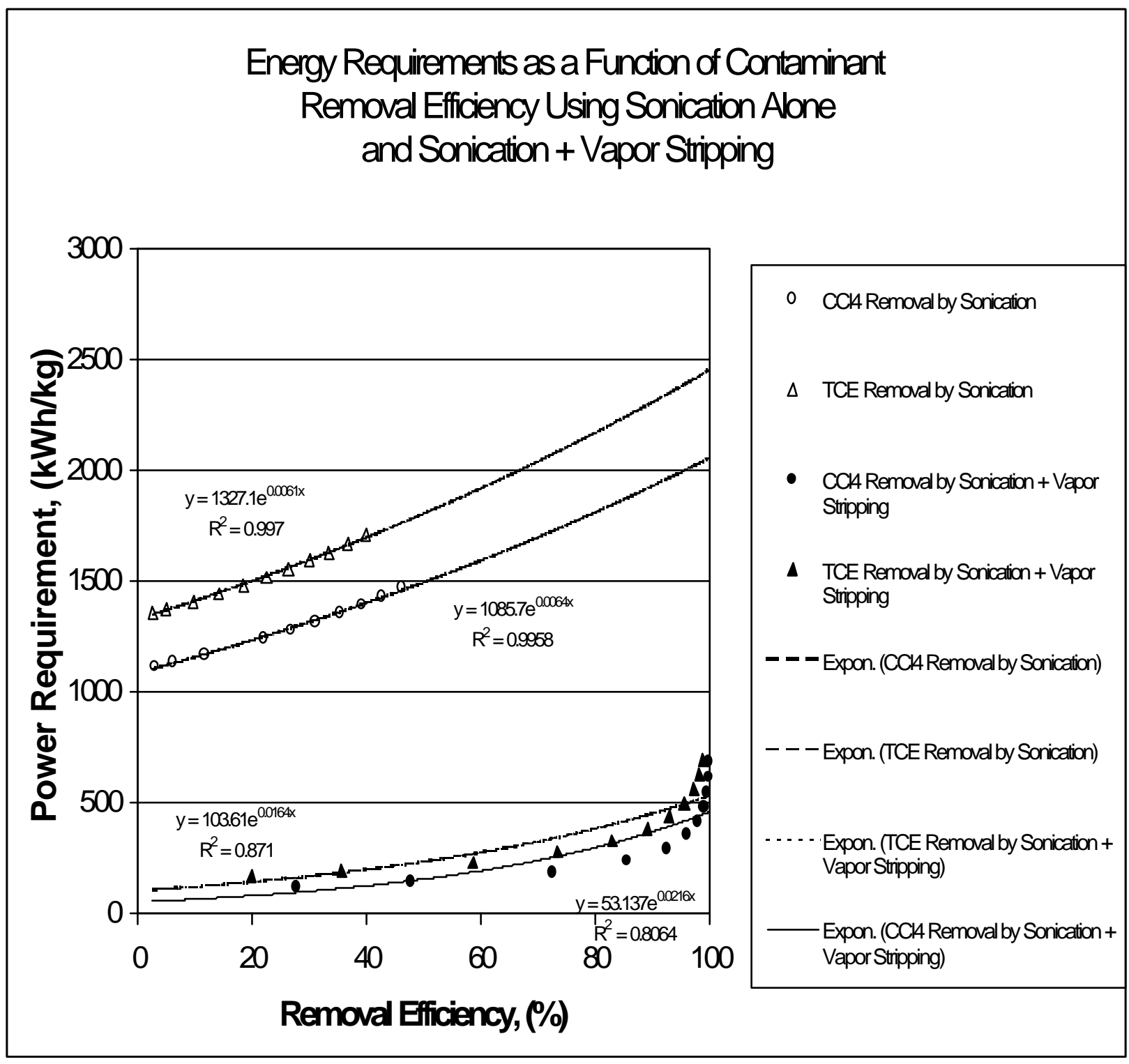

Figure 20. Energy requirements as a function of contaminant removal efficiency using sonication alone and sonication+vapor stripping. 
(3) Syracuse University: "Acoustic Probe for Solid-Gas-Liquid Suspensions"; PI: Lawrence L. Tavarides.

(4) University of California at Davis: "On-Line Slurry Viscosity and Concentration Measurement as a Real-Time Waste Stream Characterization Tool"; PIs: Robert L. Powell (U.C. Davis) and Reza Shekarriz (Pacific Northwest Laboratory).

(5) University of Illinois: "Cavitational Hydrothermal Oxidation: A New Remediation Process"; PI: Kenneth Suslick.

(6) University of Washington: "The Sonophysics and Sonochemistry of Liquid Waste Quantification and Remediation"; PI: Thomas J. Matula.

Representatives of DOE's EMSP Program were invited to attend these workshops; Drs. Robert Price and Gordon Roesler have attended these workshops.

\section{TECHNOLOGY TRANSFER ACTIVITIES}

The integrated technology involving in-well sonication, in-well vapor stripping, and insitu biodegradation has been described in an article published in Argonne's Tech Transfer Highlights [1997]. In that article, Argonne sought industrial collaborators with technical strengths in megasonics to help develop a prototype down-well reactor. More recently, the technology has been described in a recent publication of HazTECH News [2000]. Results are summarized for batch and continuous flow in-well sonication/in-well vapor stripping.

A small potato processing firm (Idaho Supreme Potatoes, Inc.) expressed an interest in the technology to treat wastewaters that contained a myriad of odorous compounds, including acetic acid, phenylacetic acid, indole, skatole, n-butyric acid, and iso-butyric acid. Work was pursued through Argonne's Industrial Technology Development (ITD) Center under a Technical Services Request to examine the applicability of this integrated treatment system involving sonication, vapor stripping, and microbial degradation, to minimize odors from their process waters.

Additionally, the results from this research have been shared (on an annual basis) with other sonication researchers (funded through DOE's EMSP Program) in the annual sonication workshop held at Argonne each year.

\section{DISCLAIMER}

The viewpoints expressed here are not necessarily those of Argonne National Laboratory or its sponsors.

\section{ACKNOWLEDGMENT}

This research project was funded by DOE's Environmental Management Science Program (EMSP). This project is a collaborative effort involving Argonne National Laboratory's Energy Systems Division and Environmental Research Division, and the California Institute of Technology and Stanford University. Additionally, a subcontract was established with the 
Illinois Institute of Technology (IIT) enabling Mr. Po-Yao Kuo and Mr. Onder Ayyildiz, graduate students in the Department of Chemical and Environmental Engineering at IIT, to be active researchers on this project.

\section{REFERENCES CITED}

Argonne National Laboratory (1997). "New Technology Cleans Contaminated Groundwater: Seeking Collaborators for Further Development," Tech Transfer Highlights, 8(1): 2.

Balch, W.E., and R.S. Wolfe (1976). "New Approach to the Cultivation of Methanogenic Bacteria: 2-Mercaptoethane Sulfonic Acid (HS-CoM) Dependent Growth of Methanobacterium ruminantium in a Pressurized Atmosphere," Appl. Environ. Microbiol., 32: 781-789.

Bhatnagar, A., and H.M. Cheung (1994). "Sonochemical Destruction of Chlorinated C1 and C2 Volatile Organic Compounds in Dilute Aqueous Solution," Environ. Sci. Technol., 28: 1481-1486.

Boopathy, R., J. Manning, C. Montemagno, and C. Kulpa (1994). "Metabolism of 2,4,6-Trinitrotoluene by a Pseudomonas Consortium under Aerobic Conditions," Curr. Microbiol., 28: 131-137.

Boopathy, R., M. Wilson, and C. Kulpa (1993). "Anaerobic Removal of 2,4,6-Trinitrotoluene (TNT) under Different Electron Accepting Conditions: Laboratory Study," Water Environ. Res., 66: 271-275.

Boyd, G., and D. Geiser (2000). "Integrated Solutions -- Meeting the Challenges of the Environmental Management Program," Plenary paper presented in the Topical Conference of "Environmental Remediation in the 21st Century: Integrated Systems Technologies," Spring National AIChE Meeting, Atlanta, GA (March 5-9).

Coates, J.D., E.J. Phillips, D.J. Lonergan, H. Jenter, and D.R. Lovely (1996). "Isolation of Geobacter Species from Diverse Sedimentary Environments," Appl. Environ. Microbiol., 62: 1531-1536.

Criddle, C.S., J.T. DeWitt, D. Grbi -Gali , and P.L. McCarty (1990). “Transformation of Carbon Tetrachloride by Pseudomonas sp Strain ILC Under Denitrification Conditions," Appl. \& Environ. Microbiol., 56:3240-3246.

Crum, L.A., and R.A. Roy, (1994). "Sonoluminescence," Science, 266(5183):233-234.

Crum, L.A., (1994). J. Accoust. Soc. Am., 95:559-562.

Daniels, L., N. Belay, and R. Boopathy (1986). “Assimilatory Reduction of Sulfate and Sulfite by Methanogenic Bacteria,” Appl. Environ. Microbiol., 51:703-709.

Drijvers, D., R.D. Baets, A.D. Visscher, and H.V. Langenhove (1996). "Sonolysis of Trichloroethylene in Aqueous Solution: Volatile Organic Intermediates," Ultrason. Sonochem., 3:S83-S90. 
Flint, E.B., and K.S. Suslick (1991). "The Temperature of Cavitation," Science, 253(5026):1397-1399.

Flint, E.B., and K.S. Suslick (1989). "Sonoluminescence from Nonaqueous Liquids: Emission from Small Molecules,” J. Am. Chem. Soc., 111(18):6987-6992.

François, O., T. Gilmore, M.J. Pinto, and S.M. Gorelick (1996). “A Physically-Based Model for Air-Lift Pumping," Water Resources Res., 32(8):2383-2399.

Francony, A., and C. Petrier (1996). "Sonochemical Degradation of Carbon Tetrachloride in Aqueous in Aqueous Solution at Two Frequencies: $20 \mathrm{kHz}$ and $500 \mathrm{kHz}$, " Ultrasonics Sonochem., 3:S77-S82.

Gorelick, S.M., and H. Gvirtzman (1993). "In-Situ Vapor Stripping for Removing Volatile Organic Compounds from Groundwater,” U.S. Patent No. 5,180,503.

Gorelick, S.M., and H. Gvirtzman (1995). "In-Situ Vapor Stripping for Removing Volatile Organic Compounds from Groundwater," U.S. Patent No. 5,389,267.

Gutiérrez, M., A. Henglein, and F.J. Ibañez (1991). "Radical Scavenging in the Sonolysis of Aqueous Solutions of I', Br, and $\mathrm{NO}_{3}^{-}$, , J. Phys. Chem., 95(15):6044-6047.

Gvirtzman, H., and S.M. Gorelick (1992). "The Concept of In-Situ Vapor Stripping for Removing VOCs from Groundwater," Transport in Porous Media, 8:71-92.

Gvirtzman, H., and S.M. Gorelick (1993). "Using Air-Lift Pumping as an In-Situ Aquifer Remediation Technique,” Water Sci. Technol., 27(708):195-201.

HazTECH News (2000). "Sonication Combined with Vapor Stripping to Remove Organics from Ground Water," HazTech News, 15(2):11-12.

Helland, B.R., P.J.J. Alvarez, and J.L. Schnoor (1995). "Reductive Dechlorination of Carbon Tetrachloride with Elemental Iron," J. Haz.. Mater., 41(2-3):205-216.

Herrling, B.J., J. Stamm, and W. Buermann (1991). "Hydraulic Circulation System for In-Situ Bioreclamation and/or In-Situ Remediation of Strippable Contamination," pp. 173-195 in In-Situ Bioreclamation, R.E. Hinchee and R.F. Olfenbuttel, Eds., Butterworth-Heinemann, Stoneham, MA.

Hoffmann, M.R., I. Hua, R. Höchemer, D. Willberg, P. Lang, and A. Kratel (1996). “Chemistry Under Extreme Conditions in Water Induced by Electrohydraulic Cavitation and Pulsed-Plasma Discharges," in Chemistry under Extreme or Non-Classical Conditions, R. van Eldik and C.D. Hubbard, Eds., Elsevier, Amsterdam, The Netherlands.

Howard, P.H., R.S. Boethling, W.F. Jarvis, W.M. Meylan, and E.M. Michalenko (1991). Handbook of Environmental Degradation Rates, Lewis Publishers, Inc., Chelsea, MI.

Hua, I., and M.R. Hoffmann (1997). "Optimization of Ultrasonic Irradiation as an Advanced Oxidation Technology,” Environ. Sci. Technol., 31(8):2237-2243. 
Hua, I., and M.R. Hoffmann (1996a). "Kinetics and Mechanism of the Sonolytic Degradation of $\mathrm{CCl}_{4}$ : Intermediates and Byproducts,” Environ. Sci. Technol., 30(3):864-871.

Hua, I., R. Höchemer, and M.R. Hoffmann (1995a). "Sonochemical Degradation of p-Nitrophenol in a Parallel-Plate Near-Field Acoustical Processor," Environ. Sci. Technol., 29(11): 2790-2796.

Hua, I., R.H. Höchemer, and M.R. Hoffmann (1995b). "Sonolytic Hydrolysis of p-Nitrophenyl Acetate: The Role of Supercritical Water,” J. Phys. Chem., 99(8):2335-2342.

Hung, H.-M., and M.R. Hoffmann (1999). "Kinetics and Mechanism of the Sonolytic Degradation of Chlorinated Hydrocarbons: Frequency Effects," J. Phys. Chem. A, 103(15):2734-2739.

Inazu, K., Y. Nagata, and Y. Maeda (1993). "Decomposition of Chlorinated Hydrocarbons in Aqueous Solutions by Ultrasonic Irradiation," Chemistry Lett., 1 :57-60.

Kabala, Z.J. (1993). “The Dipole Flow Test: A New Single-Borehole Test for Aquifer Characterization," Water Resources Res., 29(1):99-107.

Kotronarou, A., and M.R. Hoffmann (1995). "The Chemical Effects of Collapsing Cavitation Bubbles: Mathematical Modeling," in Aquatic Chemistry: Interfacial and Interspecies Processes, C.P. Huang, C.R. O'Melia, and J.J. Morgan, Eds., Adv. Chem. Ser., 244:233-251.

Kotronarou,A., G. Mills, and M.R. Hoffmann (1992a). "Decomposition of Parathion in Aqueous Solution by Ultrasonic Irradiation,” Environ. Sci. Technol., 26(7):1460-1462.

Kotronarou,A., G. Mills, and M.R. Hoffmann (1992b). "Oxidation of Hydrogen Sulfide in Aqueous Solution by Ultrasonic Irradiation," Environ. Sci. Technol., 26(12):2420-2428.

Kotronarou, A., G. Mills, and M.R. Hoffmann (1991). "Ultrasonic Irradiation of p-Nitrophenol in Aqueous Solution," J. Phys. Chem., 95(9):3630-3638.

Kriegman-King, M.R., and M. Reinhard (1994). "Transformation of Carbon Tetrachloride by Pyrite in Aqueous Solution,” Environ. Sci. Technol., 28(4):692-700.

Kriegman-King, M.R., and M. Reinhard (1992). "Transformation of Carbon Tetrachloride in the Presence of Sulfide, Biotite, and Vermiculite," Environ. Sci. Technol., 26(11):2198-2206.

Kruus, P., L. Beutel, R. Aranda, J. Penchuk, and R. Otsen (1998). "Formation of Complex Organochlorine Species in Water Due to Cavitation," Chemosphere, 36(8):1811-1824.

Manogue, W.H., and R.L Pigford (1960). "The Kinetics of the Absorption of Phosgene into Water and Aqueous Solutions," Am. Inst. Chem. Eng. J., 6(3):494-500.

Mason, T., and J. Lorimer (1988). Sonochemistry: Theory, Applications, and Uses of Ultrasound in Chemistry, Ellis Norwood, Ltd., New York, NY. 
Matheson, L.J., and P.G. Tratnyek (1994). "Reductive Dehalogenation of Chlorinated Methanes by Iron Metal," Environ. Sci. Technol., 28:2045-2053.

Mohn, W.W., and J.M. Tiedje (1992). "Microbial Reductive Dehalogenation," Microbial Review, 56:482-507.

O'Hannesin, S.F. (1993). "A Field Demonstration of a Permeable Well for the In-Situ Abiotic Degradation of Halogenated Aliphatic Organic Compounds," M.S. Thesis, University of Waterloo, Ontario, Canada.

Peters, R.W., M.L. Wilkey, J.C. Furness, and O. Ayyildiz (2000). "Development of the Integrated In-Well Sonication/In-Well Vapor Stripping System to Treat Chlorinated SolventContaminated Groundwater," Paper presented in the Topical Conference of "Environmental Remediation in the $21^{\text {st }}$ Century: Integrated Systems Technologies", Spring National AIChE Meeting, Atlanta, GA (March 5-9).

Peters, R.W., M.L. Wilkey, J.C. Furness, and O. Ayyildiz (1999). "Development of the Integrated In-Well Sonication/In-Well Vapor Stripping System to Treat Chlorinated SolventContaminated Groundwater," Paper presented at the $12^{\text {th }}$ International Conference on Bioremediation and Remediation, Orlando, Florida, (December 10-12).

Peters, R.W., O. Ayyildiz, M.S. Quinn, and M. Wilkey (1998a). "Removal of CC14 and TCE by Sonication, by Vapor Stripping, and by Combined Sonication/Vapor Stripping," Proc. 1998 Pan-American Workshop on Commercialization of Advanced Oxidation Technologies, London, Ontario, Canada (June 27-30).

Peters, R.W., M. Wilkey, O. Ayyildiz, M. Quinn, L. Pierce, M. Hoffmann, and S. Gorelick (1998b). "Use of Sonication for In-Well Softening of Semivolatile Organic Compounds," Poster paper presented at the DOE Environmental Management Science Program Workshop, Chicago, IL (July 27-30).

Peters, R.W., and J.-M. Wu (1996). "Use of Enhanced Fenton-Like Reactions for Destruction of Atrazine," Paper presented at the 1996 Spring National AIChE Meeting, New Orleans, LA.

Peters, R.W., and J.-M. Wu (1995). "Invention Disclosure: In-Well Sonication for Destruction of Organic Contaminants," ANL-IN-95-103, Argonne National Laboratory, Argonne, IL.

Philip, R.D., and G.R. Walter (1992). "Prediction of Flow and Hydraulic Head Fields for Vertical Recirculation Wells," Ground Water, 30(5):765-773.

Pinto, M.J. (1996). “Aquifer Remediation by In-Well Vapor Stripping: 2. Modeling Results," Contaminant Hydrology (in review).

Putterman, S. (1995). "Sonoluminescence: Sound into Light," Sci. Amer., 272(2):46-51.

Quinn, M.S., G.A. Moehring, and R.W. Peters (1998a). “Analyzing Headspace of Chlorinated Volatile Organic Compounds in Groundwater," Poster paper presented at the $4^{\text {th }}$ Annual Governors State University Student Research Conference, University Park, IL (May 29). 
Quinn, M.S., G.A. Moehring, and R.W. Peters (1998b). "Analyzing Headspace of Chlorinated Volatile Organic Compounds in Groundwater," Poster paper presented at the $9^{\text {th }}$ Annual Student Research Conference of the Board of Governors Universities, Western Illinois University, Macomb, IL (April 3-4).

Sehgal, C., R.P. Steer, R.G. Sutherland, and R.E. Verrall (1977). "Sonoluminescence of Aqueous Solutions," J. Phys. Chem., 81(26):2618-2620.

Semprini, L., G.D. Hopkins, P.L. McCarty, and P.V. Roberts (1992). “In-Situ Transformation of Carbon Tetrachloride and Other Halogenated Compounds Resulting from Biostimulation Under Anoxic Conditions," Environ. Sci. Technol., 26(12):2454-2461.

Suri, R.P.S., M.R. Paraskewich, and Q. Zhang (1999). "Effect of Process Variables on Sonochemical Destruction of Aqueous Trichloroethylene," Environ. Engrg. Sci., 16(5):345-352.

Suslick, K.S., D. Hammerton, and R. Cline (1986). "The Sonochemical Hot Spot," J. Am. Chem. Soc., 108:5641.

Tatara, G.M., M.J. Dybos, and C.S. Criddle (1993). "Effects of Medium and Trace Metals on the Kinetics of Carbon Tetrachloride Transformation by Pseudomonas sp Strain ILC," Appl. \& Environ. Microbiol., 59(7):2126-2131.

Weathers, L.J., and G.F. Parkin (1995). "Metallic Iron-Enhanced Biotransformation of Carbon Tetrachloride and Chloroform Under Methanogenic Conditions," pp. 117-122 in Bioremediation of Chlorinated Solvents, R.E. Hinchee et al., (Eds.) Battelle Press, Columbus, OH.

Wu, J.M., H.S. Huang, and C.D. Livengood (1992a). "Ultrasonic Destruction of Chlorinated Compounds in Aqueous Solution," Environ. Prog., 11(3):195-201.

Wu, J.M., H.S. Huang, and C.D. Livengood (1992b). Development of an Ultrasonic Process for Detoxifying Groundwater and Soil: Laboratory Research, ANL/ESD/TM-32, Argonne National Laboratory, Argonne, IL. 
APPENDIX I. Schematic Diagram of a Single Treatment Well in Which In-Well Sonication Softens and Partially Destroys VOCs and SVOCs and In-Well Vapor Stripping is Used to Remove the VOCs as a Vapor. The treatment process is performed completely in-situ wherein no water is brought to the surface.

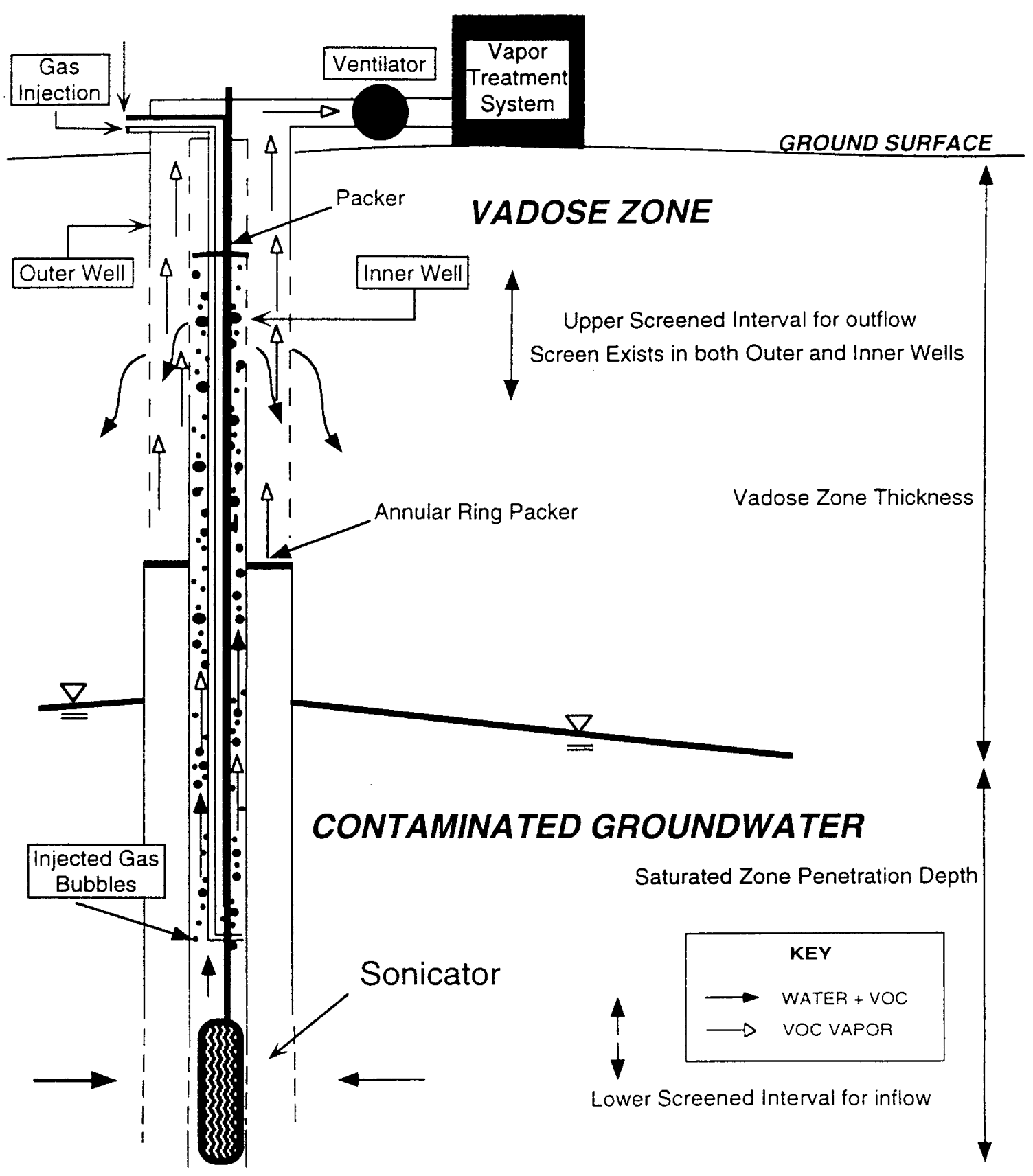

